\title{
Designing dolls according to Youkai stories and Shinto beliefs in Eastern culture
}



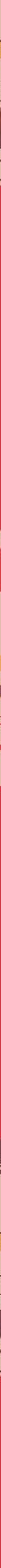


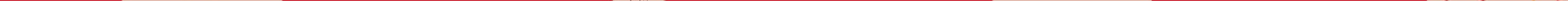





\title{
Designing dolls according to Youkai stories and Shinto beliefs in Eastern culture
}

\author{
Liu Yanxiao \\ MDI \\ A 90 point research portfolio submitted in fulfillment of the requirements for \\ the Masters of Design Innovation, Victoria University of Wellington, \\ School of Design 2019
}




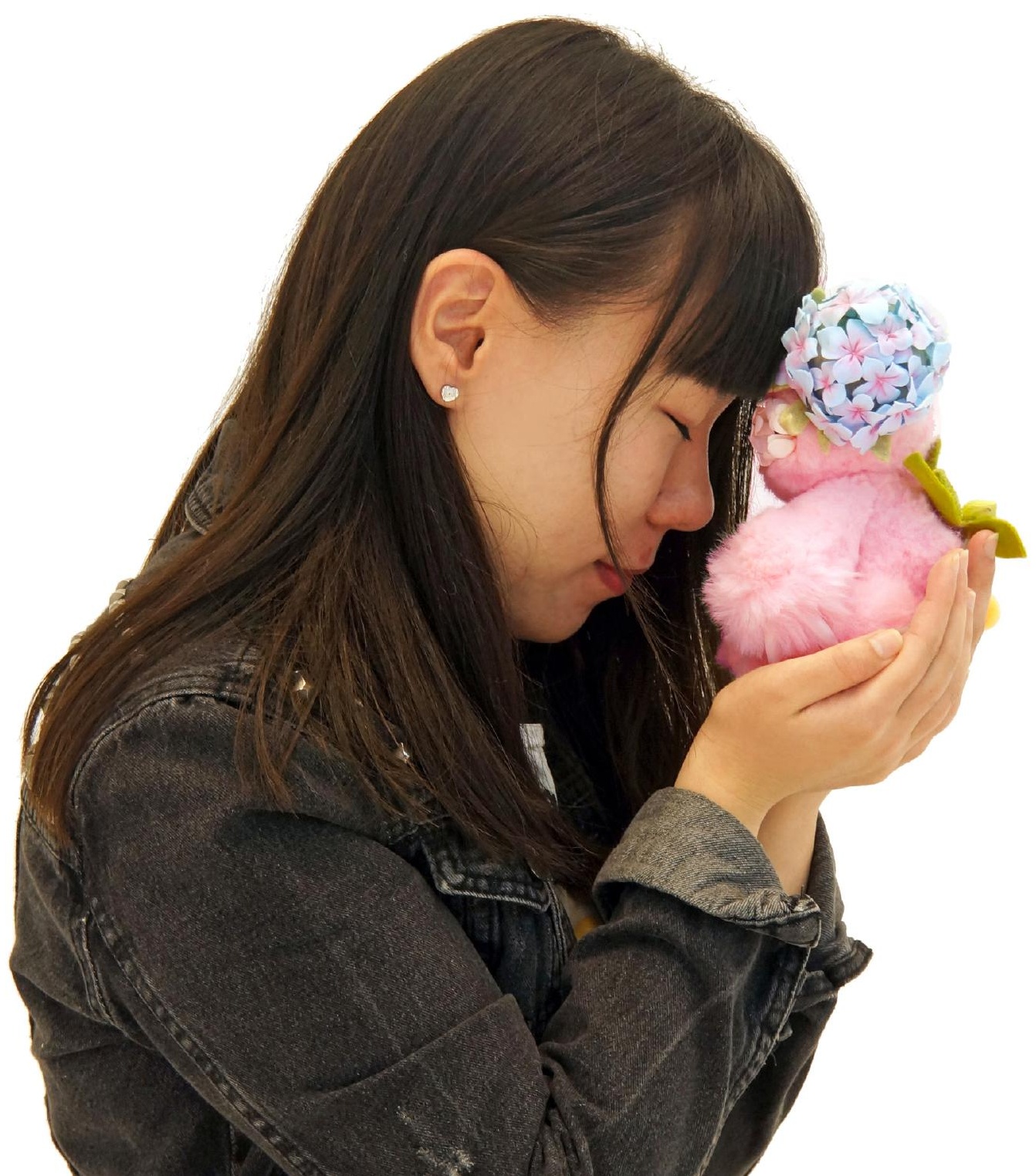




\section{Abstract}

Contrary to the contemporary views on the function and complex mastery skills of an object, the Eastern world put more emphasis on the value of the object is in its inner spirit. This view is based on Shinto beliefs, where everything is spiritual and valuable. My project undertakes a case study of the relationship between humans and things. This is done by building on the uses of Shinto beliefs to design an object that initiates a narrative. More specifically dolls. Thus, invites a relationship and engages the belief that objects have souls.

The dolls which I designed are an intersection of the spirit world and reality. By providing a process that facilitates the traditional Youkai story base on Shinto beliefs and how it has developed in modern society. In promoting participant engagement through design methods and processes, this project discovered a new vision of forming meaningful relationships between humans and objects empowers the true value of an object. This project visualizes participant experiences created an exploration of a narrative that contains the spirit. 



\section{Acknowledgments}

There are several people I would like to acknowledge as integral contributors to the completion of this project. Firstly, I want to thank my parents for supporting my studies. It was you who taught me to pursue my dreams and liberty and named me in that sense. It's your teachings that makes me unremitting efforts. Also, I would especially like to thank my supervisor, Catherine Gaudwell, for your encouragement, support, and feedback. Thank you for your interest in my topic and for helping me to promote it to an academic project. It is your support gave me enthusiasm throughout this process.

Thank you to the advice from Nan O'Sullivan, your critical ideas given me different views. Thanks, Dylan Horrocks to help me create comic books. Making my comic book is my dream since I was a child. Thank you for making it come true. Thanks to my photographer Men Yitong, your work document the most beautiful magical moment of this project. Also, I would like to thank Laura Kamau for helping me with my writing. It is your passion that made the words alive. Raincoat, Aliao, Summer and Vera, thanks all of you for participating in this project. This project literally would not have happened without you. Finally, I would like to thank my dolls. You are all my precious kids. Thank you for being born in this world. 


\section{Contents page}

- Area of interest and motivation 9

- Research questions

- Thesis structure

\section{Introduction}

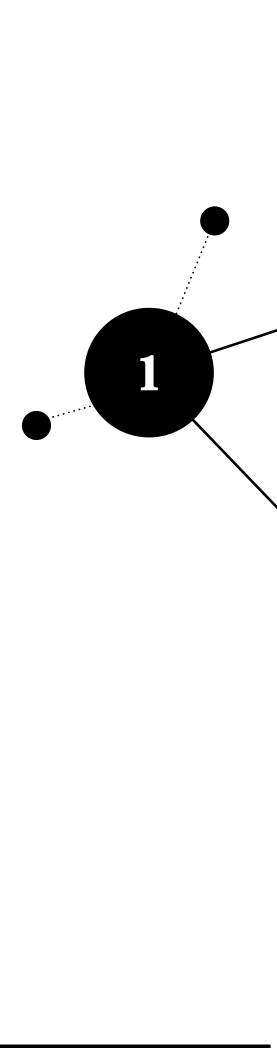

\section{The Shinto belief}

- Shinto in design and art

- The Shinto belief in doll collecting
2

Youkai stories

- Investigation

- Characteristics

- Categories and Analysis
3

Methodology

- Research questions

47

- Aims and Objectives

47

- Research through design 48

- Cultural Probes and Question 48 cards

- Narrative analysis 
- The power of handcraft and 53 nature

- Doll making 54

- Design and Sketch 54

- Handcraft process

- Birthday card

- Finished doll display
- Young adults as participants

- Adoption

- Interaction
- Collecting and clustering 89

- Answer from question cards 89

- Analyze and create new stories 89

- Narrative structure

- Visual narrative

\section{Visual narrative}

the doll

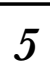

6

4

\section{Doll making}

0

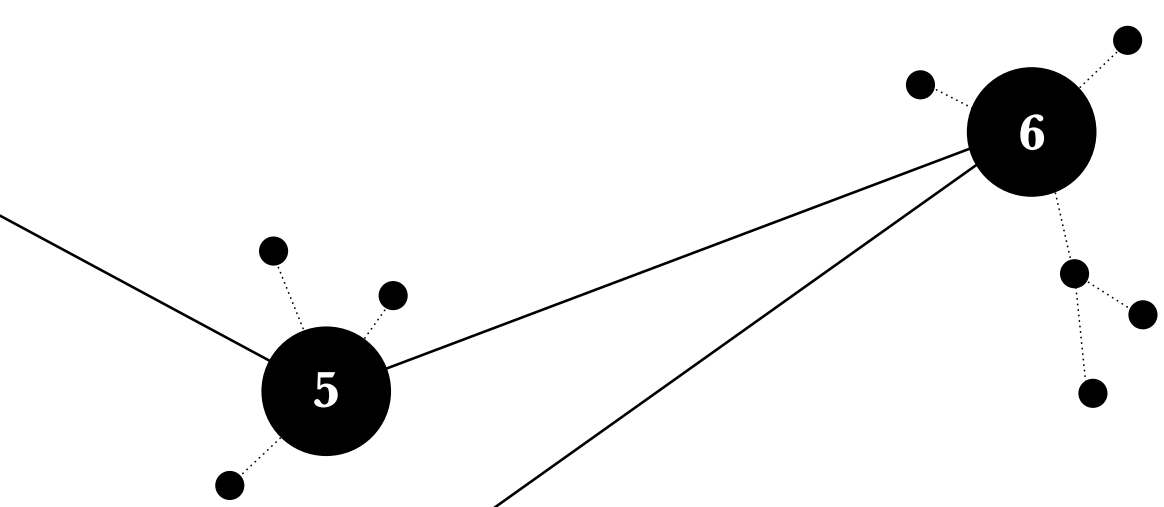

7

7

$\boldsymbol{8}$

Evaluation

143

Conclusion 
0.2

Research questions

O.I

Area of interest and motivation

0.3

Thesis structure 
0. Introduction 


\section{Introduction}

Eastern cultures believe everything is spiritual and valuable, even emptiness. Fundamental to Shinto is the belief that everything has a soul. The emotions and memories produce through the interactions of people and objects play an important role in day to day life. Kenya Hara (Hara, 2007, p. 410) argues that people wrongly look at the function and complexity of an object and celebrate the technology used to create it. Hara suggests that the true value of the object is in its inner spirit, and this belief should be paramount to designers. The Eastern word for design is "ISHO." It is the same in Japanese and Chinese. However, unlike the English word "design" the Eastern word is made up two distinct words "tone" and "heart," and acknowledges the connections between object and user (Fujita, 2016). This study acknowledges the relationship between humans and things, and building on this uses Shinto beliefs to design an object that initiates a narrative and invites a relationship. Therein engages the belief that objects have souls.

\subsection{Area of interest and motivation}

Fine art is seen as a display behind the glass that is aesthetic but also distant. Whereas a toy for a child is simply for play. The designer doll is something which combines both of those features. Within many cultures, dolls have been considered and loved as a character that has a soul or life of their own (Gerbert, 200I). Dolls have over time become more than just toys for children, they are also works of art and valued for their beauty (Budnitz, 20IO, p. 6). That led me to become fascinated with collecting and making dolls. Collecting dolls became one of my hobbies since I was a child, and I started making and designing dolls in later years.

In Asia, this phenomenon is largely influenced by Shinto belief in Japan. Youkai stories are one of the ways of expressing this idea of a storytelling doll which is another area I am interested in. The so-called Youkai is a term mostly associated with creatures and ghosts and is a widespread belief. They present a narrative of human society, and they are the mirror of people (Lupitu, 20I4). Those stories are always filled with fantasy and spirits but are also scary. This feature attracted me to do more research on these stories. Also, it is an opportunity to combine these two areas of interest through this study.

Inspired by my own obsession with dolls over my lifetime I have chosen to investigate how Eastern beliefs of Shinto can be used to enable meaningful relationships between human and objects as Hara suggests, find the inner spirt and true value of an object. 


\subsection{Research questions}

How might we design dolls according to Eastern beliefs of Shinto?

How might dolls designed according to Eastern beliefs of Shinto affect the relationship between dolls and young adult collectors?

\subsection{Thesis structure}

This thesis is structured in nine parts, an introduction, six main sections, evaluation and conclusion. The literature review is not limited in one chapter. Instead it is woven throughout the entire thesis. At the same time, I have created graphics and illustrations to visually express ideas throughout and it is designed to be read visually as well as textually.

\section{Introduction}

This chapter is the introduction of this project. it is the scope of my design research and how I identify it as a thesis proposition, as well as an area of interest in design and my motivation.

Chapter one: The Shinto belief

Chapter one includes the literature review, the cultural background of the research.

Drawing key ideas and approaches from the Shinto belief in Eastern culture to gain a greater understanding of the spiritual nature of the object. Hayao Miyazaki, Toshiyuki Kita and Kenya Hara cover the Shinto belief in different fields of the design area. Also, the investigation of how the Shinto belief influences collecting behaviors provides valuable outcomes of the true value of the doll. Those beliefs of Shinto have also developed in subsequent chapters.

Chapter two: Youkai stories

Chapter two is the extension of the literature review. Based on the Shinto belief in chapter one, this chapter narrows the focus down to Youkai stories. This is done through investigation and an analysis of Youkai stories to classify and gain a greater understanding of their categories and characteristics as the basis of this research.

Chapter three: Methodology

Chapter four presents the methodology and the research method. This chapter further details the research question, methodology and research method.

Chapter four: Doll making

Chapter four explains the doll making process. It utilizes the background knowledge from chapter one and chapter two to discover the first research question which is how might we design dolls according to Eastern beliefs of animism. This chapter documents the whole doll making process from the design and 
sketch to the handcrafting process. Also, the image of the final display of the doll will be included in this chapter.

Chapter five: connecting with the spirit of the doll

Chapter five involves the participants engaged in this research. It explored the importance of the connection between the spirit of the doll and young adult collectors through design analysis. Four young adult collectors spent one-month with the doll and documented their experience in a variety of ways. The design of question card assists the participants to engage in the design process.

Chapter six: Visual narrative

Chapter six accumulates the insights gained from chapter four and chapter five. Using the image designed from the dolls and the information gained by four participants, it creates a visual narrative which explores the spirit of the whole life of the doll.

\section{Evaluation}

The final discussion of this paper. This chapter returned to the research questions, summarizes and evaluated the first six chapters.

\section{Conclusion}

This chapter concluded the research portfolio and considered future directions for the research. 


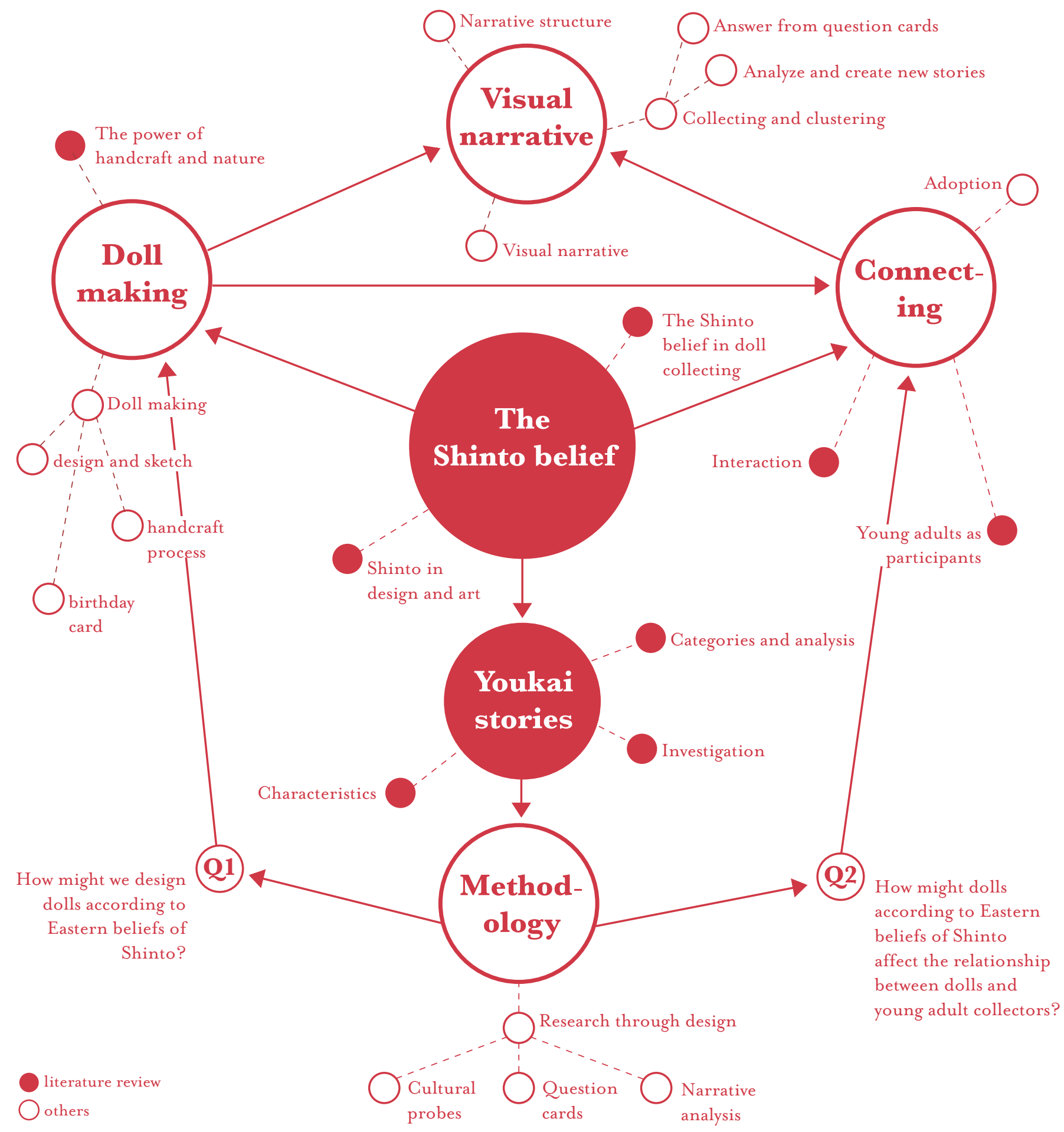




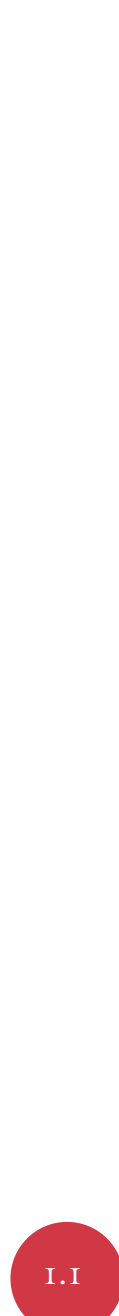

Shinto in design and art

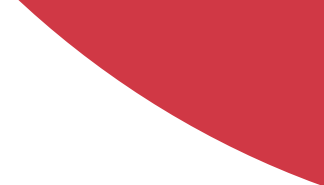

The Shinto belief in doll collecting 
1.The Shinto belief 


\section{The Shinto belief}

Shinto is reflected in the cultures of all parts of the Eastern world. These magnificent traditions and culture have largely been preserved in Japan. Shinto is a form of life-affirming animism calling upon the blessings of the numerous forces of nature and specific spirit deities (Jensen \& Blok, 2013). The Shinto beliefs are associated mainly with growth and prosperity. The Japanese respect all-natural things because they believe they have dwelled within them (Jensen \& Blok, 2013). Japanese shrines are dedicated to a wide range of gods from those associated with elements of nature to others who are real-life figures. It encourages people to be sincere, cheerful and pure and live in relation with the forces behind all things.

\subsection{Shinto in design and art}

The idea of Shinto occupies a large part of all aspects of Asian cultures. Their design is the pursuit of natural and straightforward aesthetics has more practical significance. The "emptiness" reflected in the design emphasizes the infinite inclusiveness of the design object, and it is giving the receiver a vast space to play in their imagination (Hara, 20I0, p36). This dramatically enriches our perception and understanding of Shinto. These ideas make designers not blindly follow the trend of art and design in commercial society but return to the Eastern traditional aesthetic ideas.

For instance, in animated movies, Hayao Miyazaki pondered the relationship between man and nature and expressed his deep concern about the common problems facing humankind in the 20 th century (Boyd \& Nishimura, 20I6). In Miyazaki's world, there are mysterious creatures that have the same appearance and behavior as humans but originate from nature. For instance, in Tonari no Totoro (I988) there are haunted dust elves in the country house, in Nausicaa of the valley of the wind (I984) there are horror queens, and a river was transformed into a human image in Spirited Away (200I). Throughout his works, we can easily find that he always has thought deeply and questioned the relationship between human and nature. Such an idea does not only exist in the concept created by Hayao Miyazaki, but we can see his work is informed by Shinto.

In other design areas, Toshiyuki Kita, a well-known Japanese industrial designer has put forward the concept of "The soul of design" (Kinser, 2002). He thinks that the focus of people's widespread attention to design is form and function, but he adds a third element which is the soul. Therefore, in addition to designing well-known modern products, he continuously pays attention to Japan's traditional crafts and considers how to apply them to current products and utensils (Kinser, 2002). In his view, the product needs a soul not just the form and function of the production. This idea 
makes the product not only practical but valuable and meaningful. The Shinto belief gives a kind of material spirit to the product.

The concept of the soul does not just exist in tangible products but also appears in visual information. Japanese believe there is a spirit in things even if the thing is empty. The essence of Shinto contemporary Japanese aesthetics hosts the meaning of empty is an essential space of communication (Hara, 20IO, p39). The capability of the empty vessel activates people and leads them to want to fill the void. Thus, Kenya Hara who is one of the most famous communication designers in Japan maintains that such aesthetic is "emptiness" rather than call it "simplicity" or "nothingness" because it can create energy for communication (Weishi, 20I6). The space of his work is designed to be empty, and that activates people to want to enter it. Whether in color allocation or the overall composition, it shows the beauty of simplicity and nature, but it does not flow into shallowness. The saturation of color and the depth of the picture are almost perfect. Hara strives to convey ideas and truth in the simplest and purest form. He says, "Design is not a skill, but a sense of ability and insight to capture the essence of things" (Hara, 2007, p436). While returning to nature, removing decorations and pointing to the original mind.

\subsection{The Shinto belief in doll collecting}

The Eastern culture concept of soul is not limited. Those invisible spiritual forces could be behind anything that ranges from a nameless power that inhabits a waterfall, a tree, or to a more tangible form of solid rock (Rots, 20I4). The most visible embodiment of this idea should be the design of dolls. In Asia, dolls have their origins in religious charms that are meant to absorb misfortunes or diseases that would occur otherwise in people (Gerbert, 200I).

This unique perception of dolls has had a profound effect on doll collecting. Japanese believe that the doll could have a particular emotion and character if it is treasured enough (Gerbert, 200I). The doll is not only an object but a close friend or family member to the collector. The exclusive companionship makes the doll unique. This perspective is associated with wabi-sabi aesthetics in Shinto belief. Wabisabi is a combination word for the aesthetics of the natural imperfections and obsolete (Graham, 20I4, p20). This inadvertently left traces in the production process and interaction during the time make the doll become a unique product for both makers and the collecters.

Historically, bridal dolls represented prayers for people who died before marrying will be able to marry happily in the next life (Schattschneider, 200I). People regard the bridal doll as an offering and believe that the dead could live happily with the bride on the other side. Also, this idea does not stop with ancient times. This kind of animism belief has influenced modern people's perspective of dolls.

The fascination exercised by the doll does not just appear in passing but also occurs in contemporary society. Even today, there is still an event to honor beloved dolls. These ceremonies are held annually 
in various parts of Japan. People will send old or discarded dolls to temples, or some people go to great lengths to give them the proper send-off (Mealey, 20I6). As the doll floats away, people believe that the shrines could give them a fitting end. Some dolls have special affection or have special commemorative significance for the owner which makes its owner reluctant to destroy it. The shrine will take a little fee to keep it for the owner until their master is fully prepared to release it (Schonherr, n.d.).

Therefore, many designers and collectors pay attention to the shaping of the soul of the doll. By giving them their characteristics and stories and making special memories created by collectors through interactions, it makes them unique. With those special memories, dolls become an exclusive partner of the collector. Moreover, the intimate relationship between objects and people through these activities, they become more robust in the presence of each other together to create memories. 
18 

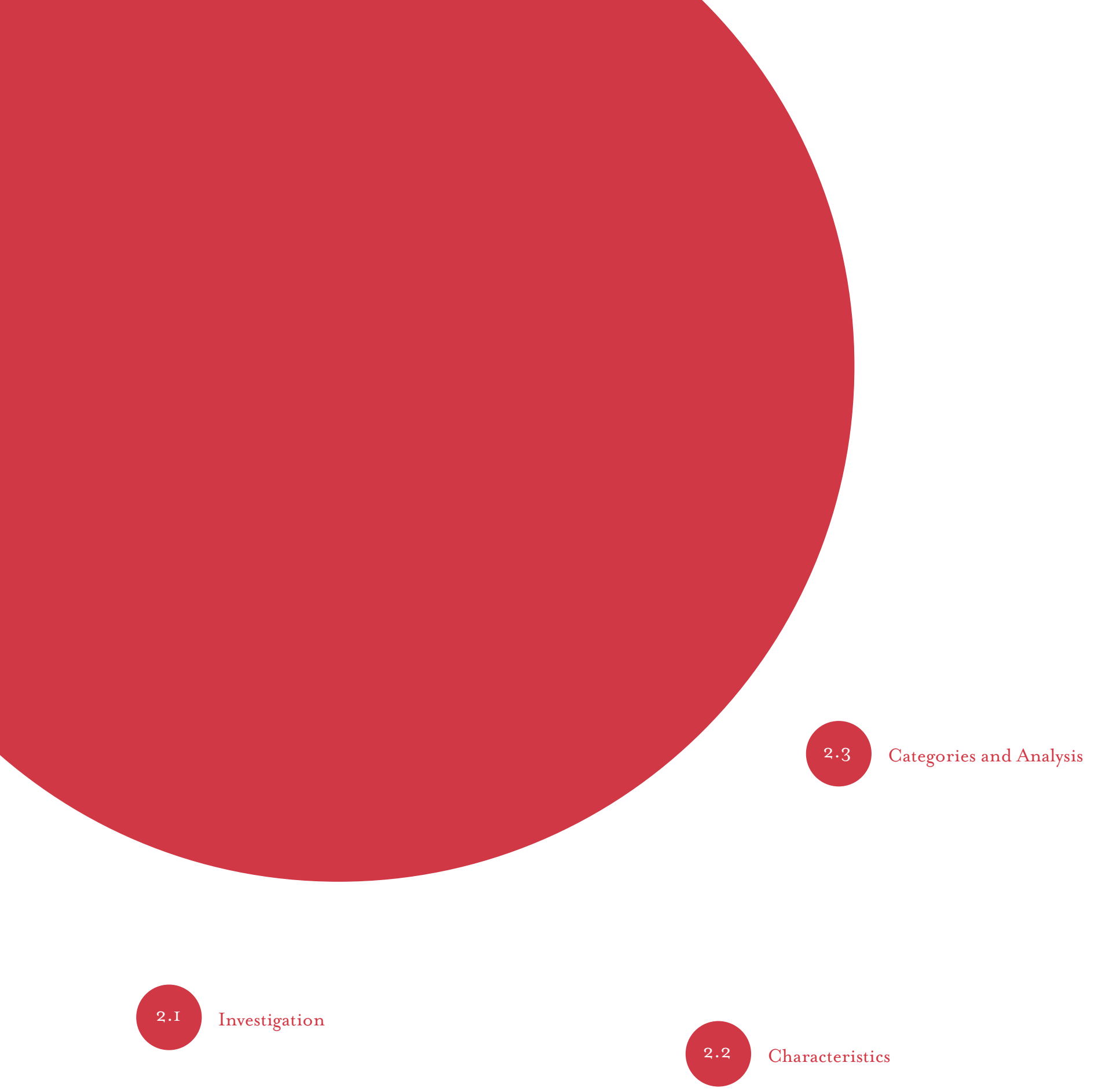
2.Youkai stories 


\section{Youkai stories}

The Youkai is the collective name for all sorts of bizarre creatures and supernatural phenomena in Japanese folklore. From the ancient past right up to the present Youkai has been very popular (Lupitu, 2014). As previously described, in the traditional Shinto way of Asia all kinds of things have their thoughts, wisdom, and soul. However, they are the products of people's imagination, and they are invisible. The Youkai story is one of the best ways to visualize those intangible things. The story applies the shape, action, behavior, and spiritual emotion and personality of the human form to the object. This achieves a psychological resonance and satisfies the emotional needs of the heart, thus giving the object personality. The so-called Youkai is a term mostly associated with Japanese folk creatures and ghosts and is a widespread belief in Asia (Spurgiasz, 2015). Youkai then are presenting a narrative of human society and they are mirrors of people (Lupitu, 2014).

\subsection{Investigation}

Starting in the 8th-century Youkai stories became popular. Entering the I6th century, Youkai began to take the form of an encyclopedia. In the I8th century, a craze for Youkai swept Japan. It was launched by Toriyama Sekien's I776 work, the illustrated Night parade of a hundred demons (Shimazaki, 2OII ). In this visual guide book, each page depicts one Youkai. According to Japanese folklore, the author drew 207 kinds of Youkai images, which vividly and artistically reflect the customs of that period in Japan. His work is of great significance to the study of Japanese Youkai culture. The book stirred the imagination of other people as he used vivid and anthropomorphic techniques to make the Youkai popular.

Meanwhile, telling spooky stories has become a popular pastime. Since then Youkai has become a favorite part of Japanese culture. They usually appear as comic characters. Gegege no Kitaro is a comic book about Youkai that has been extremely popular since it first appeared in I959. The manga artist Shigeru Mizuki created it and today's Youkai culture owes a huge debt to this man (Suzuki, 20II). He has continued and enhanced that approach to Youkai discourse. In his stories, Mizuki depicts Youkai living like human beings. Every monster in Mizuki's works has its own characteristics and personality. His illustrations are imaginative, personal and interesting, involving a large number of Japanese folklore and legends. His works made people feel even closer to Youkai even though they have been around for centuries. Youkai still remains popular in Asian culture. There are various forms but no boundaries between humans and monsters. Even today, Youkai are still favorite characters. 


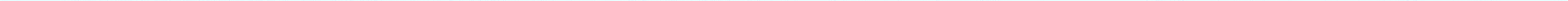




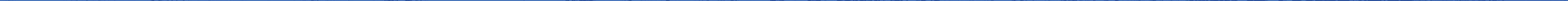




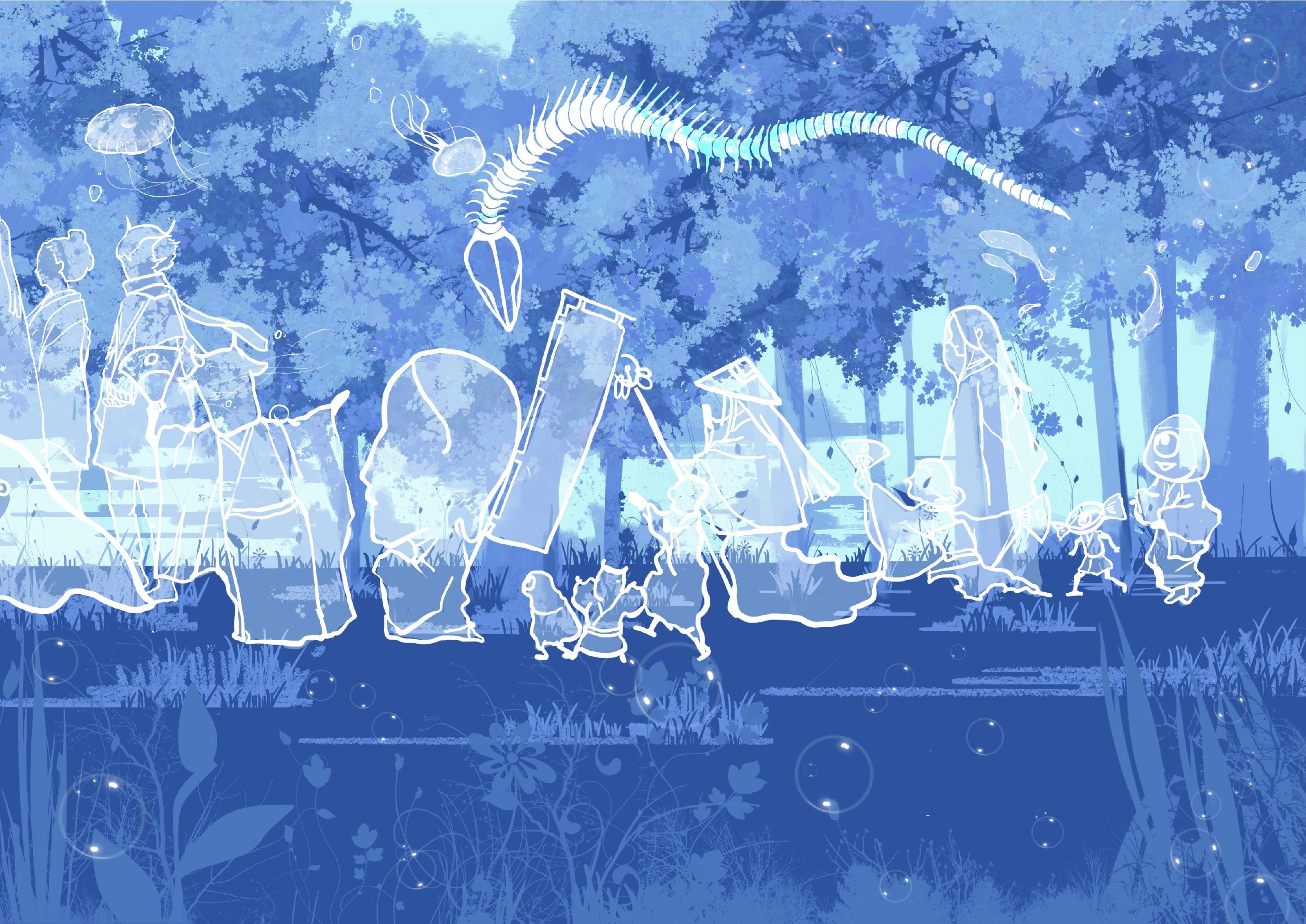


$-x+x+x$

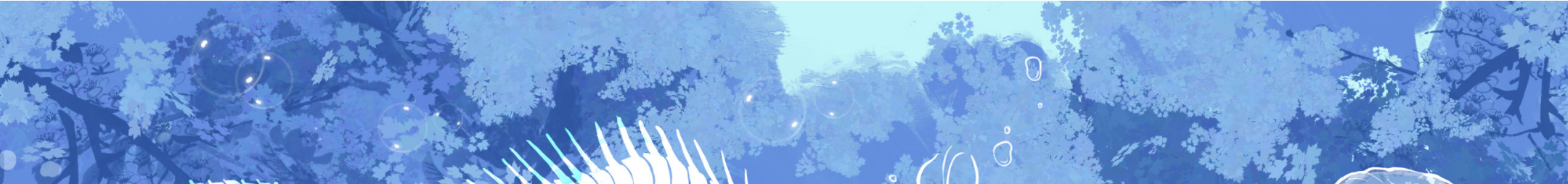

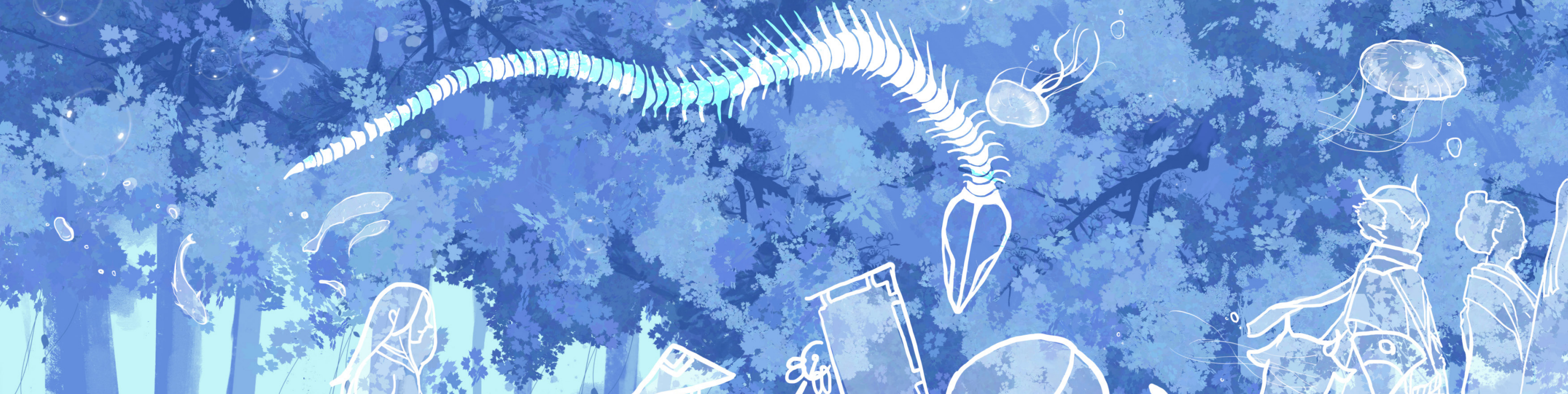

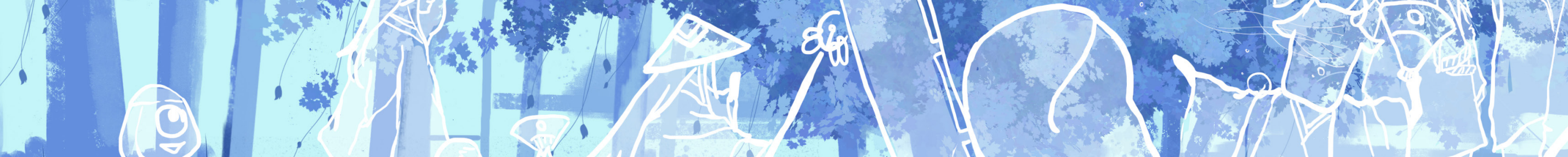

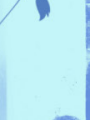

(u) (x)

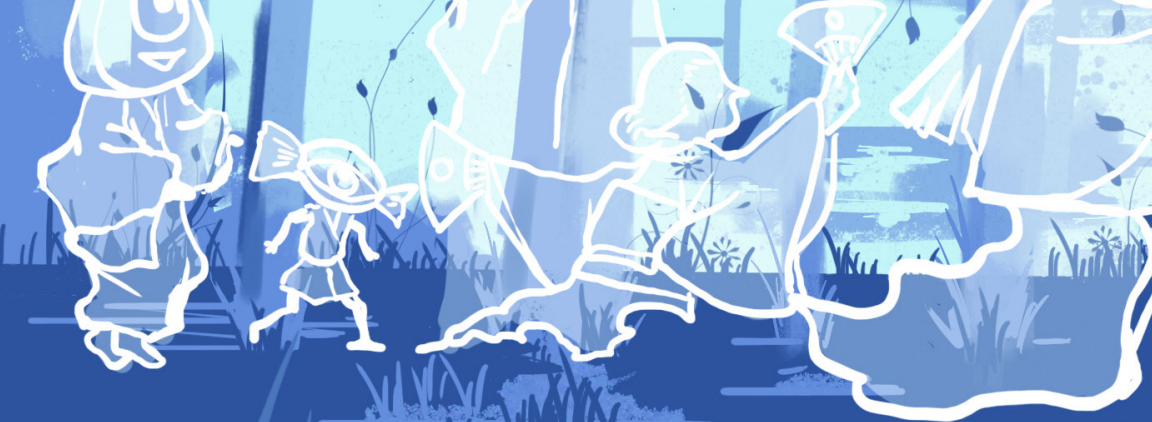
Mint $(x)$
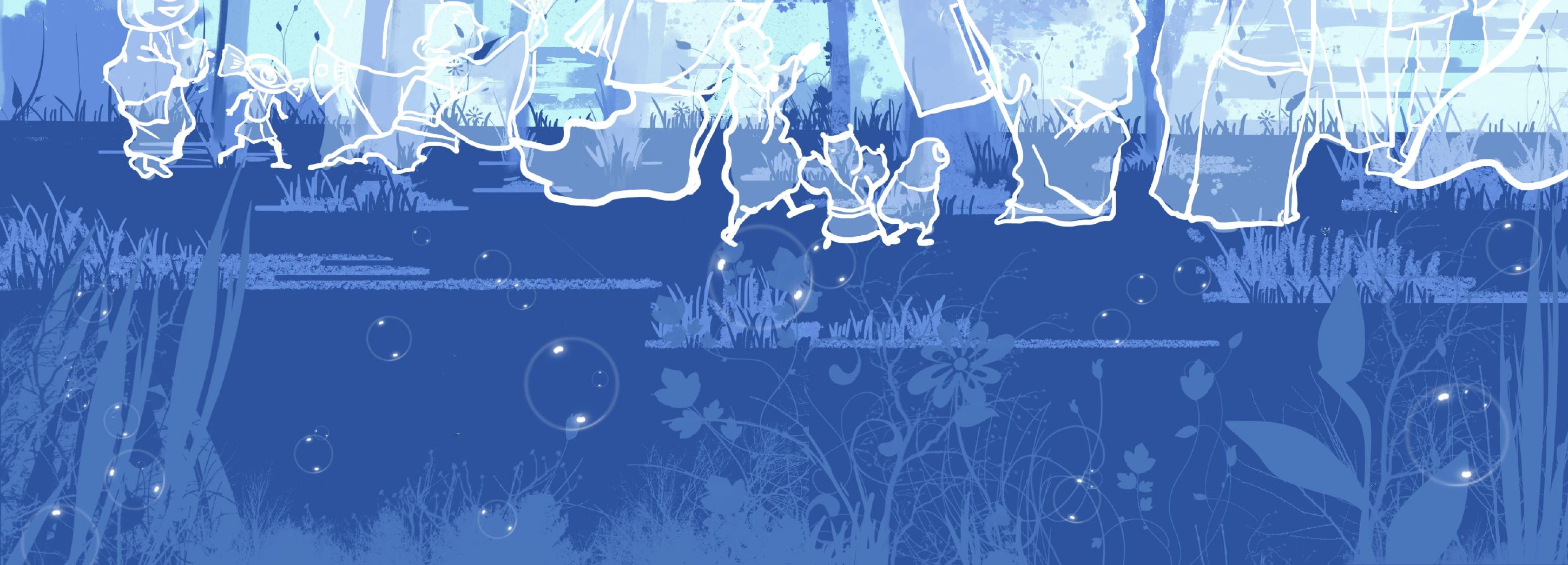


\subsection{Characteristics}

After reading a large number of Youkai stories by different authors and from a different period an interesting phenomenon of Youkai has emerged. The characteristics of Youkai do not stay constant over time. As people continuously retell the story of Youkai, their characteristics have changed. Michael Dylan Foster (2015) who is an authority on the subject of Youkai states that the characteristics of Youkai are altering over time and the stories also change when word passes from mouth to mouth. For instance, Kappa is one of the famous Youkai which is said to inhabit rivers. The ancient Japanese believe that Kappa dragged people down into the water where drownings were often seen as their work. However, today we can find many legends of Kappa which help people and not just harm them. They finally have become a mark of some products as a lovely character (Foster, 1998). Such contrasting characteristics are typical of other Youkai. Thus, Youkai is not defined as good or evil. Even if it is an evil Youkai if we treat it kindly, it will become good. It only depends on what story they are in and what relationship they shared with people. By putting a frame around them, they become predictable. Also, by moving those farther away from their original stories, Youkai becomes something people love. Because of this mutability, stories about them become more attractive.

Figure 1. Kappa

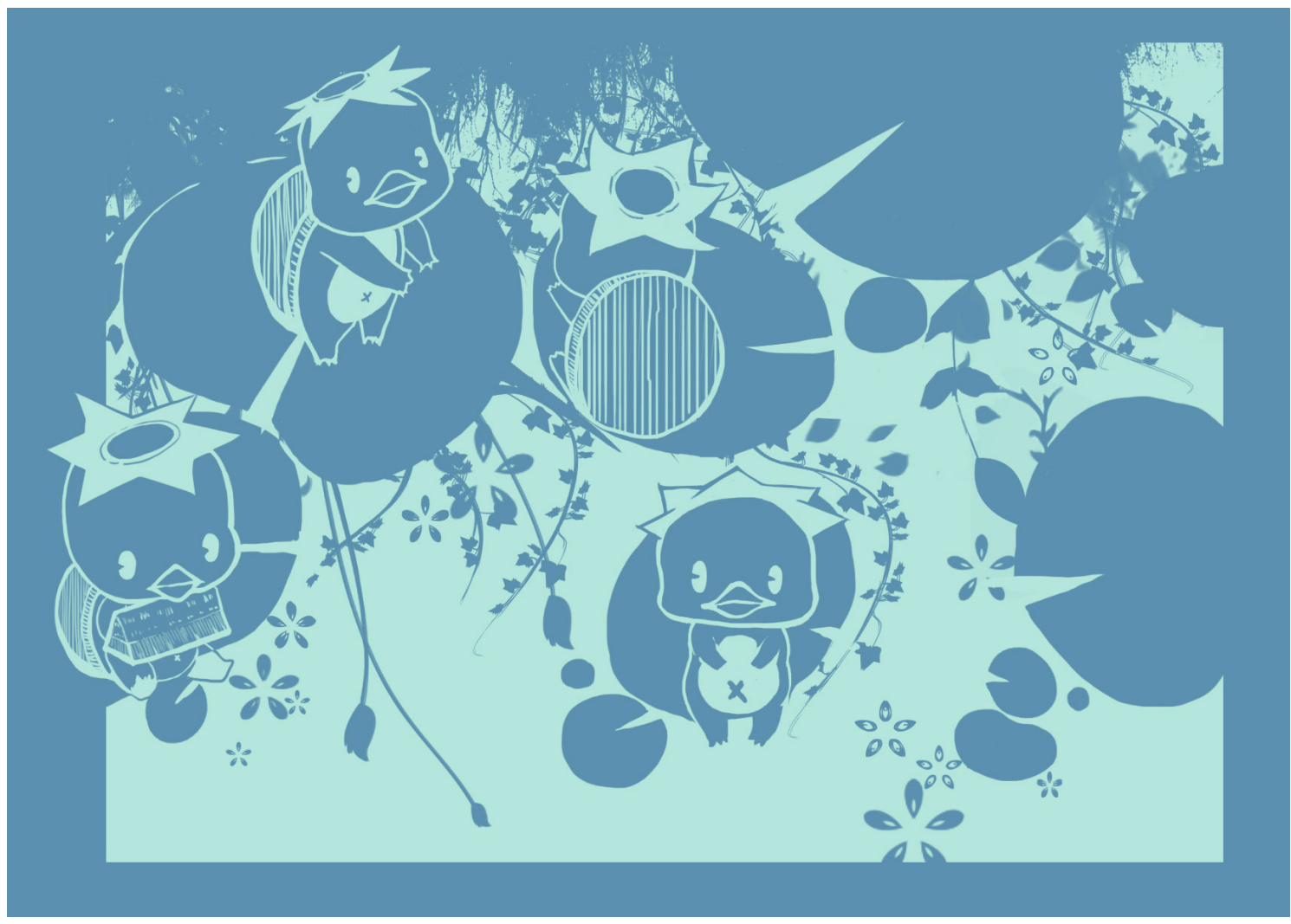




\subsection{Categories and Analysis}

Unlike monsters in Western cultures, the Youkai in Eastern cultures are not only scary and bad. The mysterious events in life have been embodied as Youkai, and it has given a vivid characteristic of Youkai (Wilson, 2013). Many legends about the existence of Youkai persist to this day. Also, there are multiple ways to categorize them. This project is only one way to do that.

Thus, in order to understand the source of Youkai stories with their features and characteristics I integrated them into the dolls which I designed. This paper groups the Youkai in five different categories based on their unique features and the origin of the source. These being; human, plants, animal, object and mythology.

\section{Human (Figure 4):}

Youkai with a human body or which has part of a human body. To distinguish them from humans, they usually wear masks. The legends behind them are often sad, bitter and resentful and they turn into monsters when they die. Some are powerful gods, so they can have the image of human beings.

Plants (Figure 5):

Youkai with plant features. Some plants, such as some ordinary plants are immovable, others have the characteristics of other species and can move around. Most survive for hundreds of years and have the local spirit. It also became Youkai because of special events.

\section{Animal (Figure 6):}

Youkai with an animal body or in an unmistakable animal posture, Most of them are the messengers of gods or shrines. There are also appearances and folk tales that often make mischief in the world.

Object (Figure 7):

Youkai is from natural phenomena or man-made objects. Usually it has been cherished and used before, but it has been abandoned or their important parts appear in any famous stories.

\section{Mythology (Figure 8):}

Figure 3. Youkai in five different categories

Youkai which are formed by people's imagination. Human beings extract some features from different species and fuse them together. This type of Youkai is usually dominated by gods.

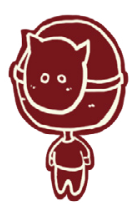

Human

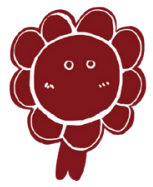

Plants

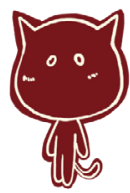

Animal

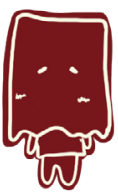

Object

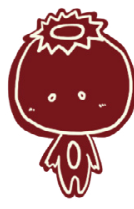

Mythology 

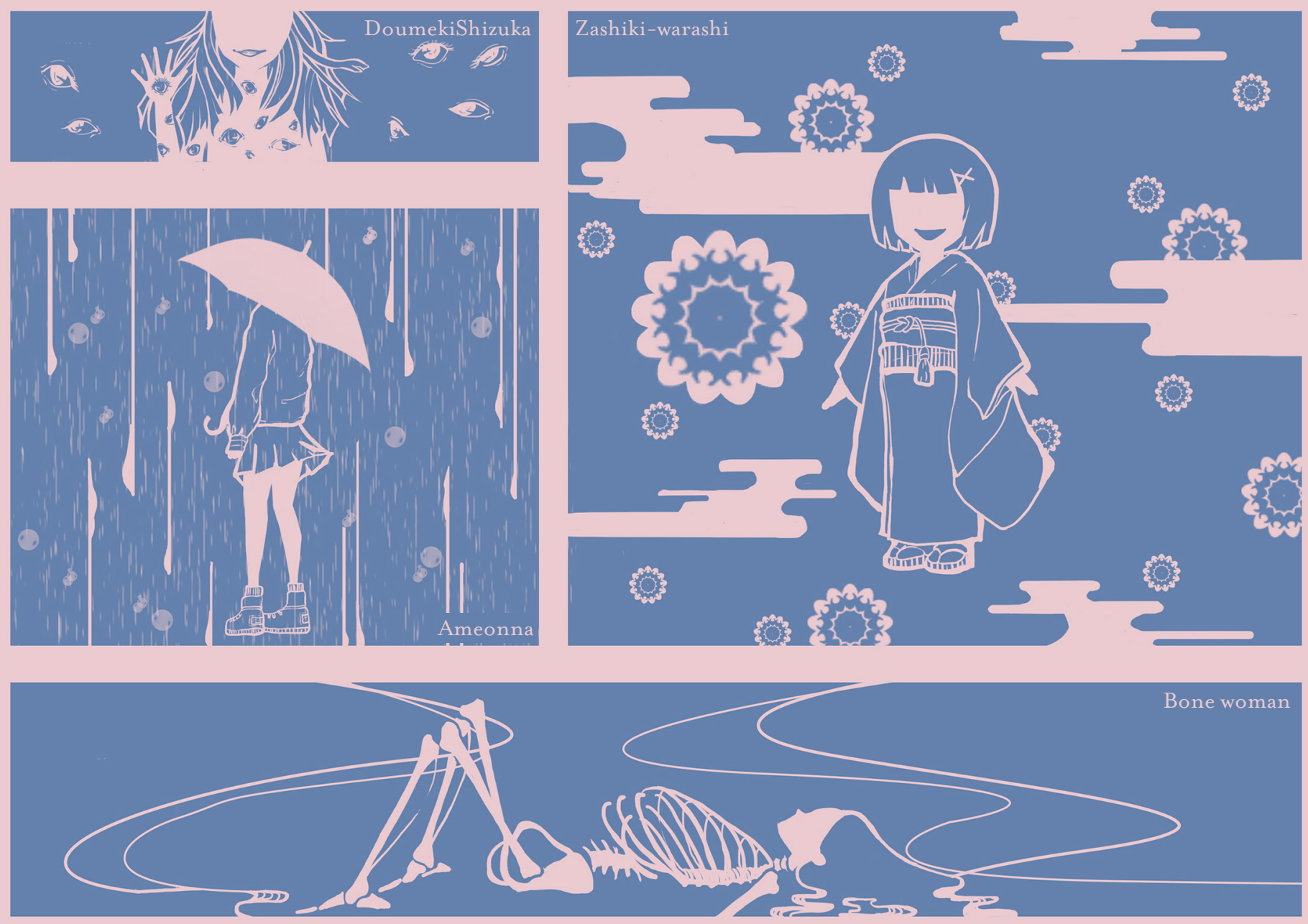

Figure 4. The common human Youkai 

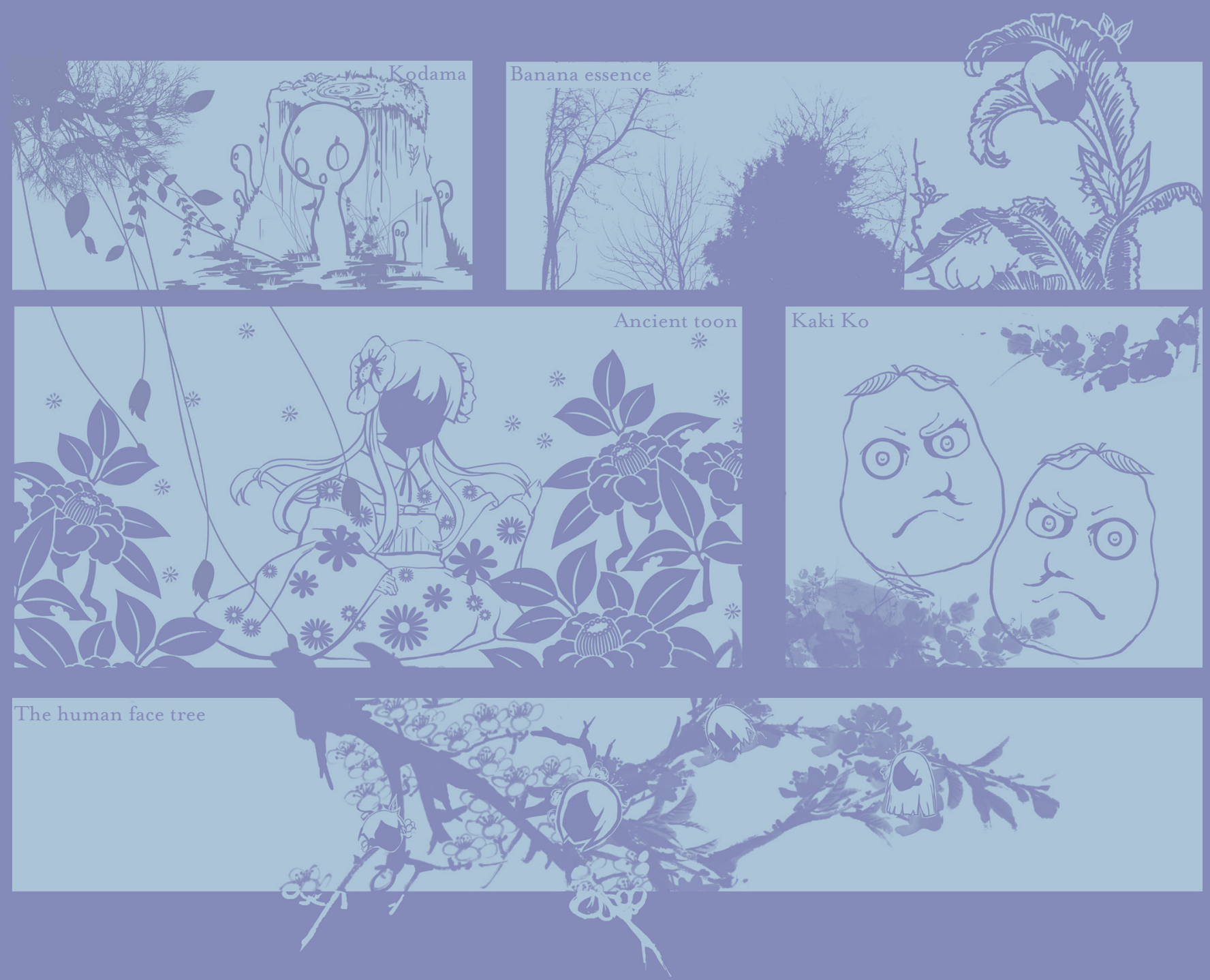

Figure 5. The common plants Youkai 

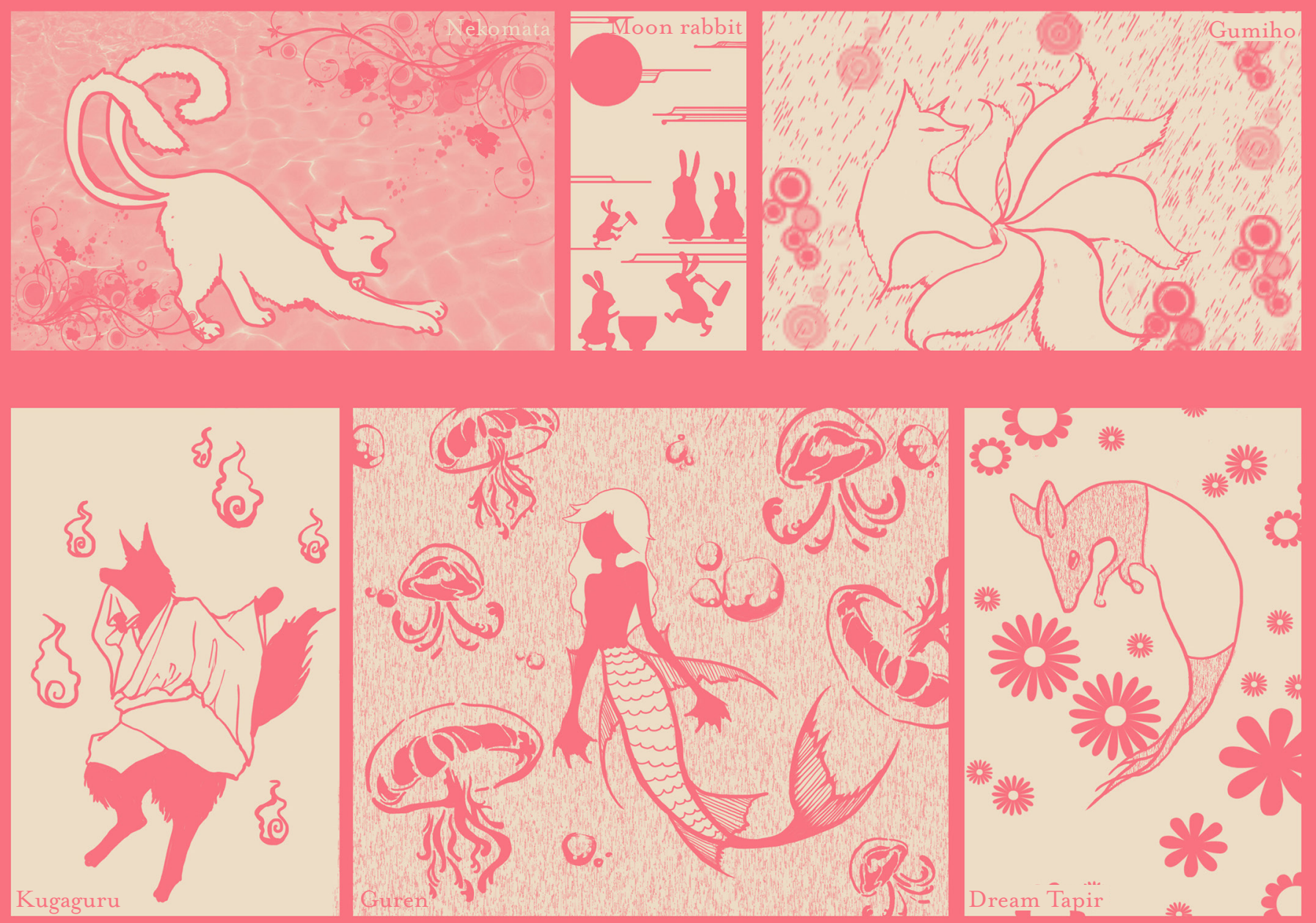

Figure 6. The common animal Youkai 

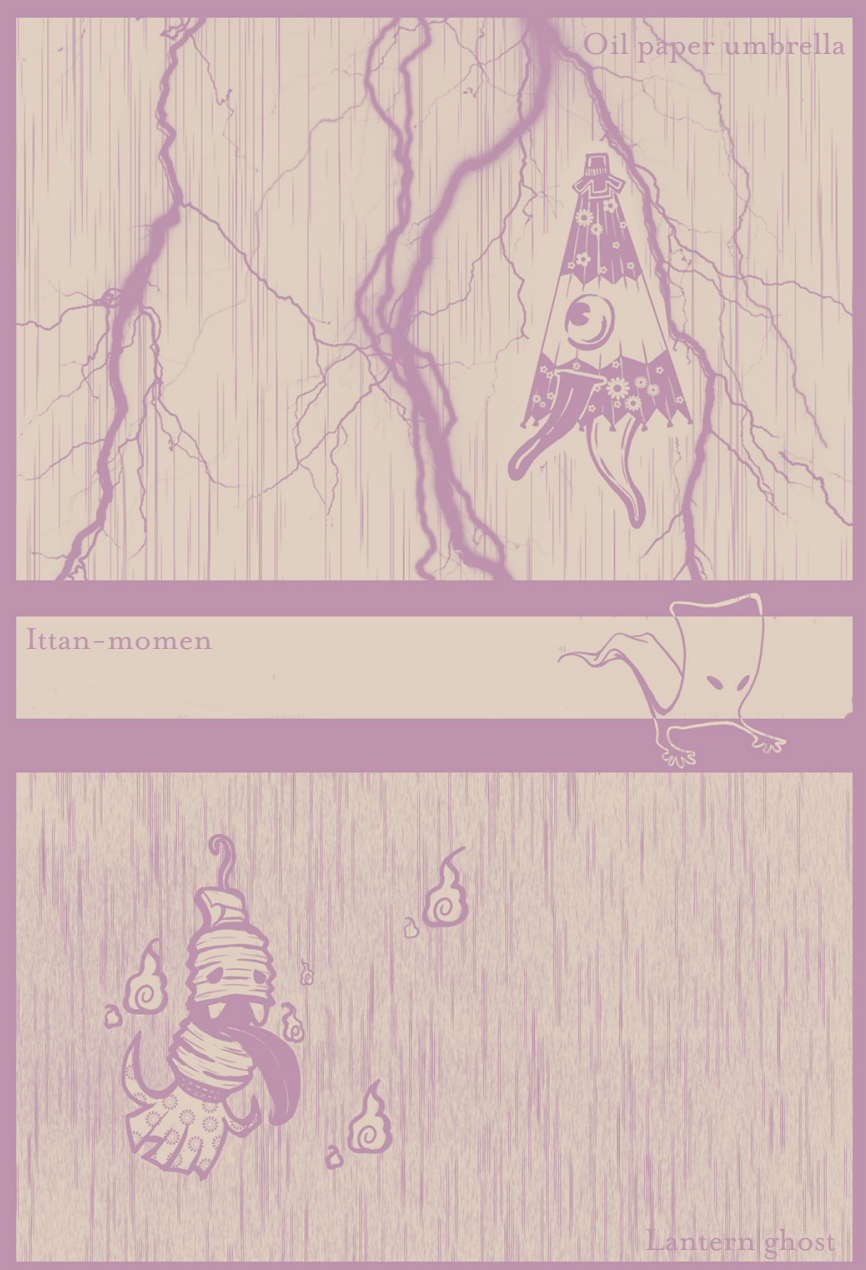
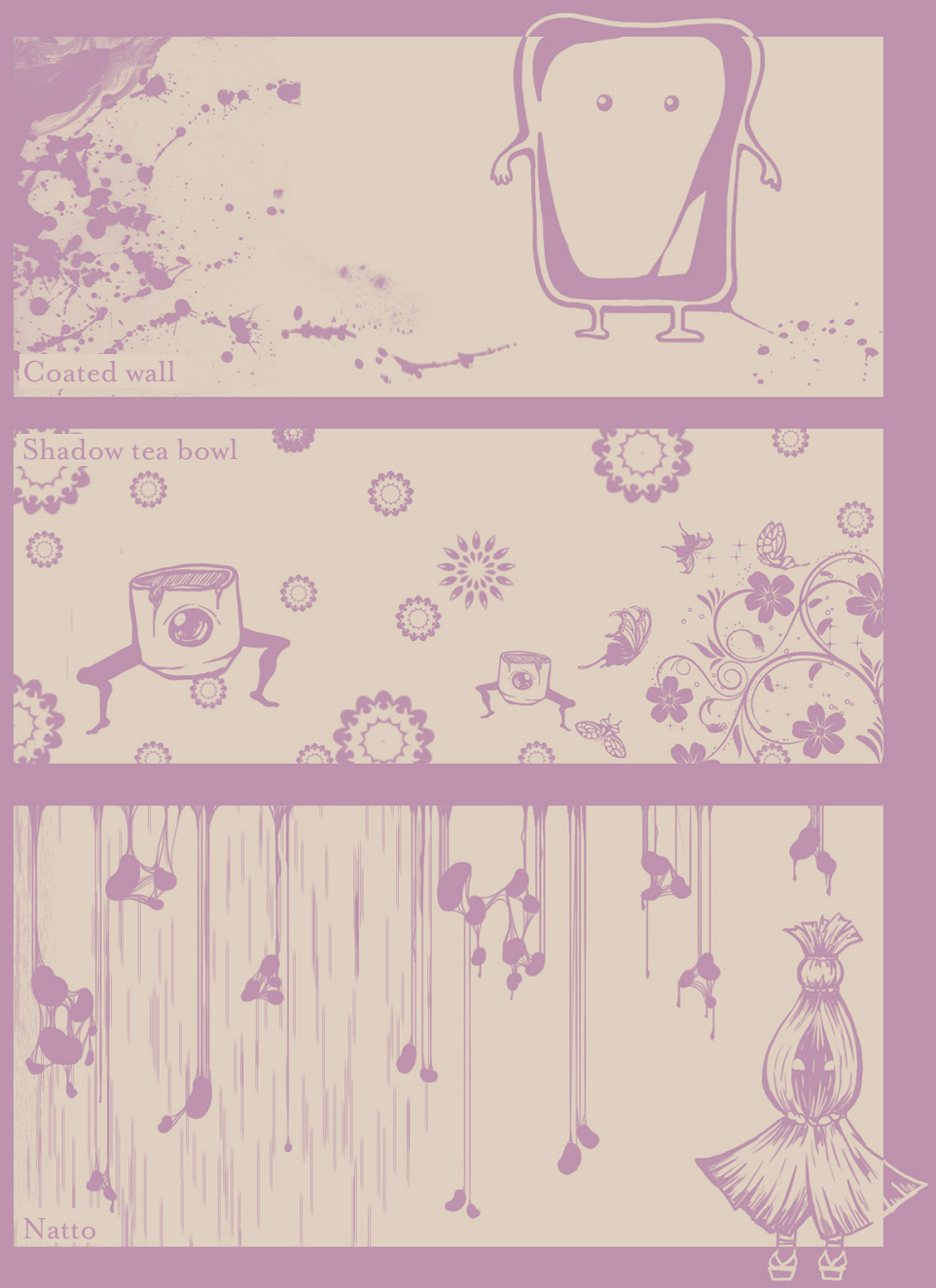

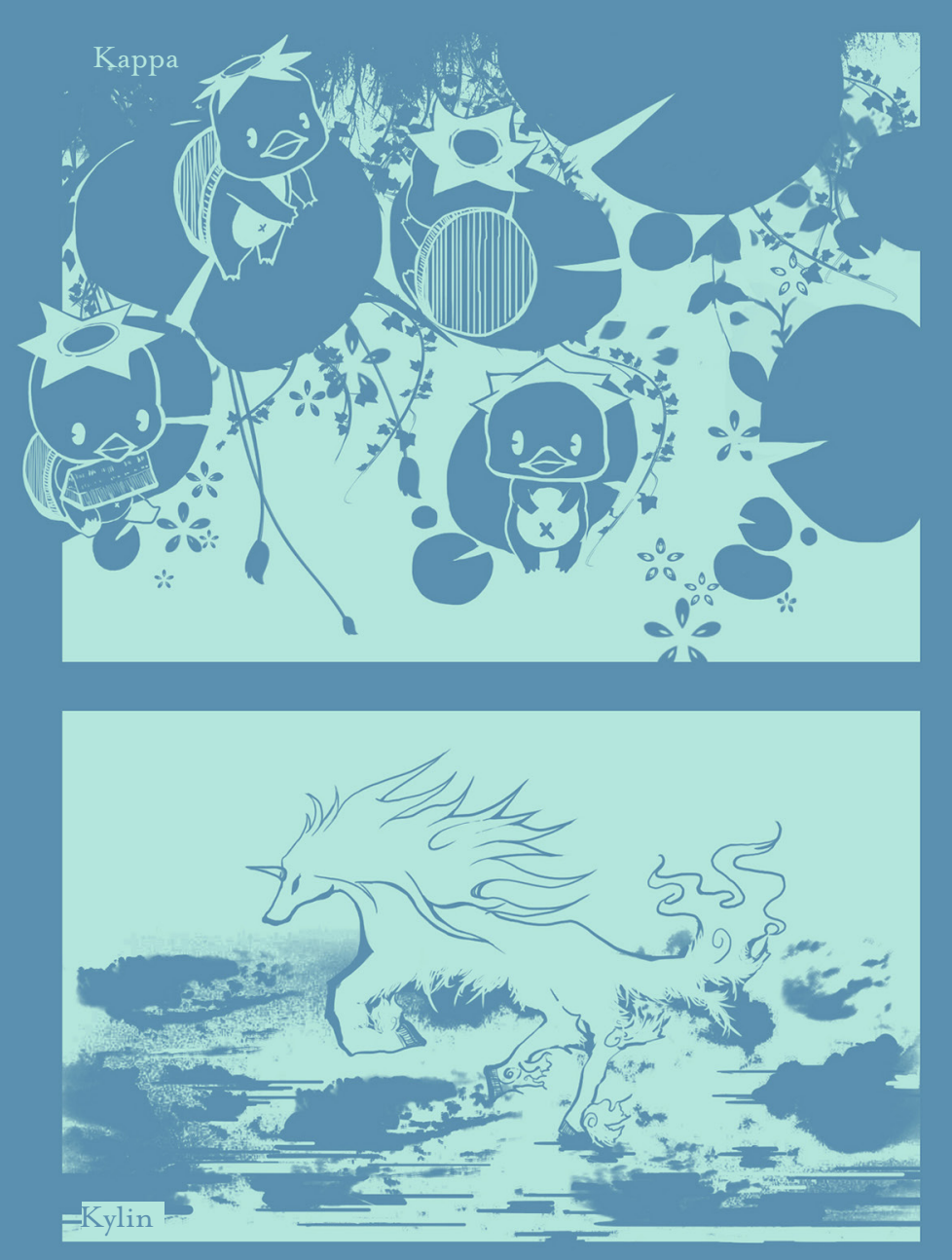
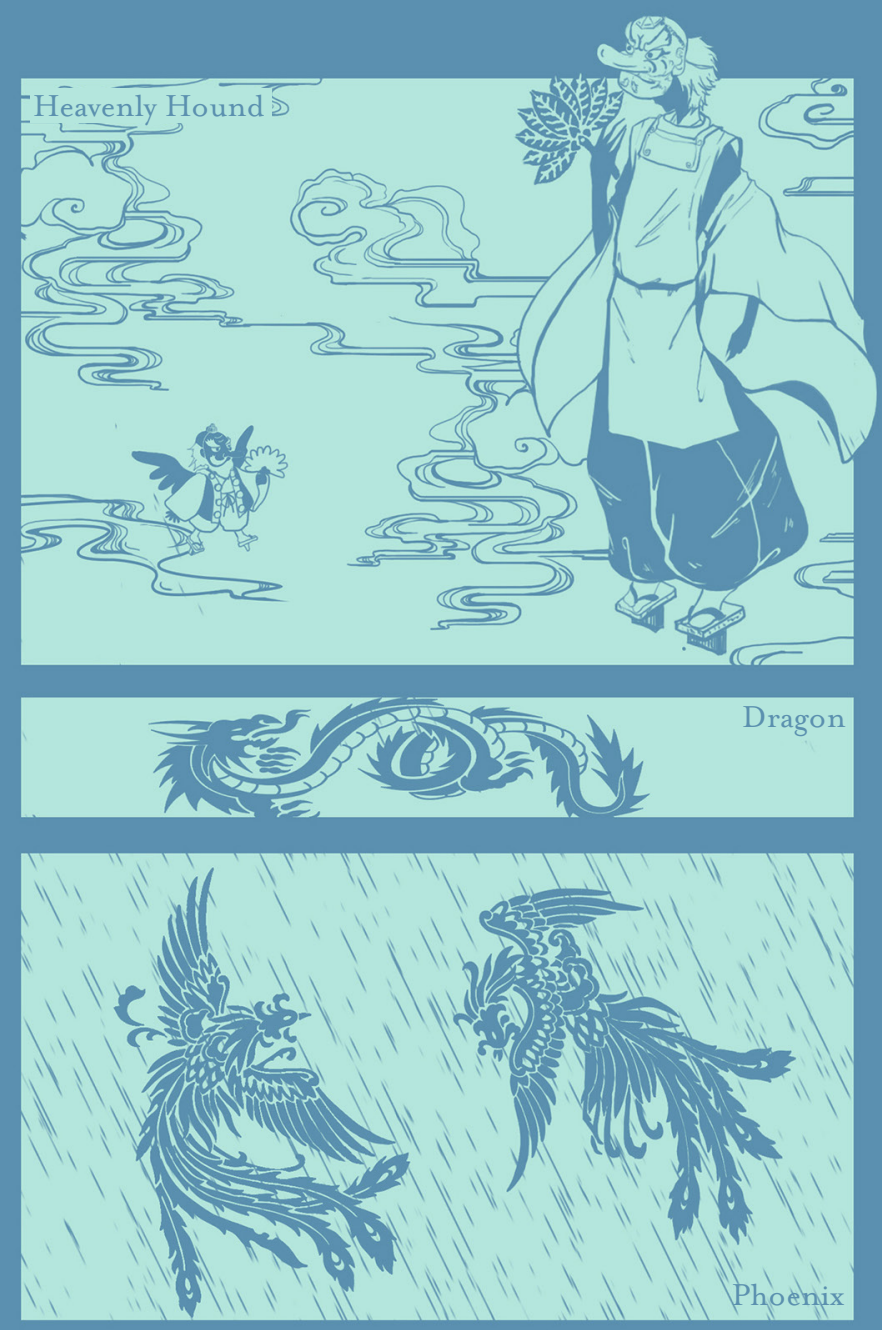
Crossing all categories of Youkai there is an imaginative hybridization showing on all types of them (Nicolae, 2012). Also, this feature makes the categories of some Youkai ambiguous. When placed in Youkai as a whole, they are elusive because they are inconsistent and unstable. The appearance of Youkai is always peculiar. In order to distinguish them from ordinary people or animals, monsters are strange in appearance and have obvious characteristics. Even if they are transformed into normal people, once they are discovered, the true shape under the disguise is still unusual. Finding out the common features of all monsters can assist better design of the features of dolls. 


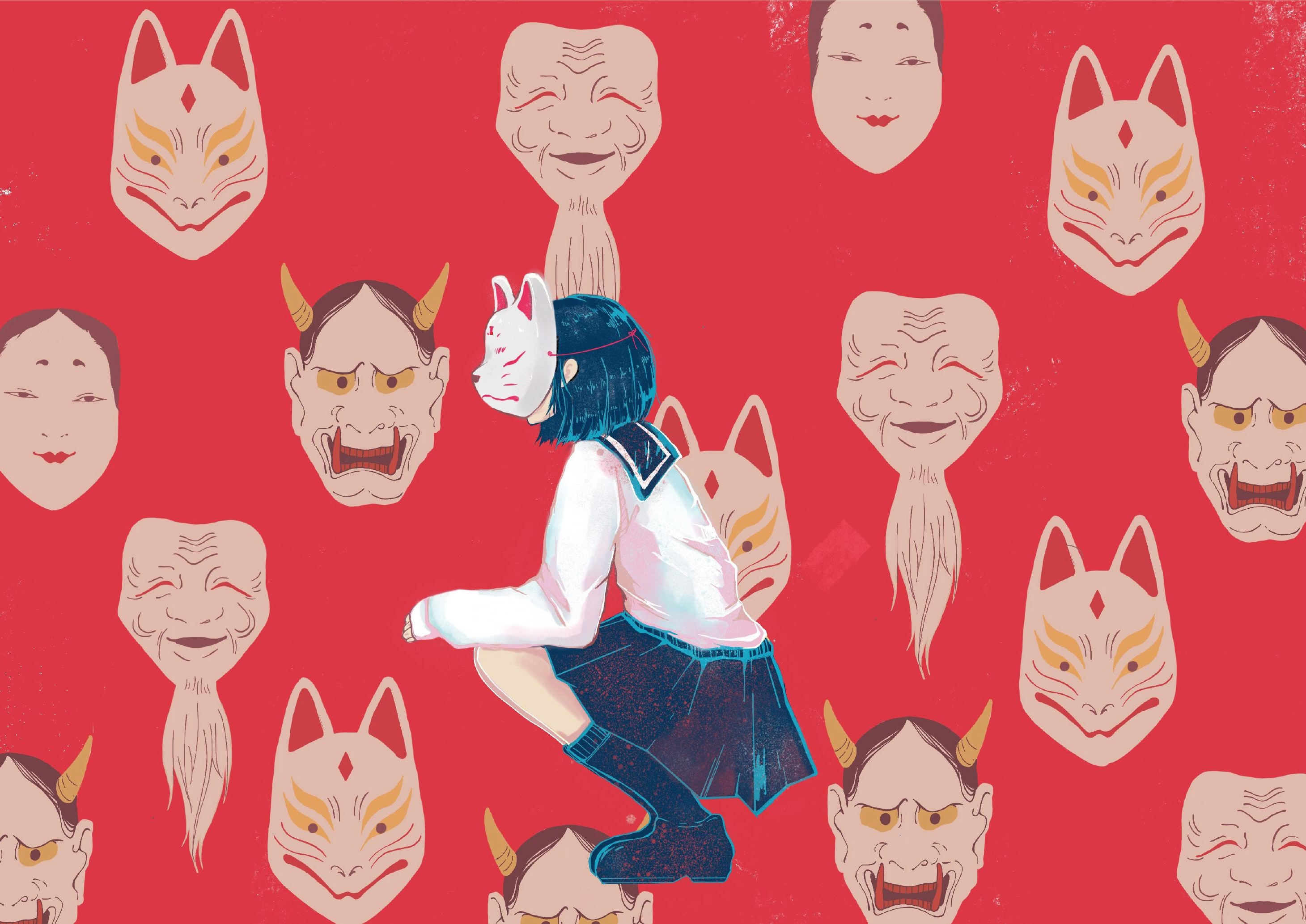


The human Youkai

Youkai with a human body or which has part of a human body. To distinguish them from humans, they usually wear masks. The legends behind them are often sad, bitter and resentful and they turn into monsters when they die. Some are powerful gods, so they can

have the image of human beings. 


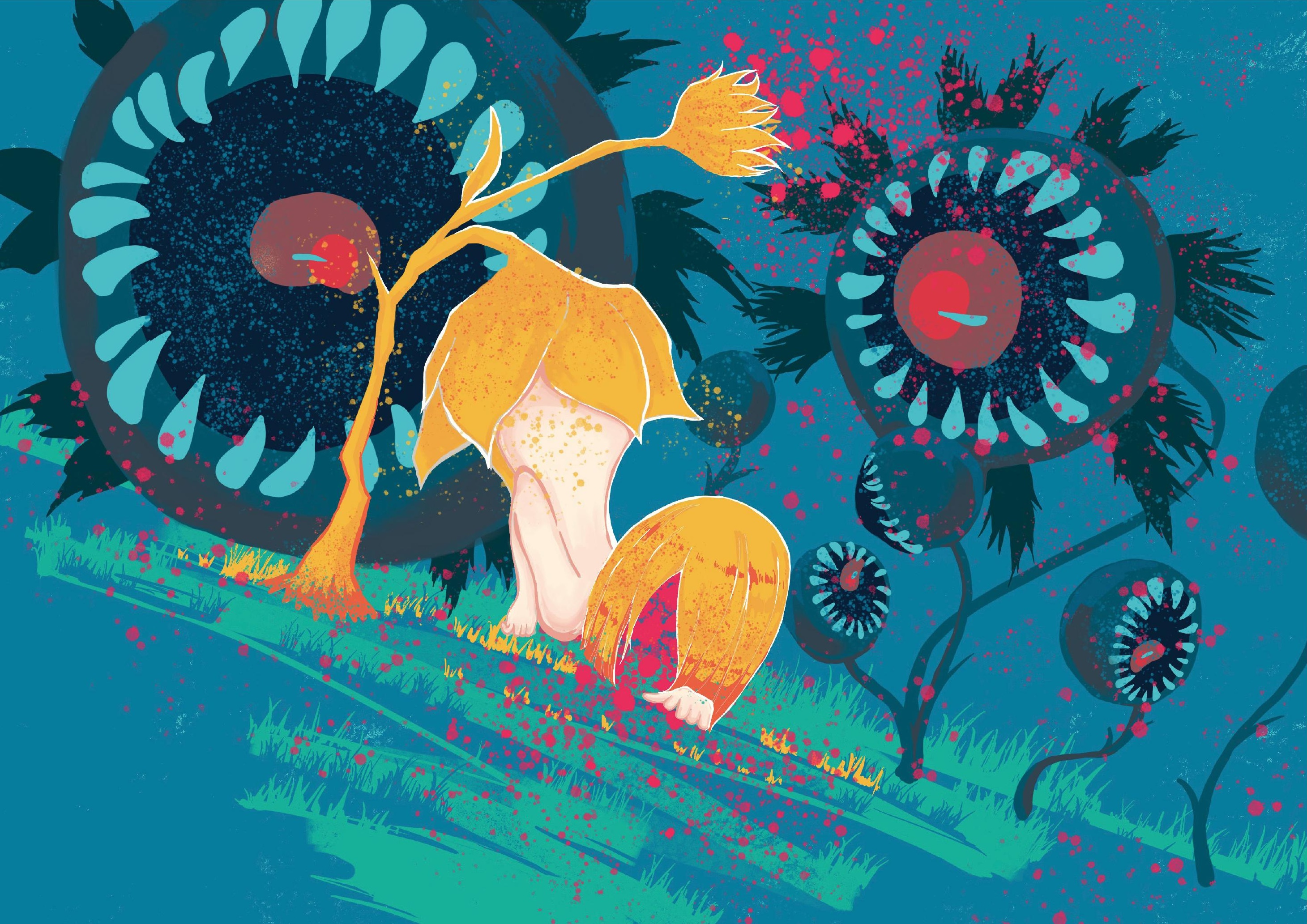




\section{The plants Youkai}

Youkai with plant features. Some

plants, such as some ordinary plants are immovable, others have the

characteristics of other species and

can move around. Most survive for

hundreds of years and have the local

spirit. It also became Youkai because of

special events. 


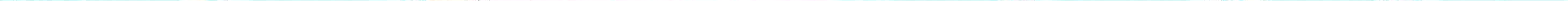




\section{The animal Youkai}

Youkai with an animal body or in an unmistakable animal posture, Most of them are the messengers of gods or shrines. There are also appearances and folk tales that often make mischief in the world. 


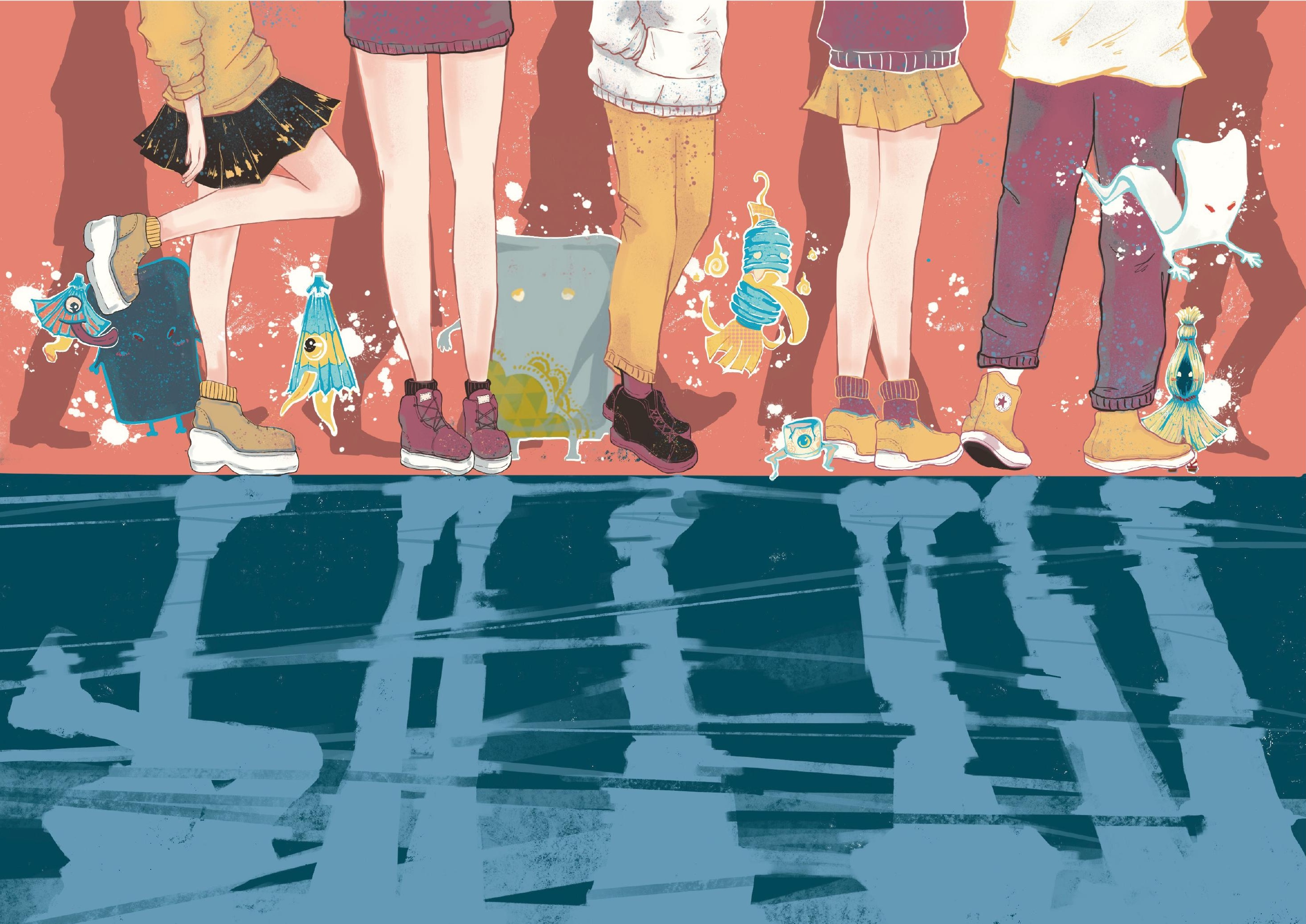




\section{The object Youkai}

Youkai is from natural phenomena or man-made objects. Usually it has been cherished and used before, but it has been abandoned or their important

parts appear in any famous stories. 


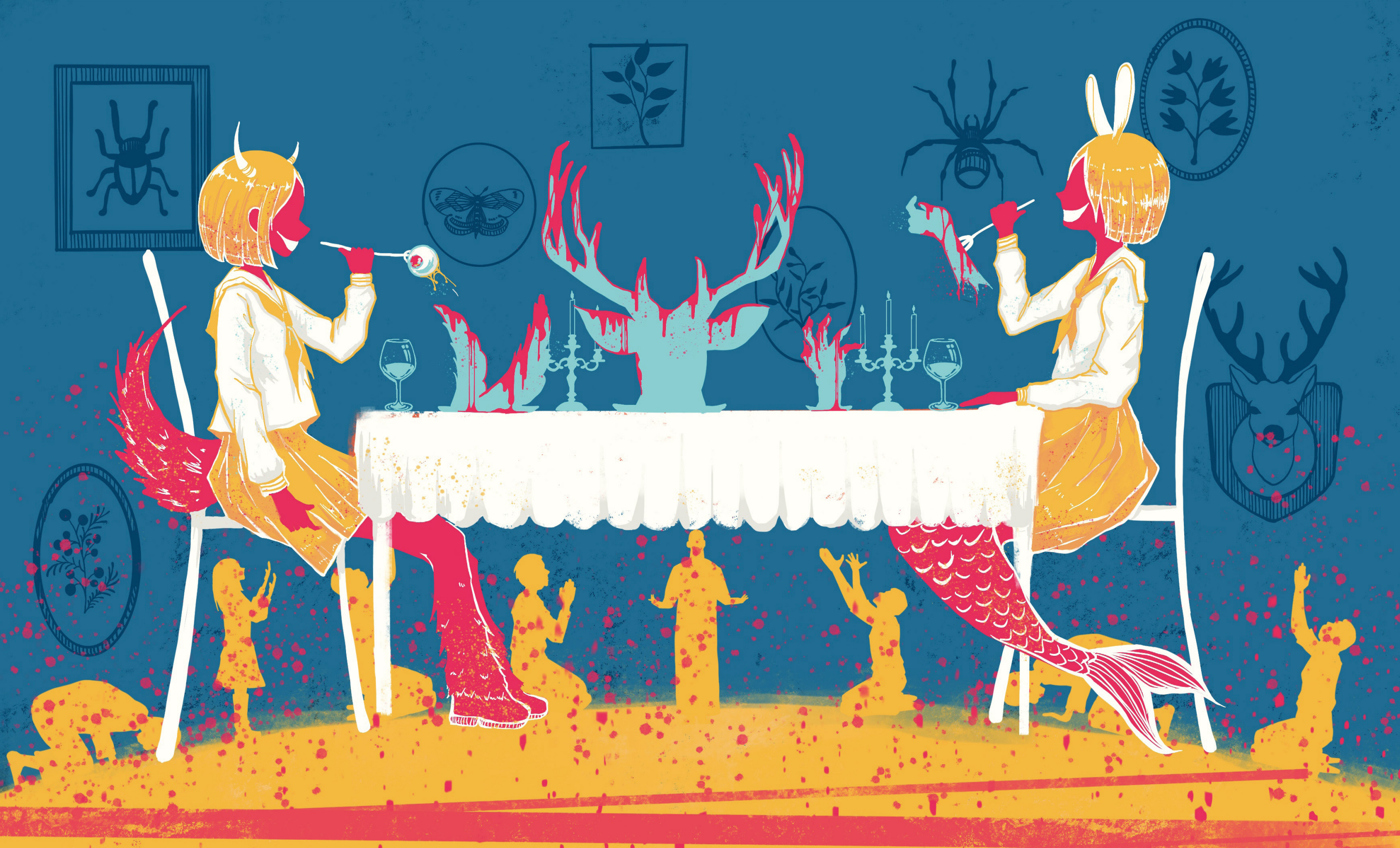


The mythology Youkai

Youkai which are formed by people's imagination. Human beings extract some features from different species and fuse them together. This type of

Youkai is usually dominated by gods. 


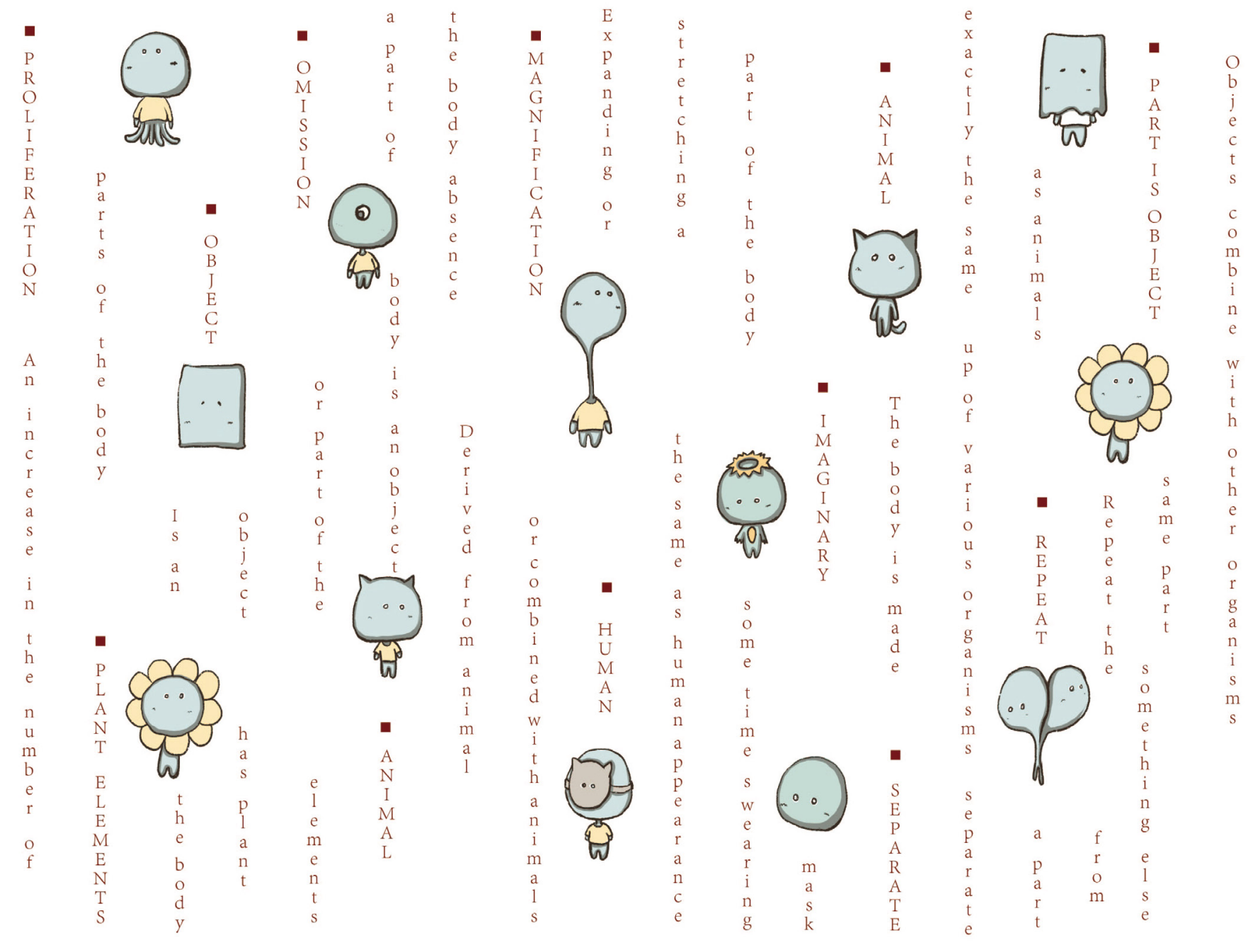

Figure 9. The common feature crossing all categories of Youkai 
3.4 Cultural Probes and
Question cards

3.3 Research through design 
3.Methodology 


\section{Methodology}

The current study used different methods, where I have separated my investigation into two areas. The first area is the design of dolls according to Eastern beliefs of Shinto. The second area is to understand the relationship between dolls and young collectors. In order to understand those two areas, I required a foundation of the relevant history and culture of Shinto as well as the interaction between sharing dolls with young adult collectors. This requirement led me to develop a combination of methods of research, which is research through design, cultural probes, question card, and narrative analysis. Also, ethical Approval was accepted for participant engagement and data collection.

\subsection{Research questions}

I. How might we design dolls according to Eastern beliefs of Shinto?

2. How might dolls according to Eastern beliefs of Shinto affect the relationship between dolls and young adult collectors?

\subsection{Aims and Objectives}

Aim I: To understand how the traditional Youkai story has developed using the doll in modern society

Objectives:

I. Identify relevant traditional Youkai stories and develop those characters based on them.

2. Design and share dolls with young adult collectors.

Aim 2: To understand the connection between the spirit of the doll and young adult collectors. Objectives:

I. Collect and document the experience with the doll through interactive exchanges with their participants.

2. Analyze stories that investigate the relevance of young adult collectors and develop their experiences with the doll.

Methodology: research through design

Research methods: Cultural Probes, Question cards, Narrative analysis 


\subsection{Research through design}

Research through design methodology is used when a researcher desires to gain new knowledge through the practical exploration of design methods (Frankel, 20IO). This research area includes the study of form and function with human activity, as well as the study of making process. Overall, this design process consists of four main stages.

The first two stages are directly related to the first research question. To answer the question of how might we design dolls according to Eastern beliefs of Shinto requires a systematical analysis and moves beyond the specifics of critical discourse analysis (as detailed in chapter 2). Thus, analysis is important for the Shinto beliefs and identification of relevant Youkai stories, which is the foundation of this project. The aim is to have a better understanding of these cultural assumptions of the text as well as find common themes that are significant in defining wonder and worth in this research field. This includes comparing existing Youkai stories as well as finding common features and characteristics of Youkai. The second stage is based on the result of the first stage. The doll is entirely handcrafted, and the characteristics of the doll are based on the Youkai stories that have been discussed.

The second stage of this research is largely related to engaging with participants. Ethical approval for this aspect of the project was granted by the Victoria University of Wellington Human Ethics Committee (appendix I). To understand the connection between the spirit of the doll and young adult collectors and solve the question of how dolls according to Eastern beliefs of Shinto might affect the relationship between dolls and young adult collectors. Therefore, it is necessary to build a relationship with participants. This is because the collective experiences between participants and dolls are the most significant fact within the second stage. Thus, in order to study the connection, I also collected and documented the participants' experience through question cards, images and video. The participants played with dolls in various ways and shared their stories and experiences with me. They condensed these experiences into answers based on the question cards and agreed it was the best way to document their stories. In addition to the use of question cards messaged the stories, a social media app (WeChat) was used up as a conversation tool for all participants and myself to engage in discussion and collected all visual information (images and videos). This process also employs design tools and interventions to recruit participants to promote real expression through illustration. The story was being evaluated through the recreation of visual communication.

\subsection{Cultural Probes and Question cards}

In order to understand the question of how dolls designed according to Eastern beliefs of Shinto might affect the relationship between dolls and young collectors, a cultural probes method needs to be introduced. The cultural probes method is a technique used to inspire ideas in a design process (Gaver et al., I999). It is a tool for gathering data about people's lives. The time that participants shared with 
the doll is valuable data for this project. Cultural probes method provokes inspirational responses from the participants.

Participants can play with dolls in any way they like. I did not give participants any restrictions or interfere with the way they play with the doll. To assist them to create the story, I provided question cards to encourage the participants to express themselves.

The question cards method is a strategy for gathering detailed information from participants and translates their stories into an experiential structure (Koskinen et al., 2003, p. I26). The cards have some questions about participants' perspectives on dolls and their experiences shared with the doll. After one-month, the experience that participants shared with the doll becomes a memory. That information facilitated storytelling in the second part of the research. Thus, the cards are the connection between the participants and the designer.

In order to build a better story, I enlisted the question card method. Those cards guided the story and it assisted participants to illustrate the information in detail. These instructions led to a practical session about the questions that the participants would feel capable of answering and stories that they would able to create.

To attract the participants' attentions, the back of the question cards was made as a picture puzzle. The first three questions are an attempt to lead the participants to create the character of the doll. Question four and question five are trying to get information about some particular event that occurred during this period.

Whereas the last question is more flexible as it provided an impetus to stimulate creativity.
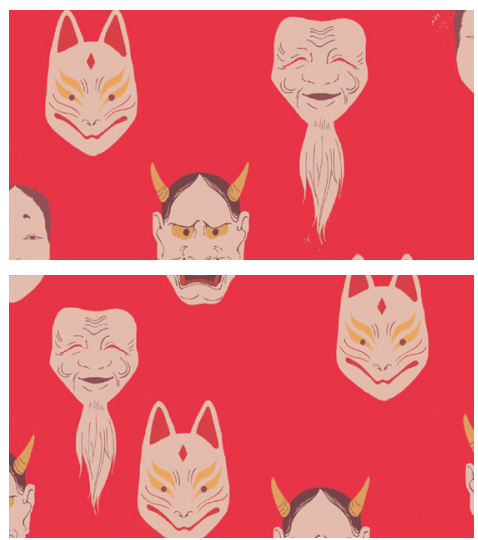
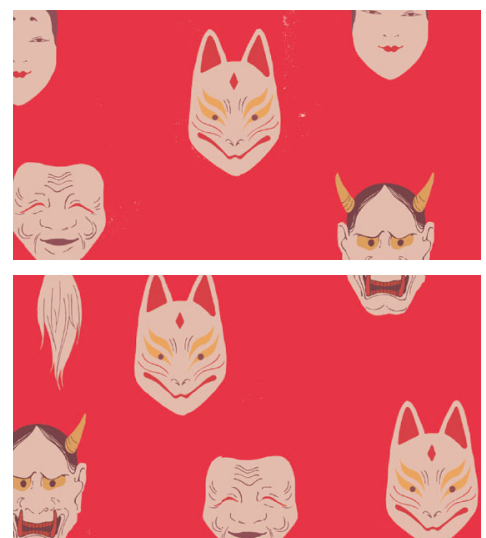
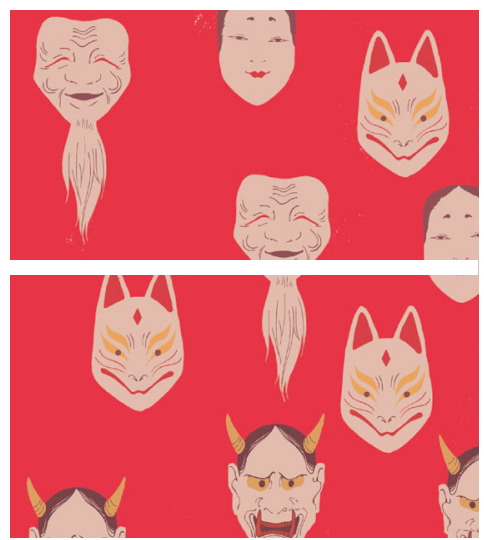
Figure 16. The front of the question cards
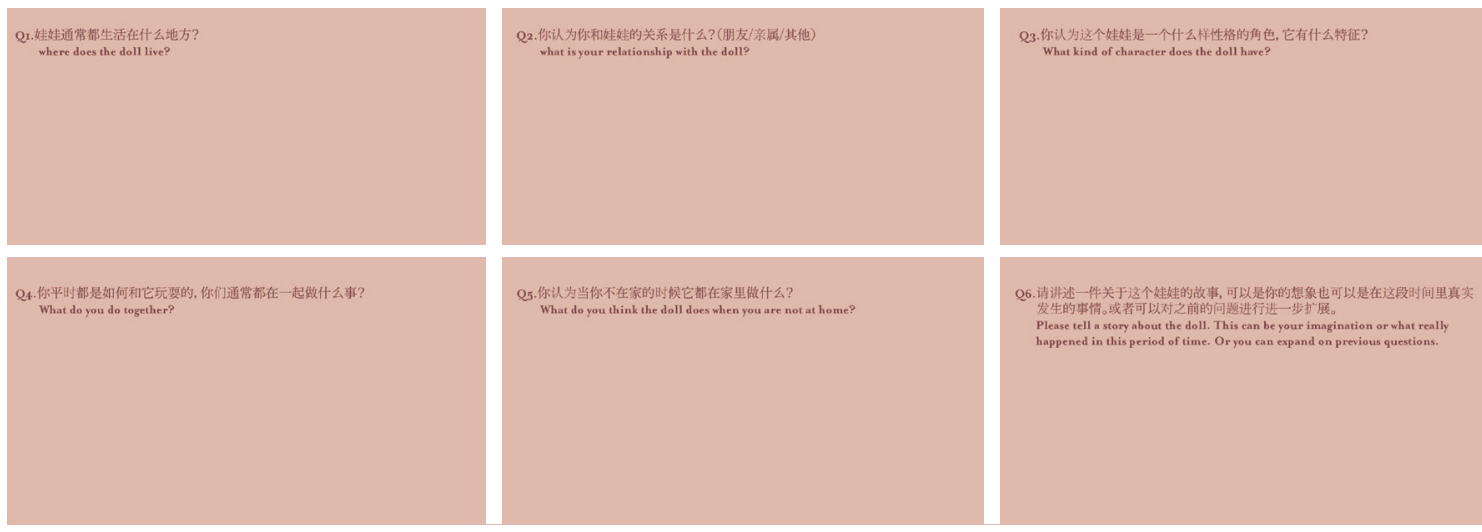

\subsection{Narrative analysis}

Narrative analysis explores how people make and use stories to interpret the world (Smith, 2000). This method is used to analyze stories that investigate the relevance of young adult collectors and to develop the story of the doll. The narrative analysis assisted focus on studying individual participants and gathered data through their stories. I created visual narratives to report the experiences that participants shared with the doll. The stories developed a chronological order. The story resulted in a visualization of the themes and bought together extensive information. The fantasy life they shared with the doll is embodied through the content of the participants and the unique words they use. 


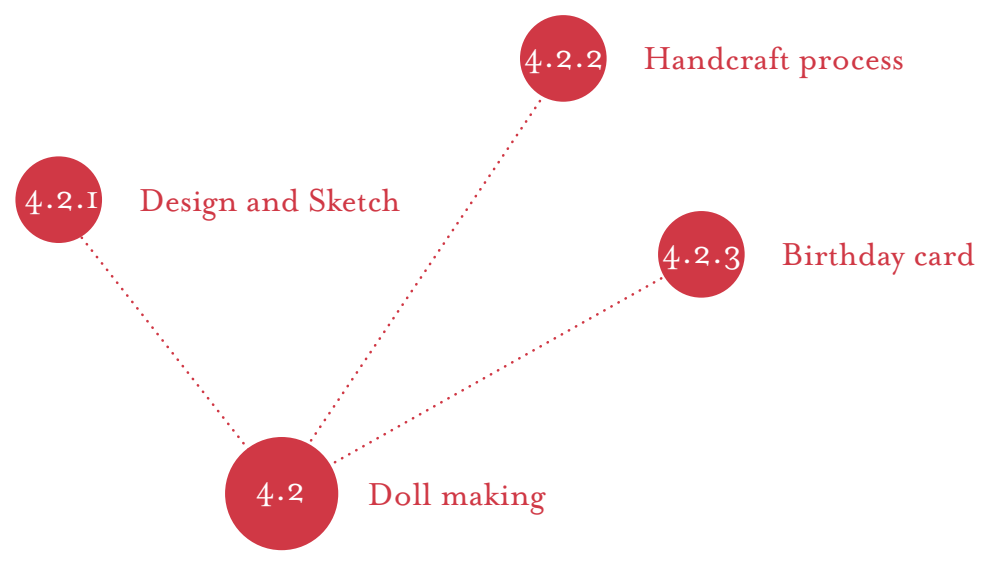

4.I The power of handcraft and nature

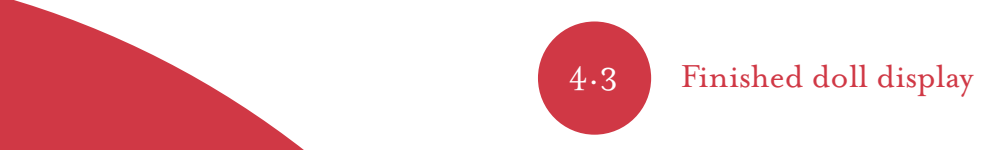




\section{Doll making}




\section{Doll making}

If the study the Shinto belief and Youkai stories are the process of trying to prescribe the doll a soul and character, then the making process is to turn this intangible character into reality. The images of Youkai that can be obtained through research usually appear as stories or pictures. Using the extracted characteristics of these images from the last chapter and turning them into dolls as a tangible object is part of this research.

\subsection{The power of handcraft and nature}

In modern manufacturing, most products are made mechanically. However, I have been fascinated by traditional handcrafted products since a young age. I think hand-made accidents and traces are infectious. The aesthetic in Eastern culture, greatness always hides in obscure and negligible details. The time, environment and the slight accident during the making process creates a special form for the object. Also, the handcraft process limits the quantity of the product. This approach lends the quality and value of the doll much greater than the manufacturing figure.

Contrary to Western beliefs that is obsessed with perfection, symmetry and ideal proportion. Eastern aesthetics are very different indeed. They emphasized the beauty in imperfection and depicted a rough or often faded beauty. One reason for this difference is captured in a term of wabi-sabi (Prusinski, 20I2). Wabi-Sabi is part of the Shinto belief in Japan. In the understanding of wabi-sabi, a wilted flower is beautiful, a bunch of unmodified huts is beautiful, and a colorchaotic teapot is gorgeous. Because of the concept of wabi-sabi, Eastern culture appreciates not perfect symmetrical objects made by machines but hand-made traces. These arrangements should be flawed to make the items more natural and casual. Wabi-Sabi aesthetics concentrates the essence of Japanese Shinto culture and art culture, but also concentrates the aesthetic consciousness from the senses to the heart, from objects to nature.

In the field of doll design, the persistence not only embodies the charm of handicrafts but also explains the craftsman spirit in silence. For instance, Artist Marina Bychkova who made Enchanted Dolls believes that dolls are not just toys because, they have meaning and souls (Doll reader, 2009). The appearance of every hand-made doll is like giving the soul the same story from their eyes and the expression. Moreover, the doll-maker of this doll is also like being enchanted, shaping their beautiful dreams day and night. She considers eyes are the window to the soul and that is the most time-consuming part of the making usually taking four weeks, a doll takes Iooo hours (Doll 
reader, 2009). There are many failures of the ceramic body burning. Each doll is unique high-end customization. Thus, the spirit of the work of craft is to call all kinds of things and sense. In other words, to emphasize how the craftsmen have awakened the sleepy soul devoutly by hand and gives a new soul of the objects using such artistic activities.

\subsection{Doll making}

\subsubsection{Design and Sketch}

The doll-making process started by deciding on the characteristics and features of the doll. All the characters of dolls are chosen from the categories of Youkai stories discussed previously. Because of the doll was a present for the participant. Therefore, I did not choose the story with a curse. The Youkai I chose were neutral or had a double side. This enabled the participants to accept the dolls and expand their stories better. At the same time, this setting helped me to gain a better understanding of the relationship between dolls and participants.

The feature of the doll is extracted from the previous study of relevant Youkai stories and with my original design. Four of them come from different categories and each of them has a particular feature. This characteristic is not just emerging as some particular feature from the Youkai but it also shows the color, balance and the material. Furthermore, for enhancing the value of the dolls, all dolls are made with designer doll style which is realistic, sophisticated and beautiful.

Figure 17. Sketch of As designer dolls, their template designs are confidential. Over the years of doll design process, I the doll with animal created my own unique template. All designs evolved from this template.

Youkai Characteristics-

Mametanuki

Figure 18. Sketch of

the doll with mythology

Youkai Characteristics-

Hakutaku

Figure 19. Sketch of

the doll with plants

Youkai Characteristics-

Momijigari

Figure 20. Sketch of

the doll with human

Youkai Characteristics-

Kokakuchou 
(1)

animal

$\left[\begin{array}{ll}\ddot{B} & y 9\end{array} \rightarrow\right.$ Manetanuki」

- tace

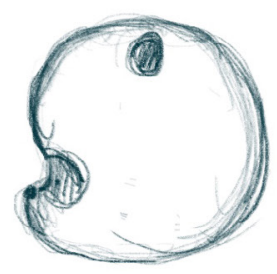

(1)
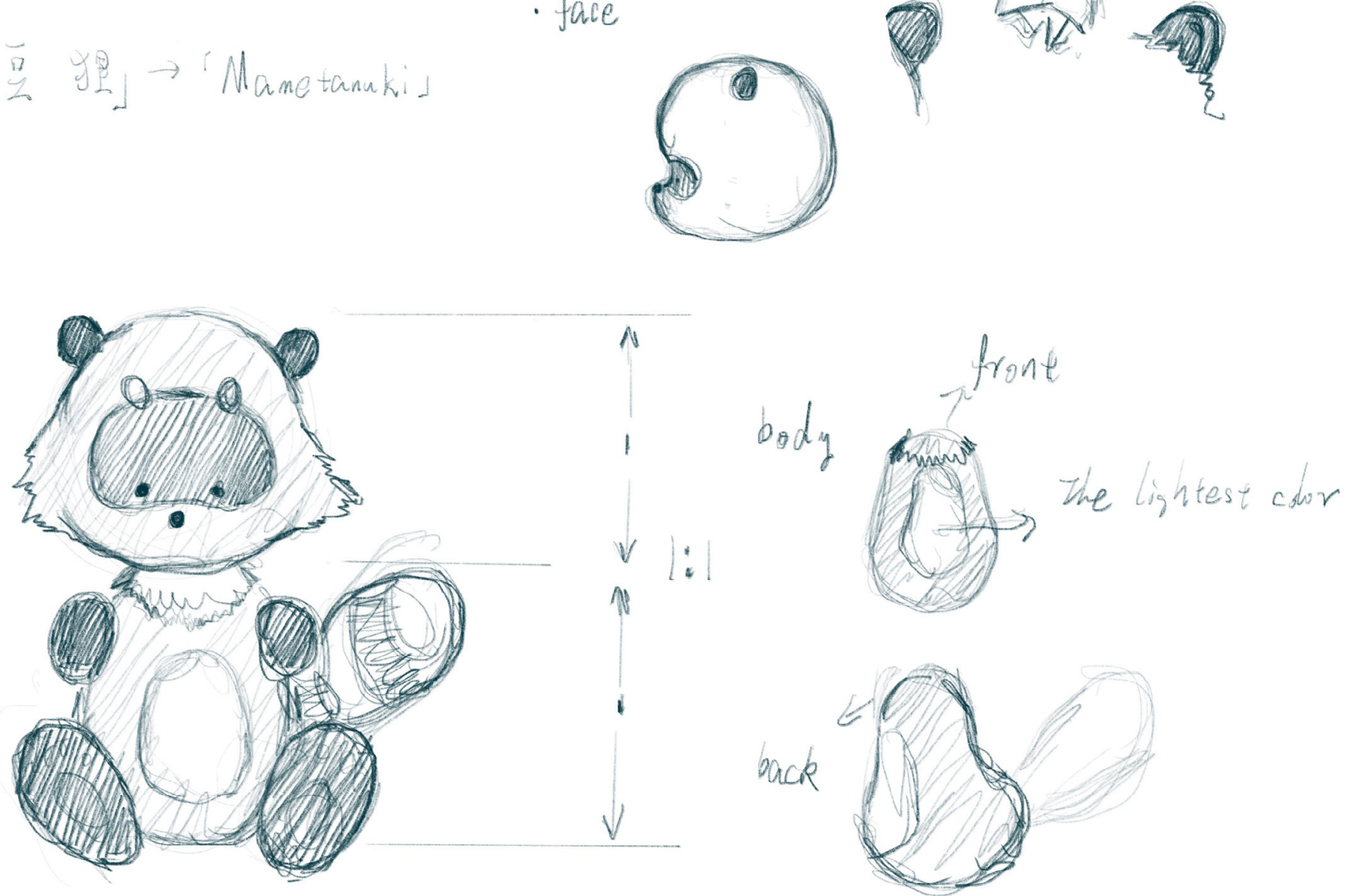

arm
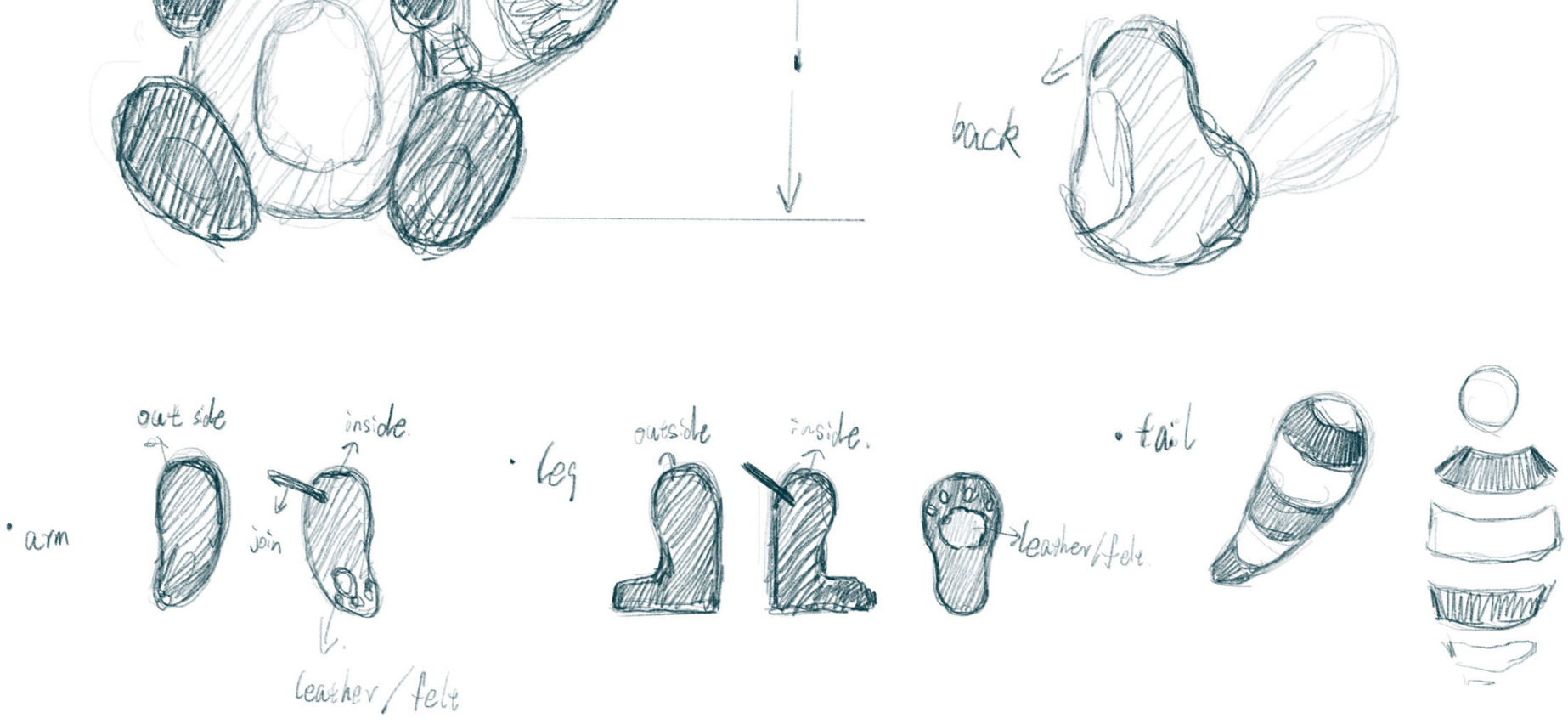
(2) imare / fantasies
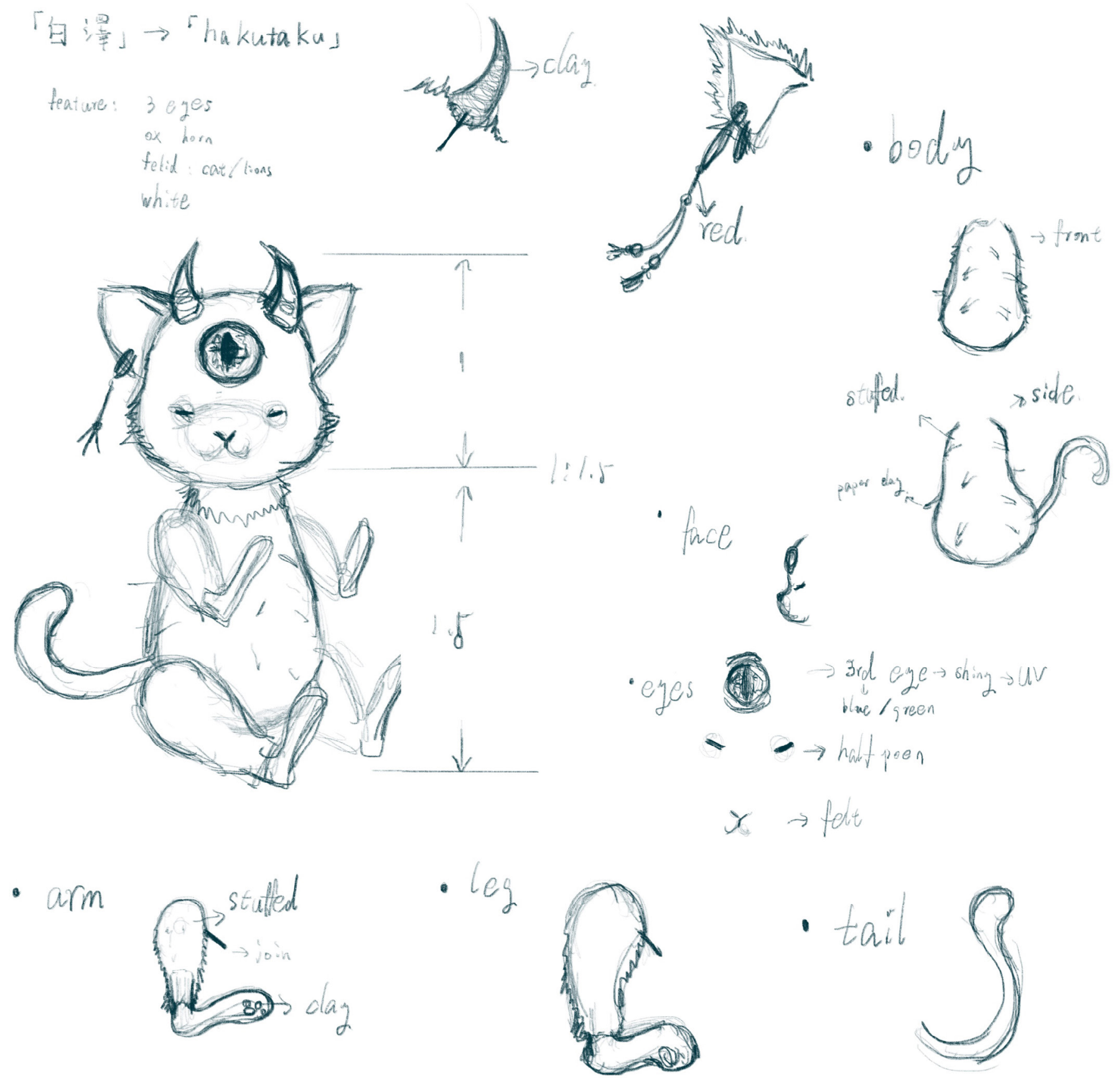
(4) plant

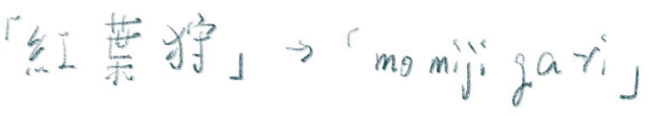

features: red.

plant
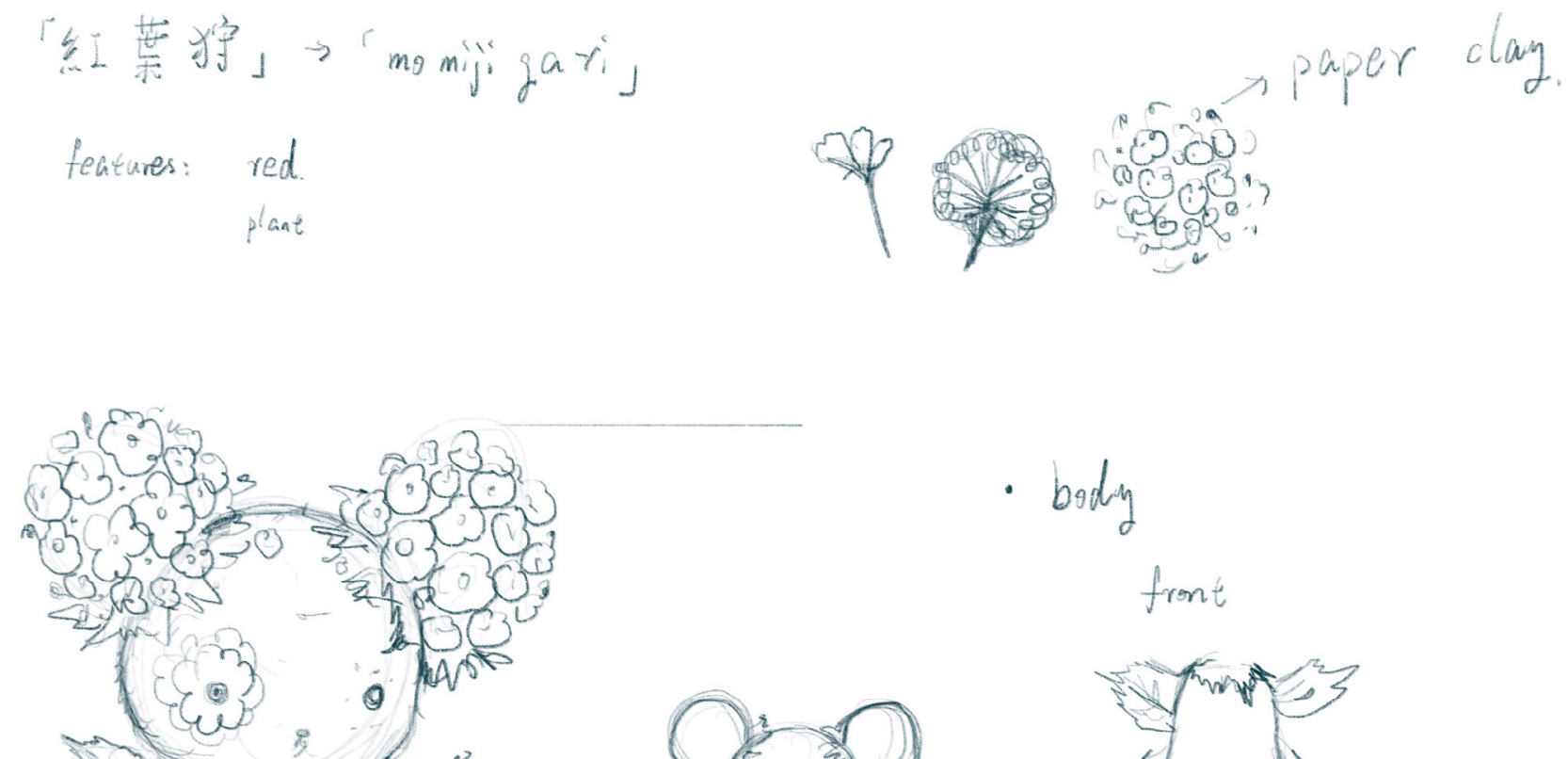

- body
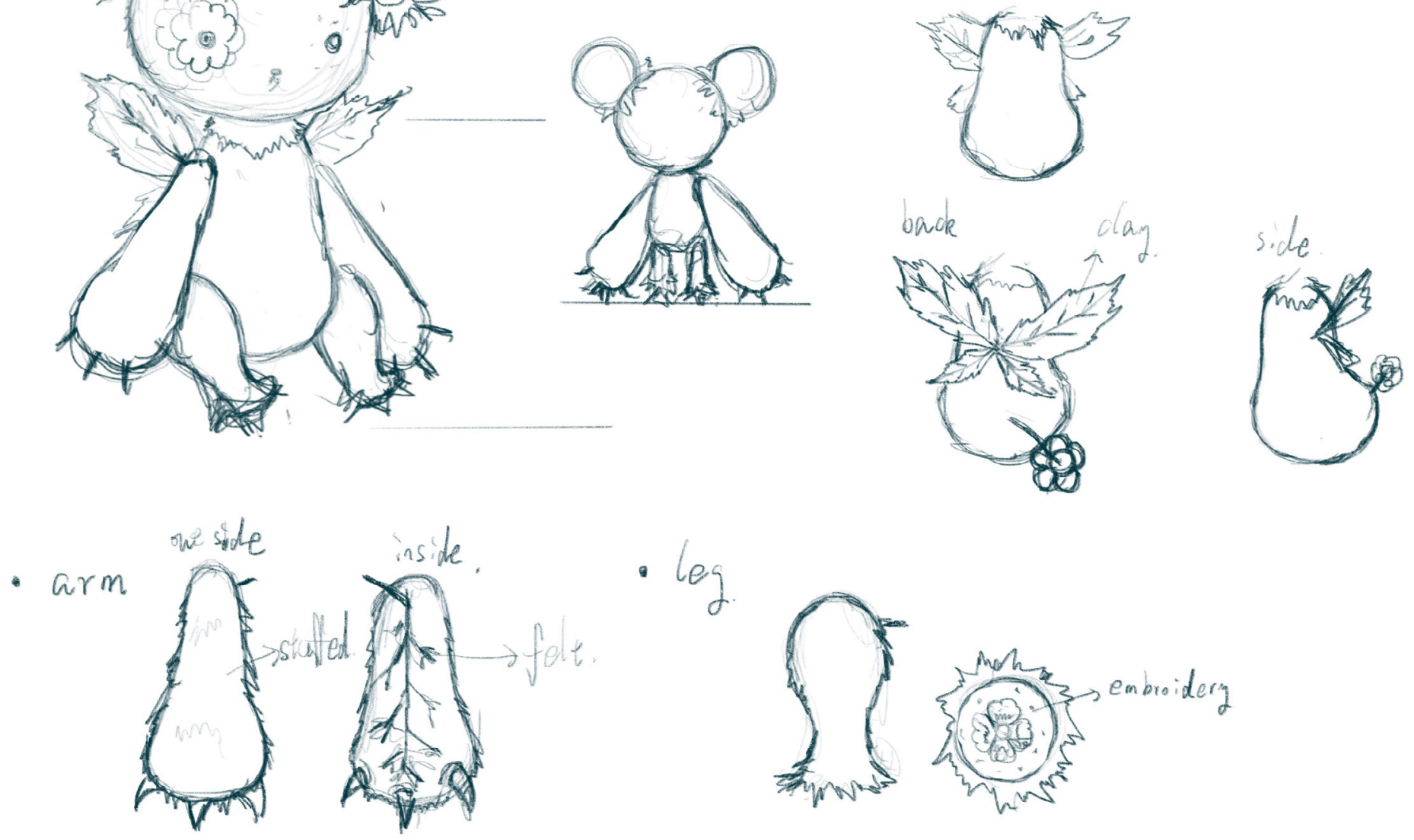

- leg.
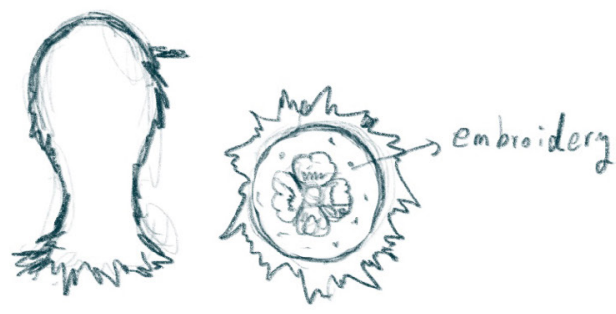
(3) has human teratres

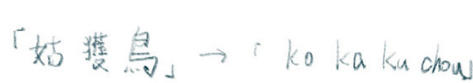

fexiures; womant brid
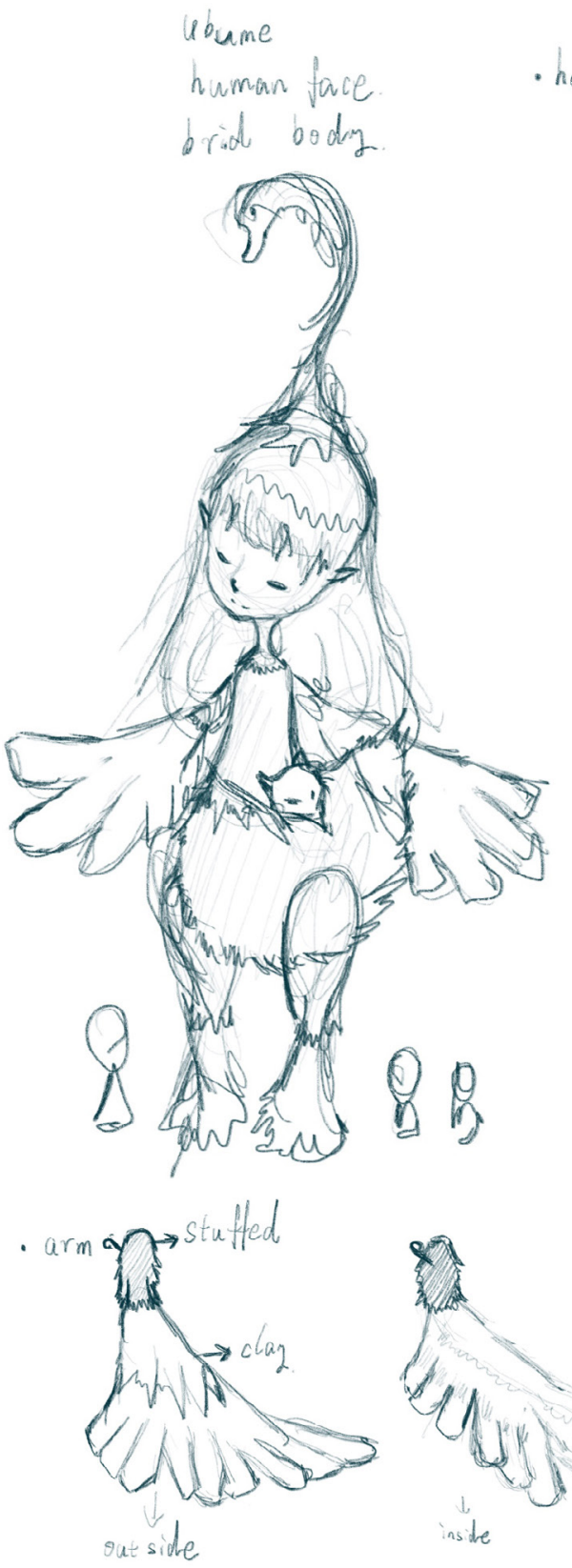

- ohildren

繁彩

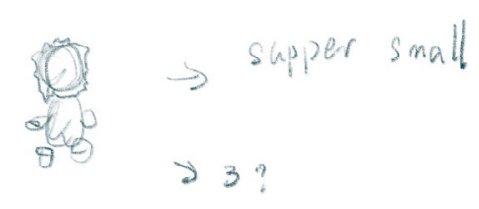

- body.

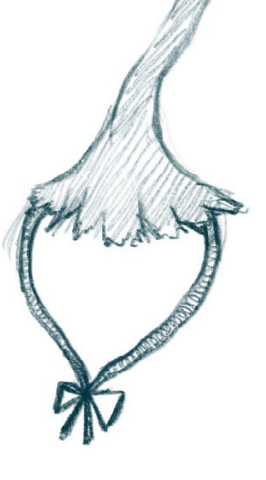

sido front

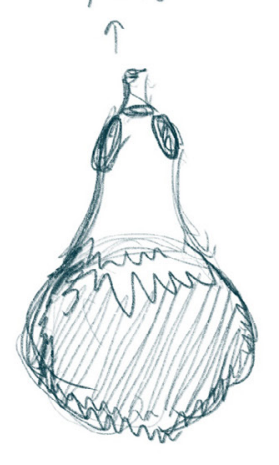

- mask

ary

Les 


\subsubsection{Handcraft process}

Tools: fabric, felt, felt fabric, clay, paper clay, acrylic paint, wire, plastic eye, waterproof pigment, feather, wig, false eyelashes

The value of designer dolls is that each of them is one-of-a-kind, whether it is from the character design or crafting process. Each of them has an original template from the shape of the design to the detail of the decoration. Also, it is the time I put everything I have into the dolls. According to Shinto beliefs, when I put my time, energy and emotion into the dolls, the miracle of awakening of doll started to happen. Because these dolls are all purely made by hand, they are not the same as industrial designed products that have the same shape and the same design. The minor changes in production make them even more special and unique. Each of them can only be created at one

Figure 21. Handcraft process time, that situation and by me at that moment. They are all one.

Mametanuki
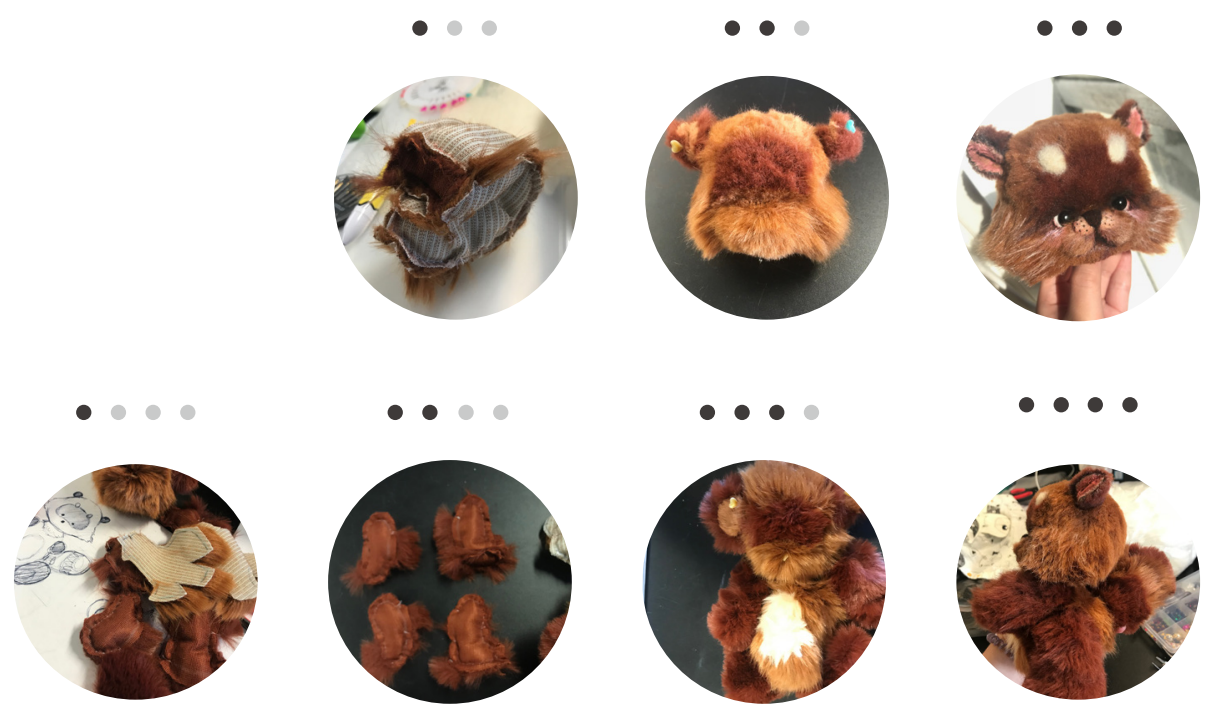
Hakutaku
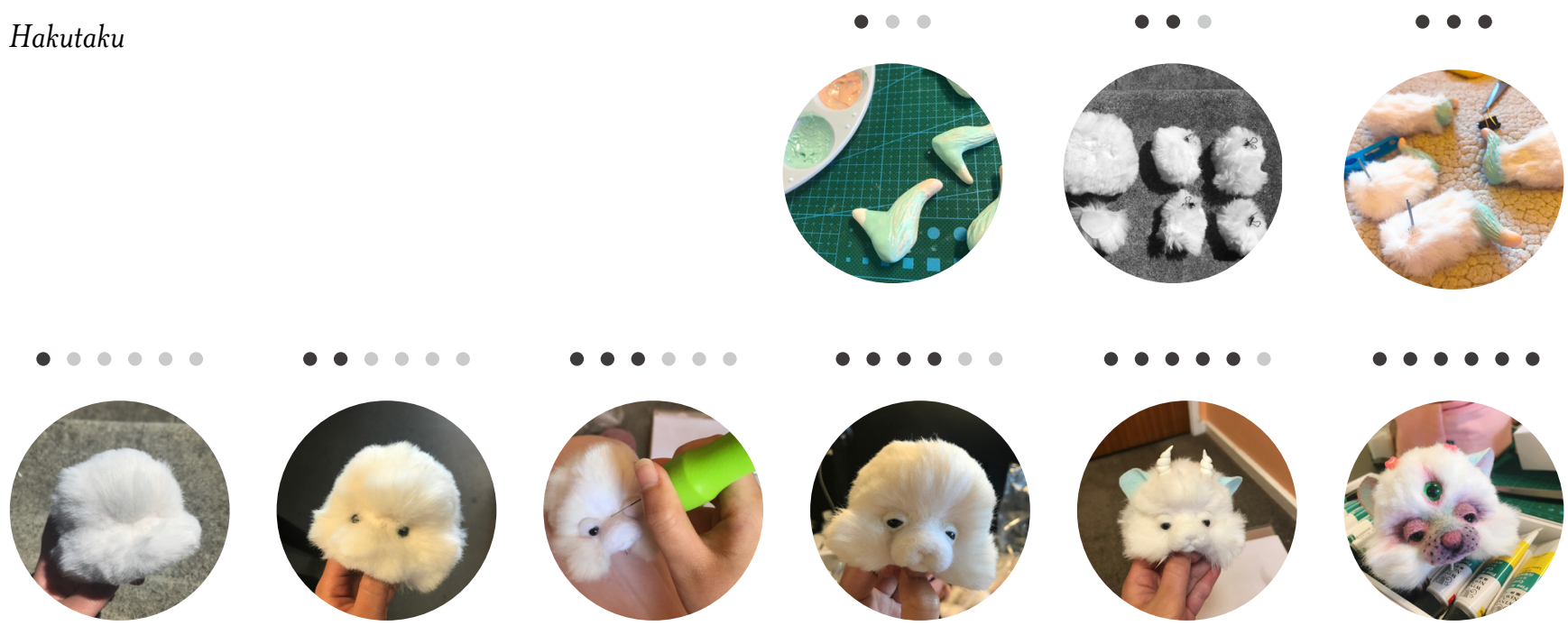

Momijigari
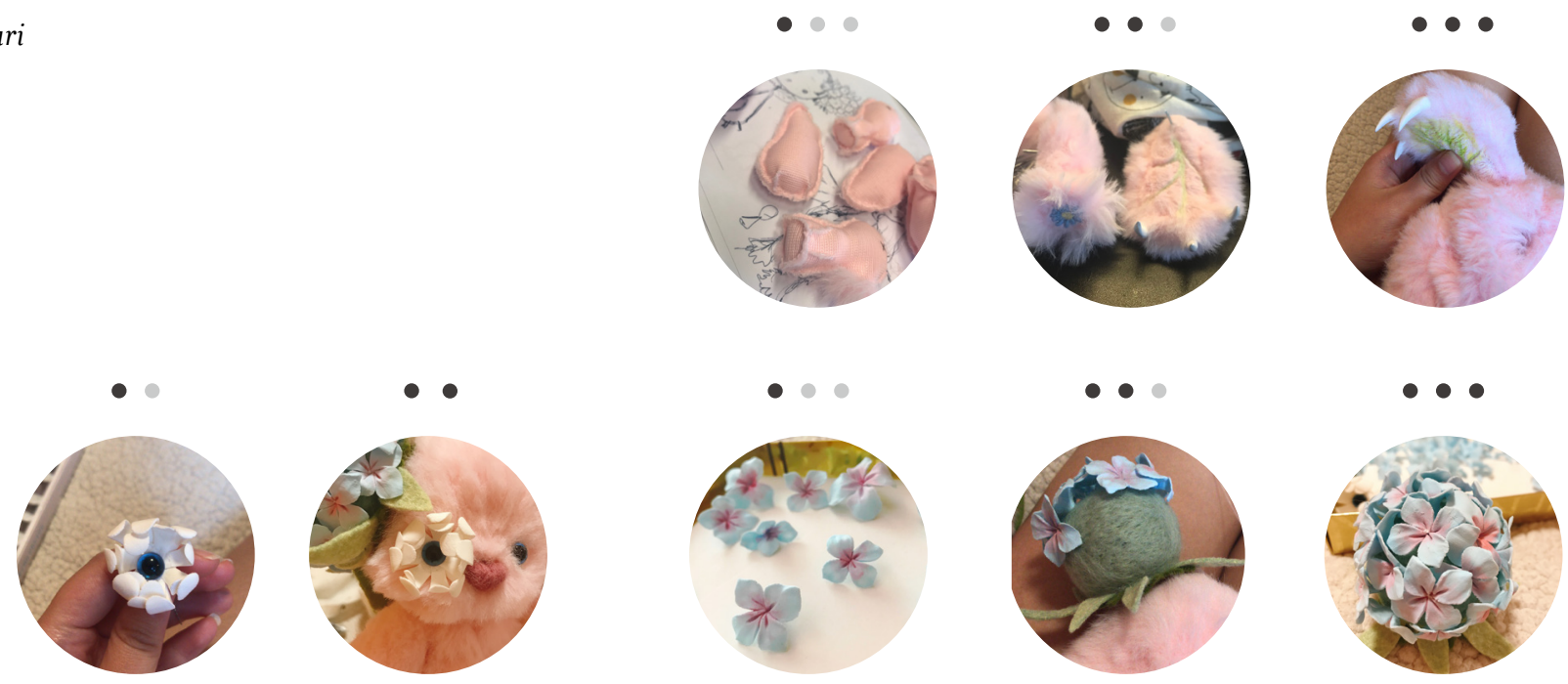

Kokakuchou
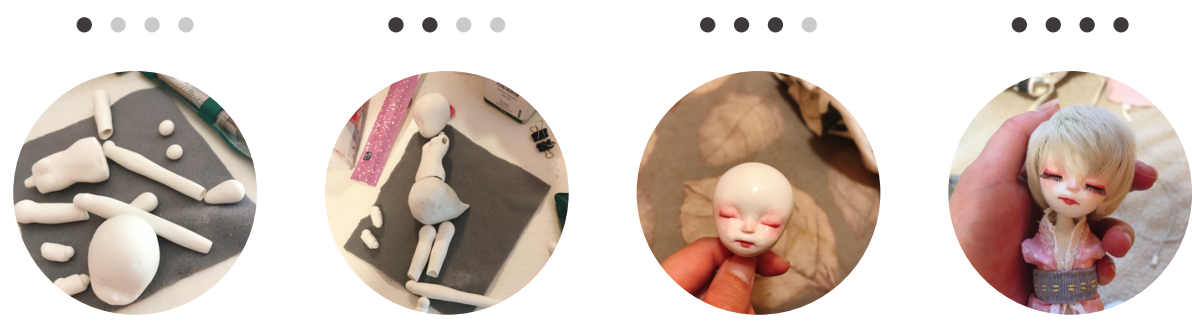

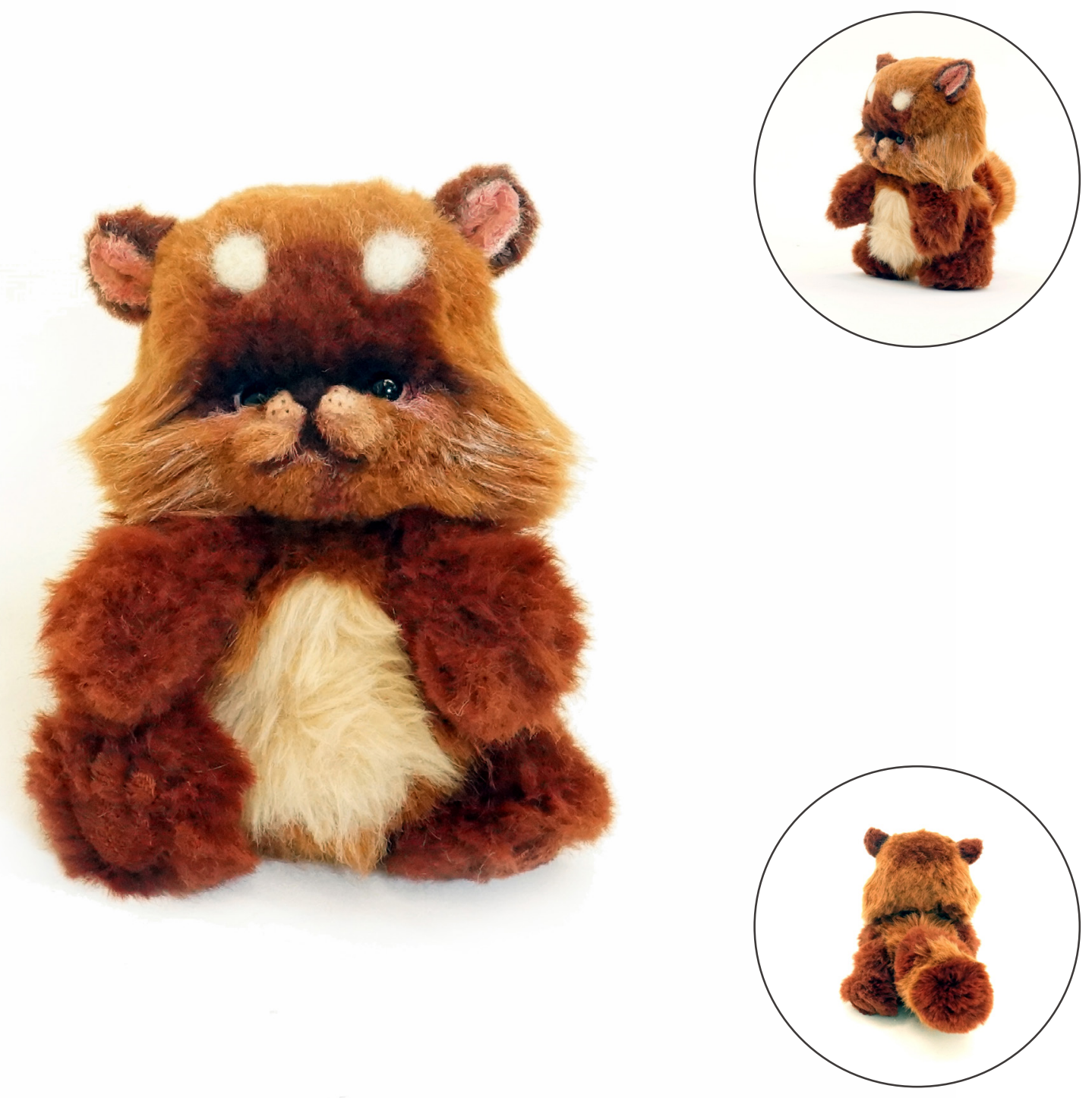

Figure 22. Mametanuki 1 


\section{Mametanuki}

The design is based on animal Youkai.

Characteristics: original character tanuki (raccoon dog)

Design inspiration: The Mametanuki is the cute character. The feature is based on the animal tanuki. To increase this image, the doll is designed with a big head, big tail, and short legs. The head and the body balance is one to one which is like a child. The design feature is almost relying on the tailoring pattern. There is no fancy decoration and complex shape which makes the character resemble a child.

Image: big head I: I body balance, three colors, brown basic , duck hair in the middle of the face, big white eyebrow at the top of the head, small eyes, small ears, and red inside, fluffy beard and white color inside, big tail.

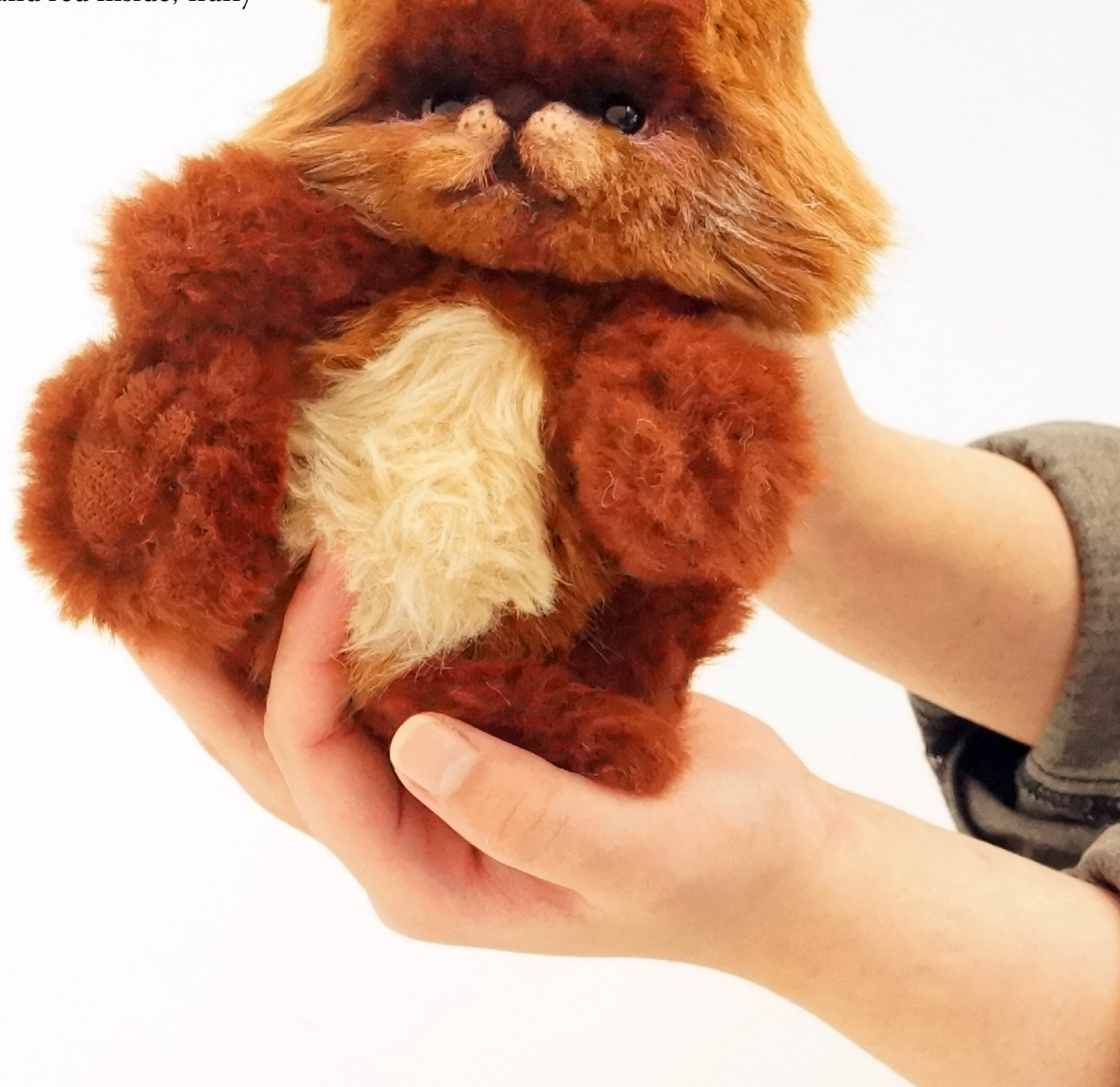



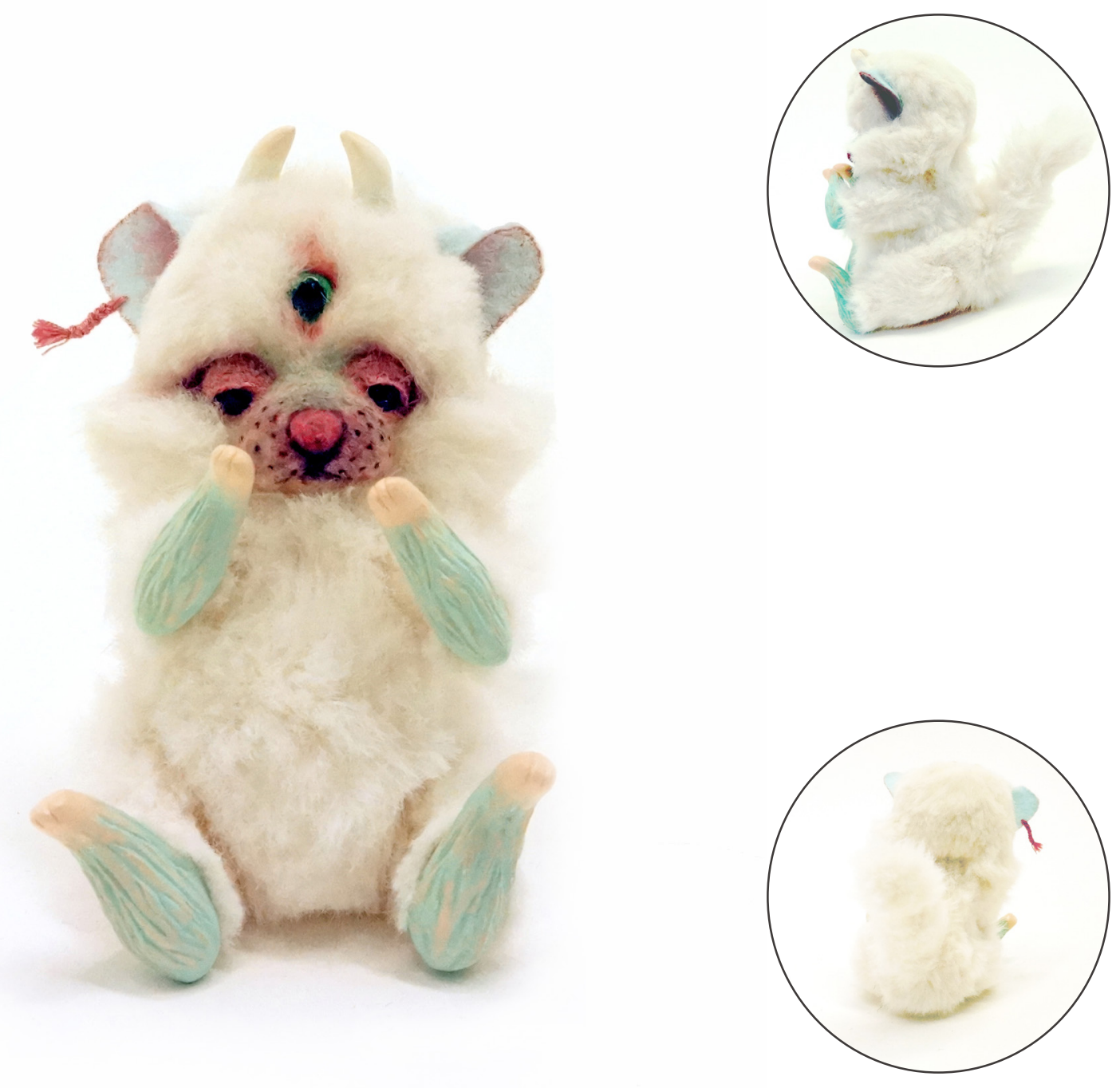

Figure 24. Hakutaku 1 


\section{Hakutaku}

The design is based on mythology.

Characteristics: The original character is from a fantastic beast from Chinese legend.

Design inspiration: The Hakutaku is the cool character. The feature combined with different animal elements.

These are enhanced by the sophisticated design on the face and the hard material was used on the legs. Thus, the color of the doll has a white base which shows the mystery of the mythological characters and the color on the face is colorful which shows the fantasy element of the character.

Image: White basic and blue in parts, small head, cat face, three eyes, two black and one blue, big ears and one with earing, pink eye shadow, pink nose, long tail, cat legs.

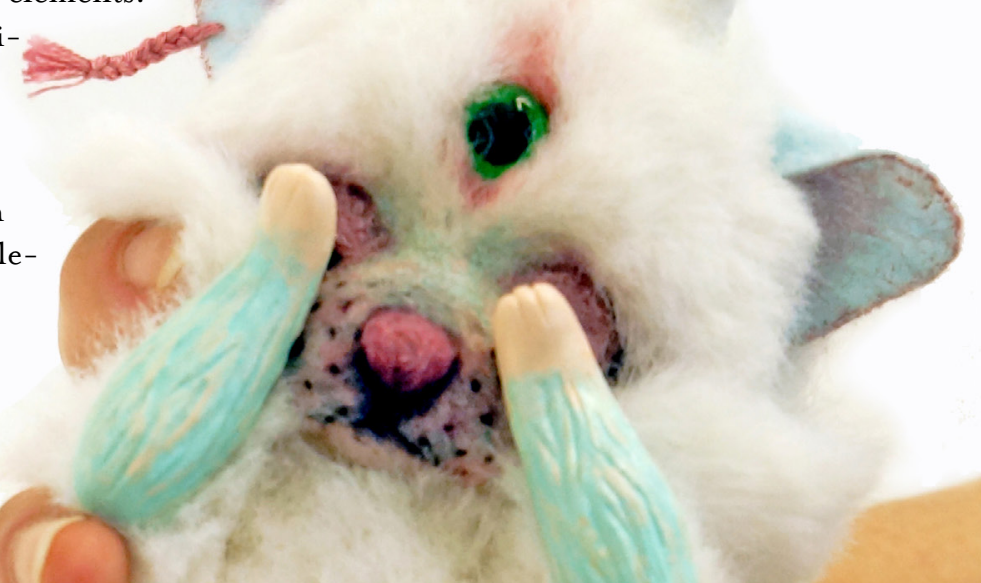



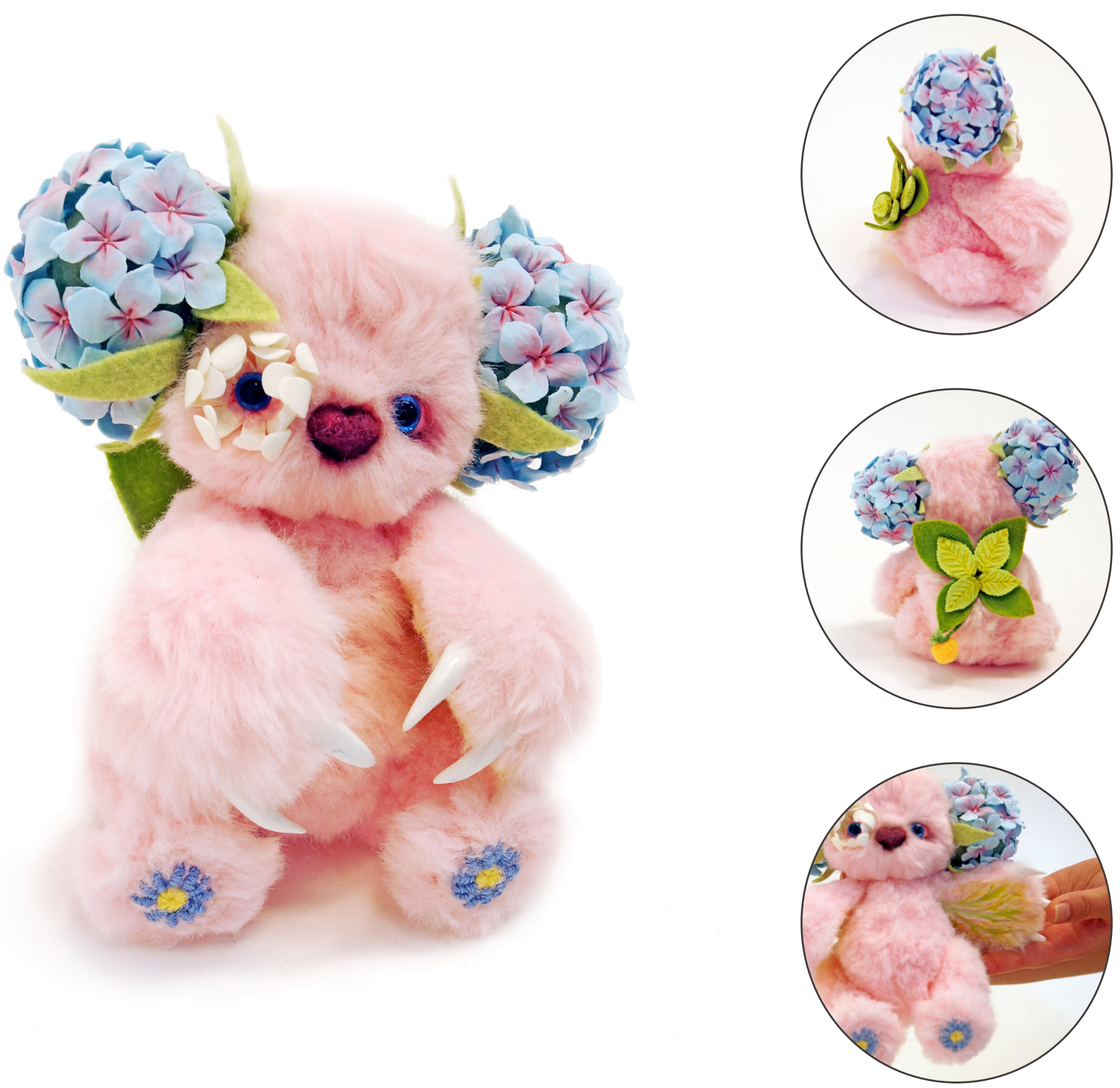

Figure 26. Momijigari 1 


\section{Momijigari}

The design based on the plant Youkai

Characteristics: The Momijigari comes from plant stories

Design inspiration: The Momijigari is a fascinating character. The features are based on the Hydrangea flower. In order to have a better demonstration of the decoration, the body of the doll was designed more simply and all the intricate details are shown on the decoration. Furthermore, I made the design to look less gaudy some of the decoration is hiden inside. It is also surprise element when someone holds the doll.

Image: pink basic, one eye with white flower, two big blue flower ball, leaf wings, yellowtail, hands with paws, leaf vein inside the arms.

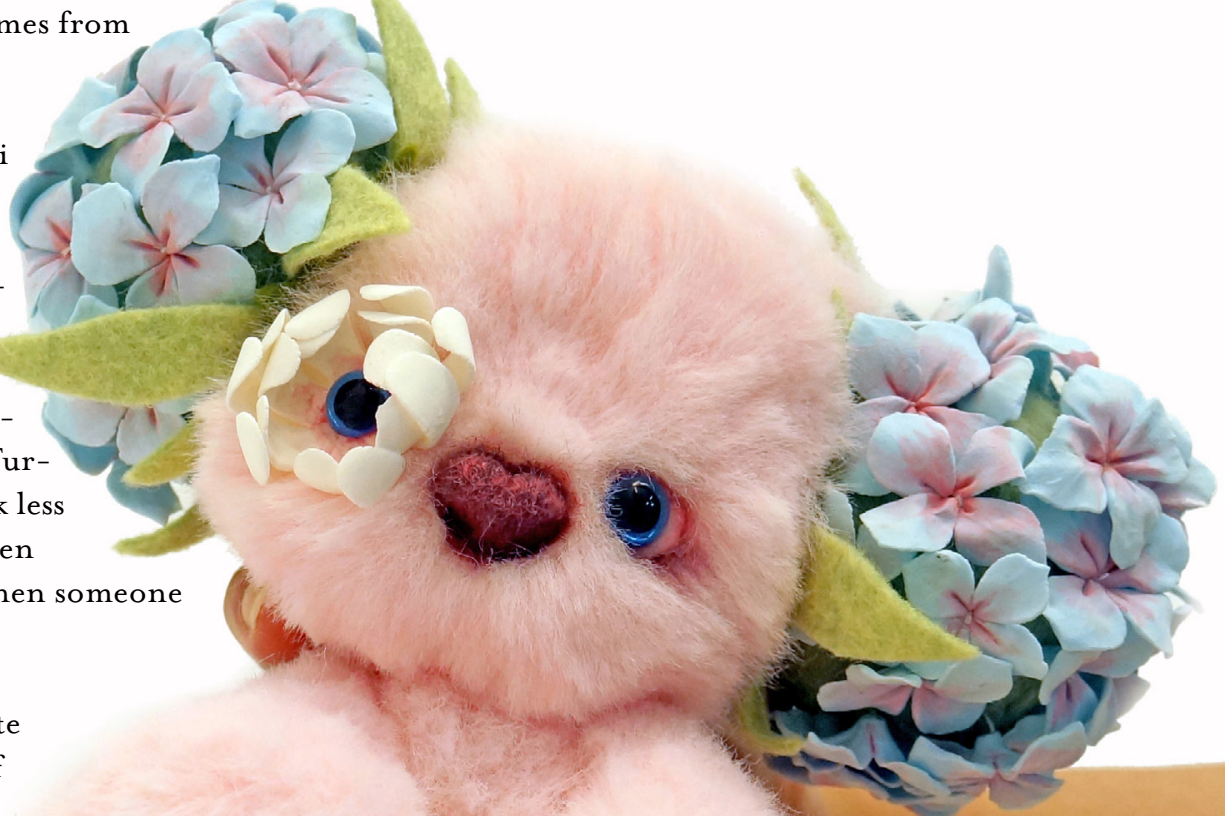



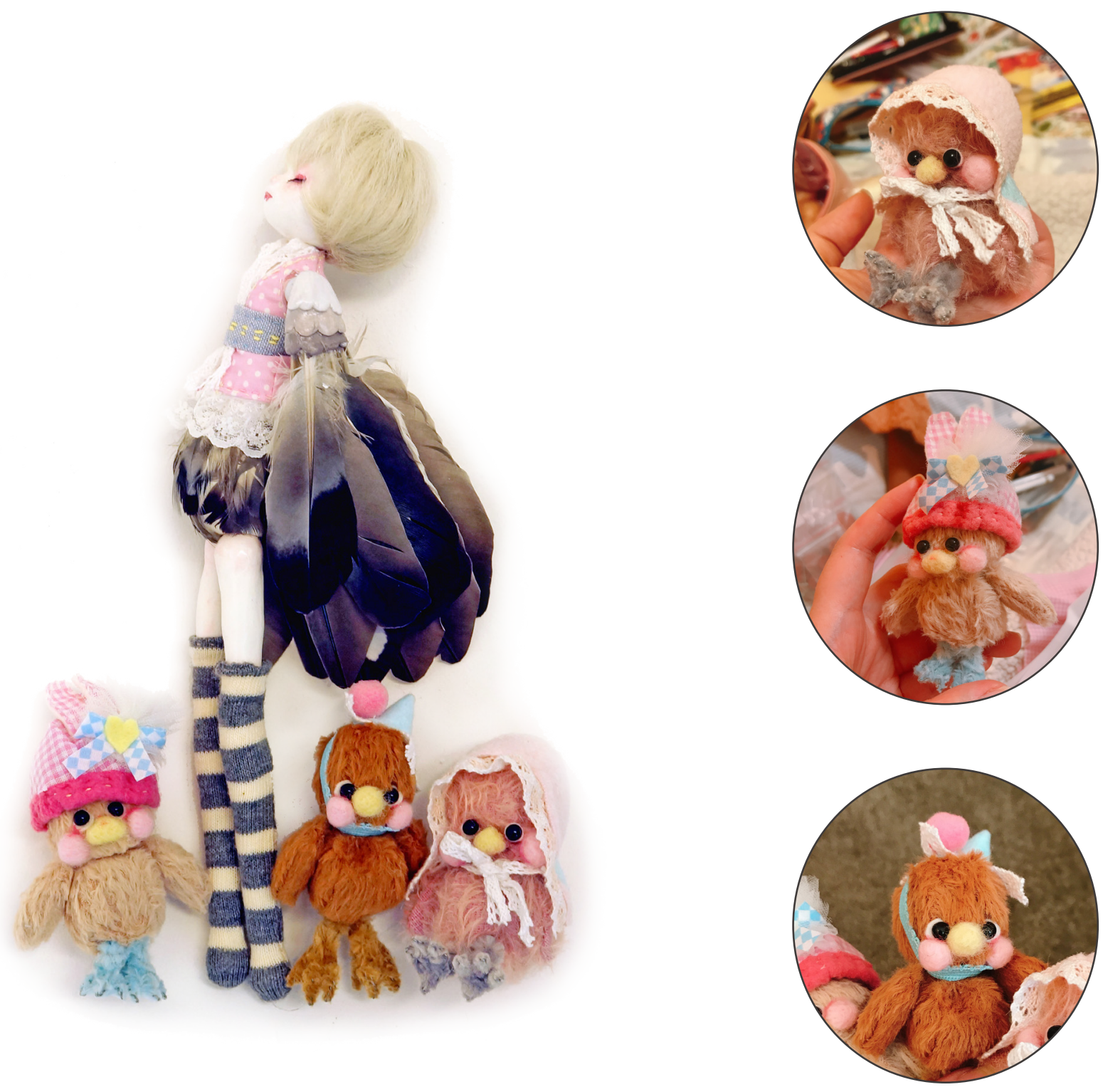

Figure 28. Kokakuchou 1 


\section{Kokakuchou}

The design based on human Youkai.

Characteristics: The Kokakuchou is a bird-like

Design inspiration: The Kokakuchou has a different making method with others. The character is based on human Youkai story. In order to enhance the human character, the doll used join ball making method. The face of the doll designed in full accordance with the human feature. On the other hand, some parts of the body look like a bird.

Image: the human face, short hair, eyes closed, arm with a feather, thin legs, feather-covered body, three little birds.

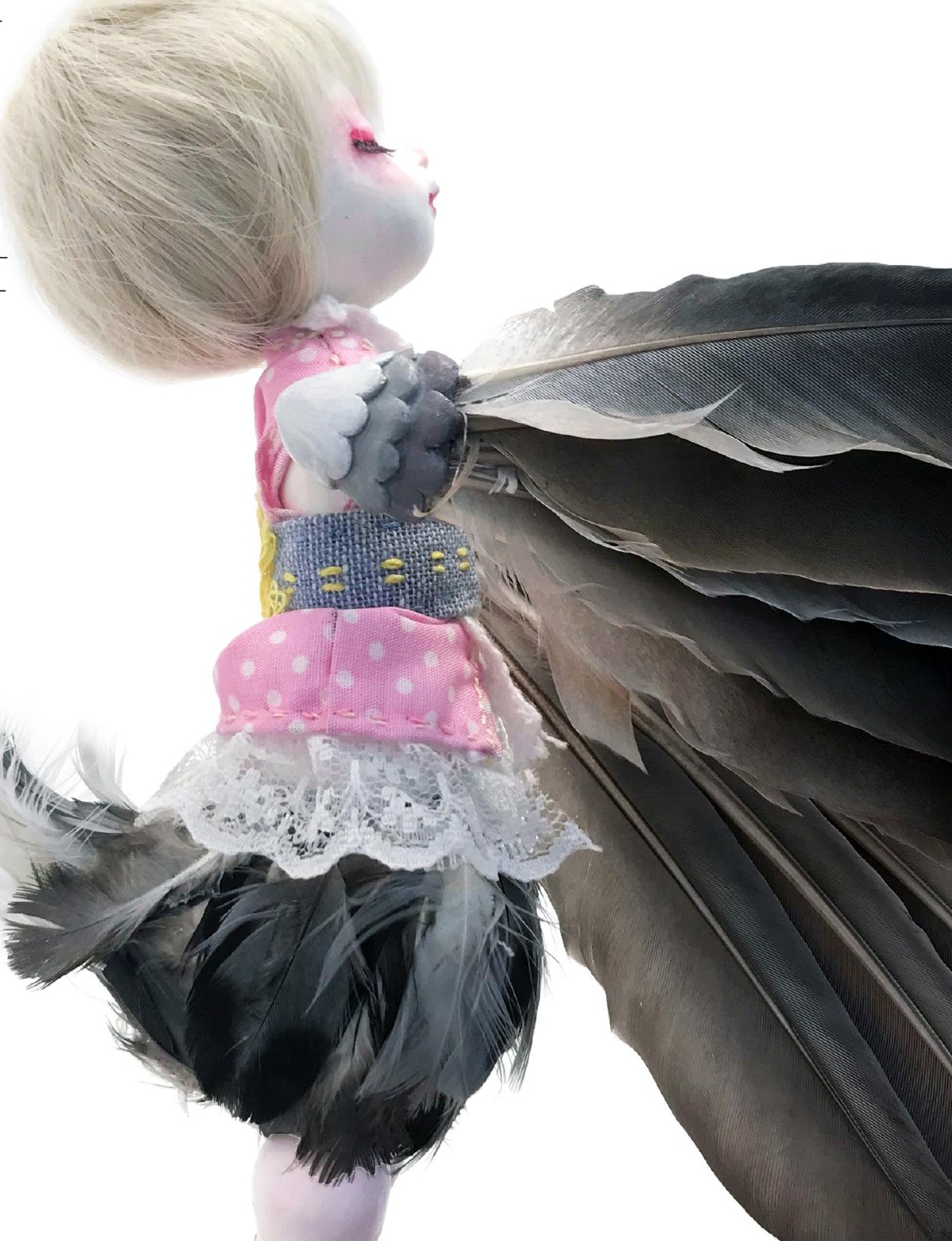




\subsubsection{Birthday card}

The doll making was influenced by Shinto belief throughout the entire process which is the spirit of the doll. From designing the character to making the image of the doll. The spirit gradually became clearer. There is a moment the doll emerges from a suppositional character to an imaginary being. However, the moment is different for a collector and designer. For participants, the doll will be awakened by the moment of opening the box. As a designer and doll maker, I consider the miracle moment initiates when the doll been entirely made. It is the moment which I filled all my ideas, skills and emotion fully into the doll, and it is the moment the doll can live by itself. To commemorate this moment, I often design a birthday card for the doll. It is the ceremony of their birth, and it is proof of their existence.

Front: On the front page it has the image of the doll, the date of their birth and the name of the original Youkai.

Back: At the back, it has the origin of the original Youkai character. Also, there are random letters with different colors from other words. Those letters can spell the word 'Youkai' by connecting them.

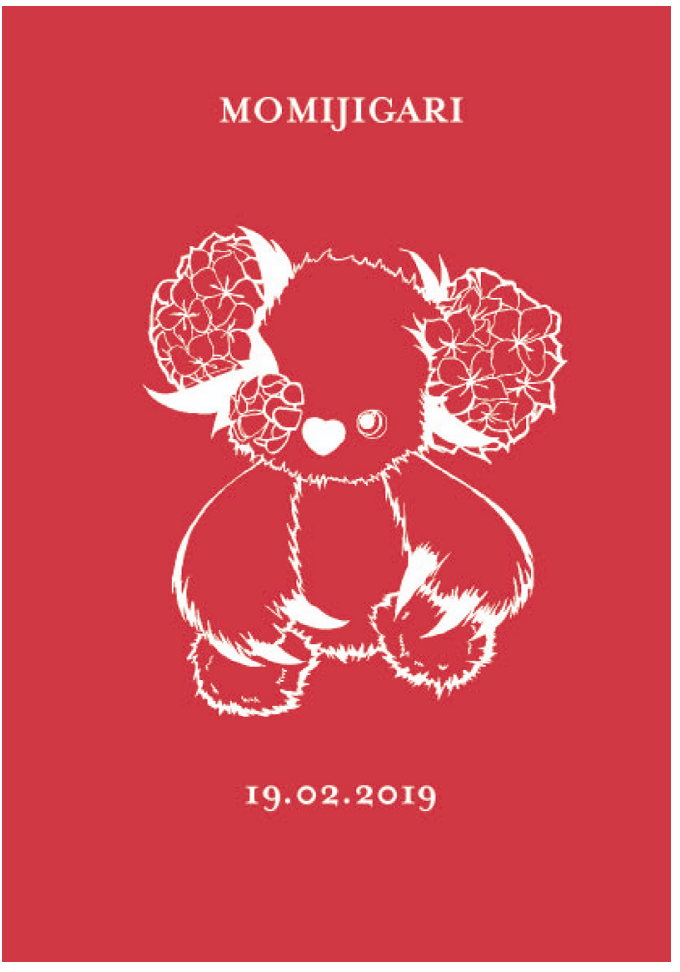

A beautiful woman of seemingly high rank (played by

the shite or lead actor), along with her retinue of

female attendants (the tsure) are visiting

Togakushi-yama, a mountain in Shinano Province,

here for the seasonal maple-leaf viewing. The group

commence a banquet.

A warrior of the Taira clan who has been out

deer-hunting approaches. He is Taira no Koremochi

Rather than to disturb the party by riding past, he

dismounts, intending to leave. But he is accosted by

the lady to drink sake with her. Koremochi becomes

drunk, and the lady forces more drinks on him. At

this point the lady's dance increases a more furious

tempo, changing from chū no mai to kyū no mai.

When Koremochi falls asleep, she abandons him,

saying never to wake from his dream. There is a change

of scenery, and everything turns bleak and dreary. A

deity of the Take-uji ("samurai"), acting as emissary

from the Hachiman shrine appears to Koremochi

and reveals to him that the lady is actually a demon

which needs to be defeated, granting Koremochi a

"divine sword".

The lady has now transformed into a fire-breathing demon in the glow of lightning (the noh mask used are traditionally shikami but hannya has come into use.) but the warrior is undaunted, and after a pitched

Figure 30. Birthday card I battle, slays the demon with the sword. 

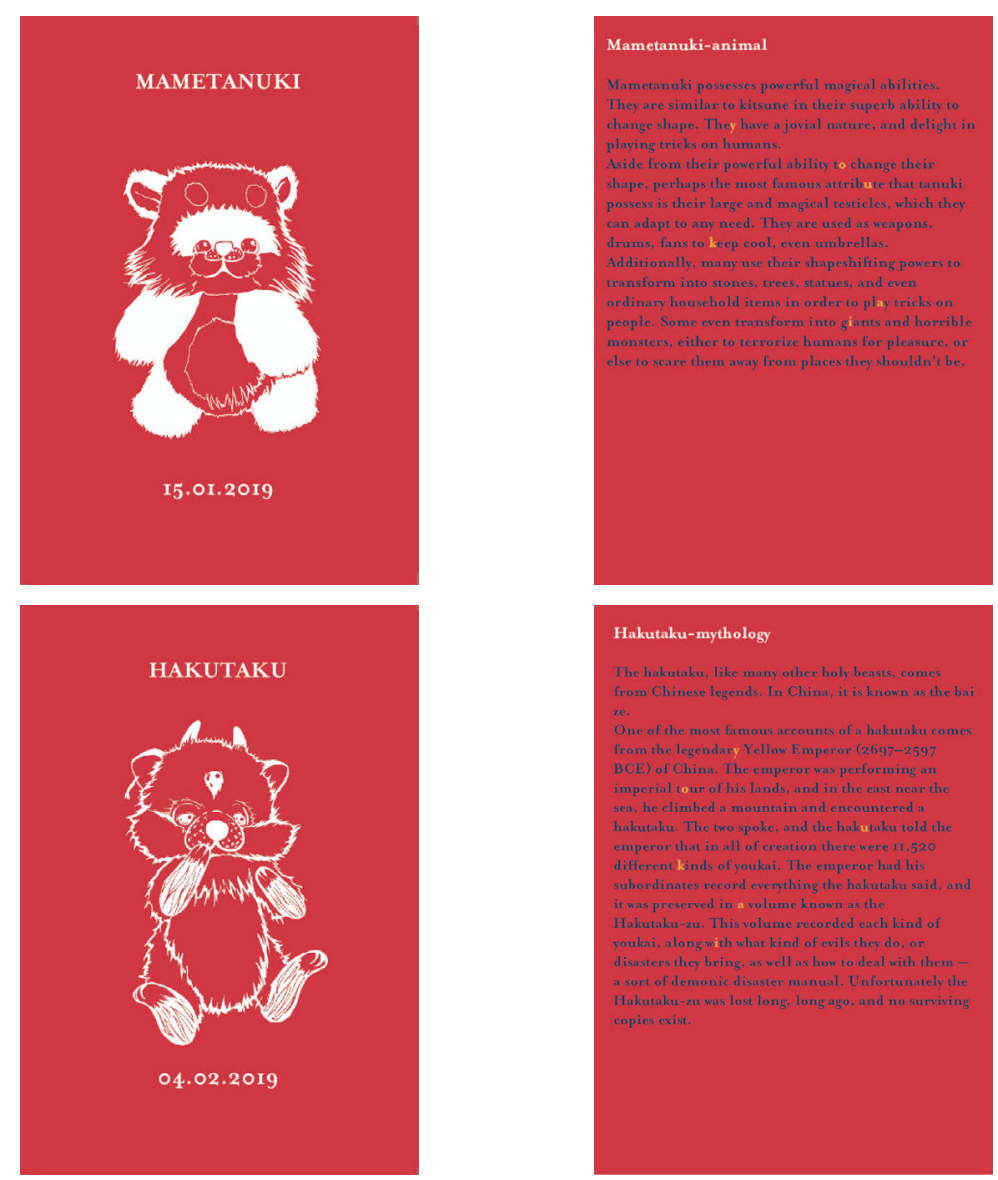

Hakutaku-mythology

The hakutaku, like many other holy beasts, comes

The hakutaku, like many other holy becasts, comes
from Gbinese legends. In China, it is known as the bat

Ke.

from the legendary Yellow Emperor (2697-2597

BCE) of China. The emperor was performing an

imperial tour of his lands, and in the east near the

sea, he clim hed a moumtain and eneountered a
hakutaku. The two spoke, and the hukuk taku told the

Leakutaku. The two spoke, and die hiklu taku tolit
emperor that in all of creation there were 11,520

emperor that in all of creation there were 11,520
different kinds of youkai. The emperor had his

subordinates record eventhing the hakutaku said, and

it was pr

Hakutaku-zu. This volume recorded each lind e.

youkai, along with what kind of erils they do, or

disasters they bring, as well as how to deal with them -
a sort of demonic disaster manual. Unfortunately the

Hakutaku-zu was lost long, long ago, and no survivin:

copies exis

Ubume (also known as Kokakuchou) is a figure from

both Chincse and Japanese youkai, She represents the

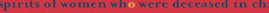

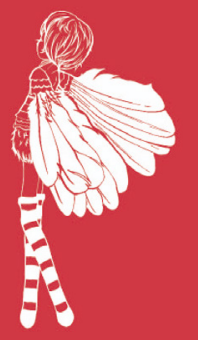

14.03 .2019

Figure 31. Birthday card 2 


\subsection{Finished doll display}

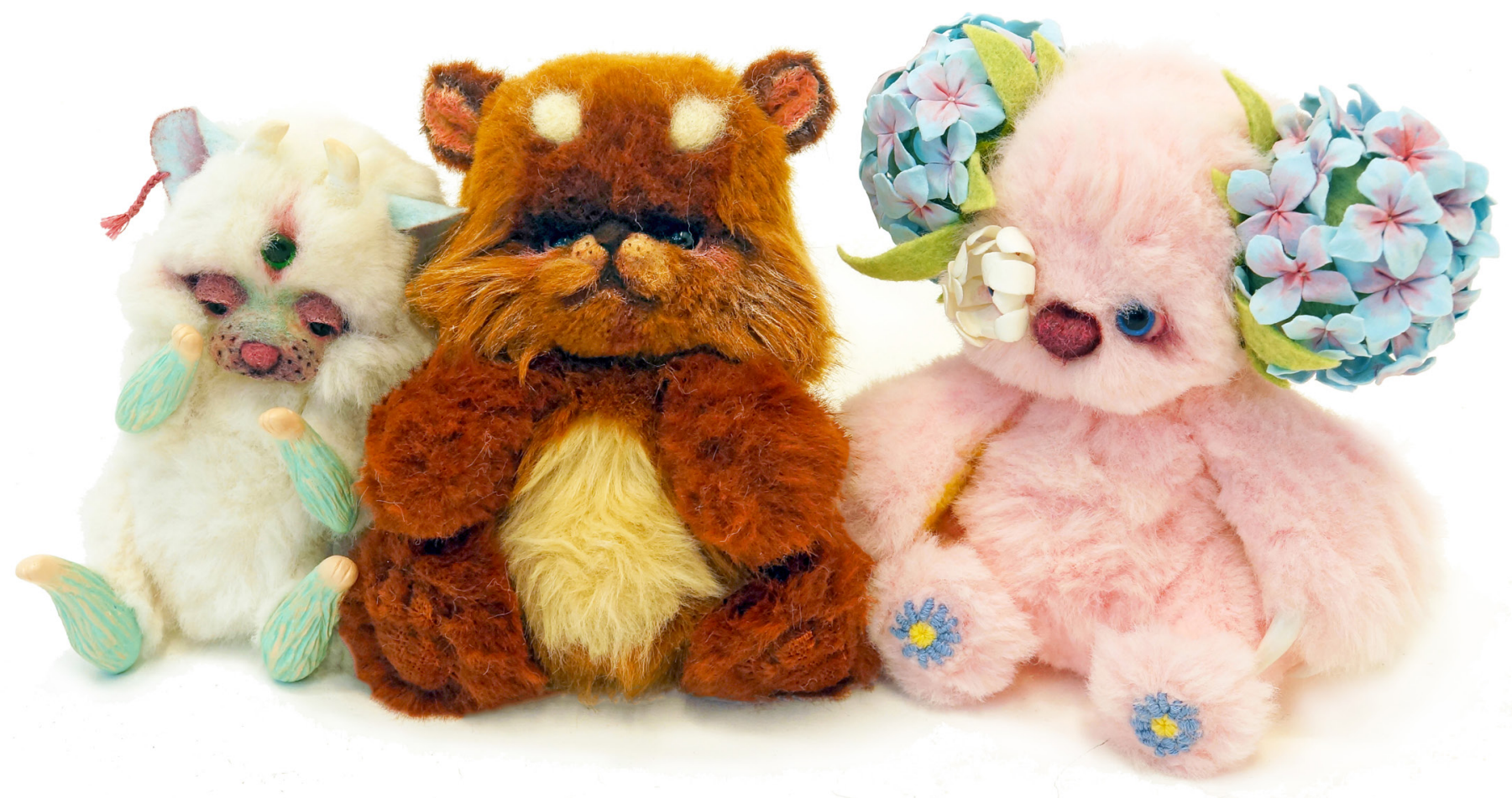



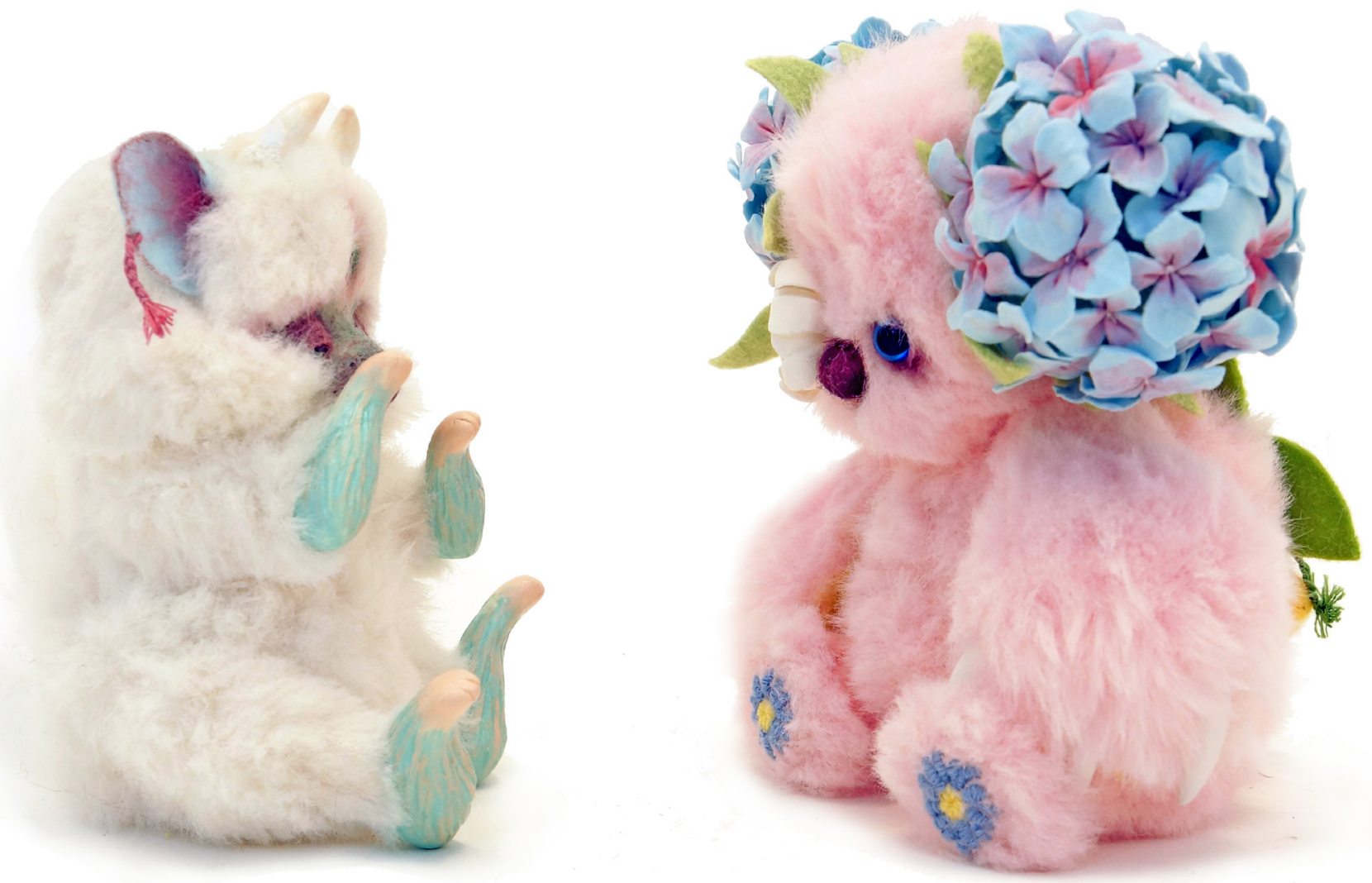

Figure 33. Finished doll display 2 


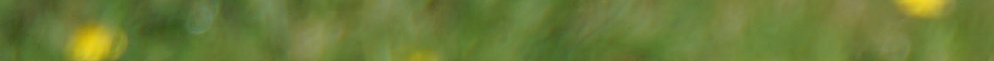

(3) a

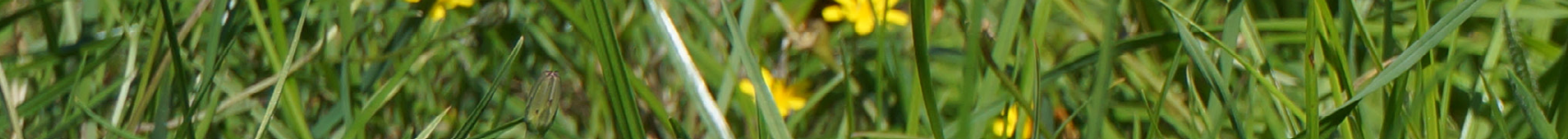
1.2. 10.1 到

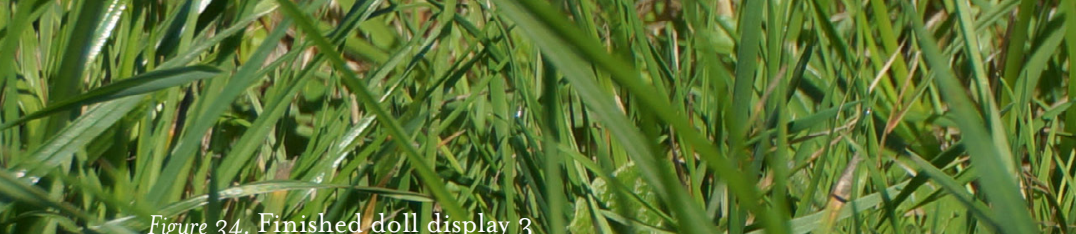
4 


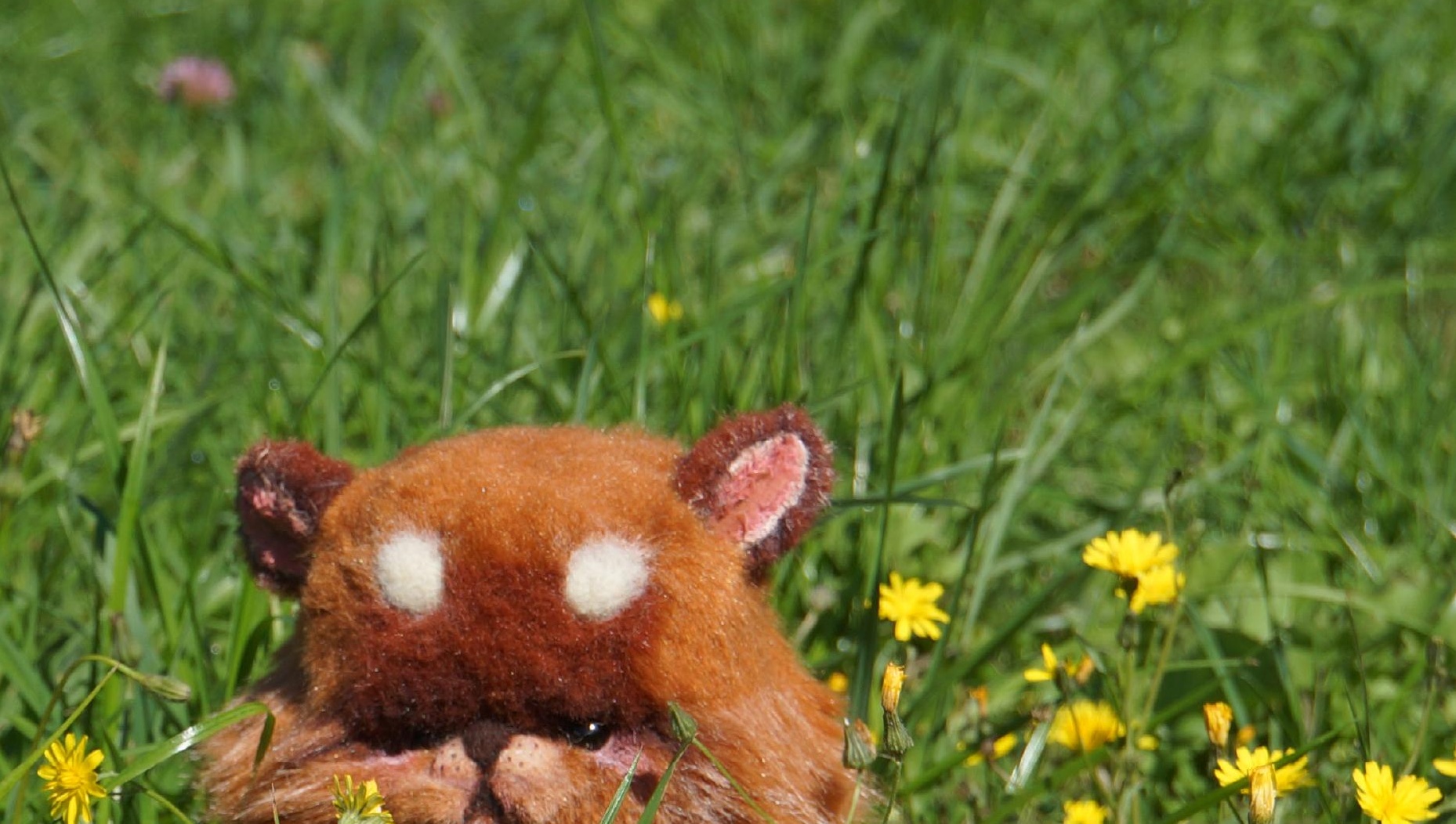
6.

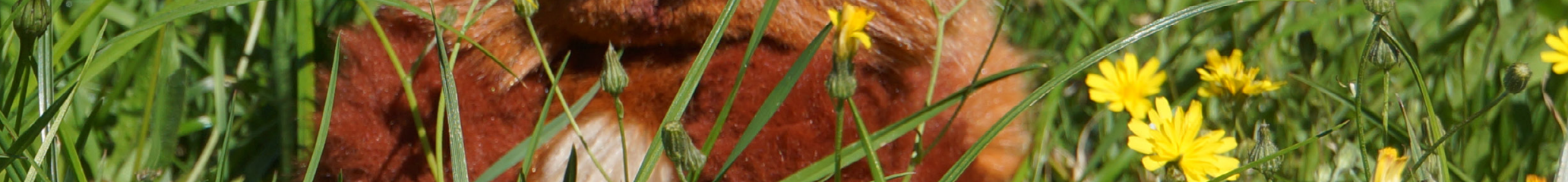
$(121.12=$ (1) (1)

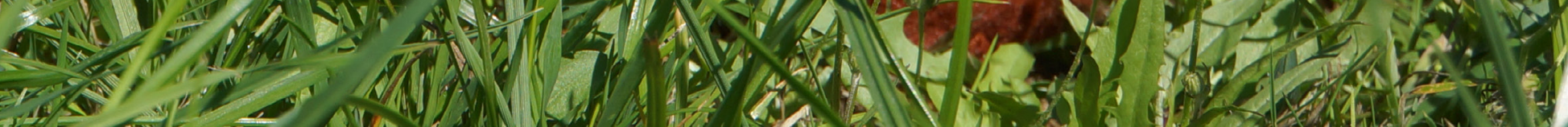
D. 10 


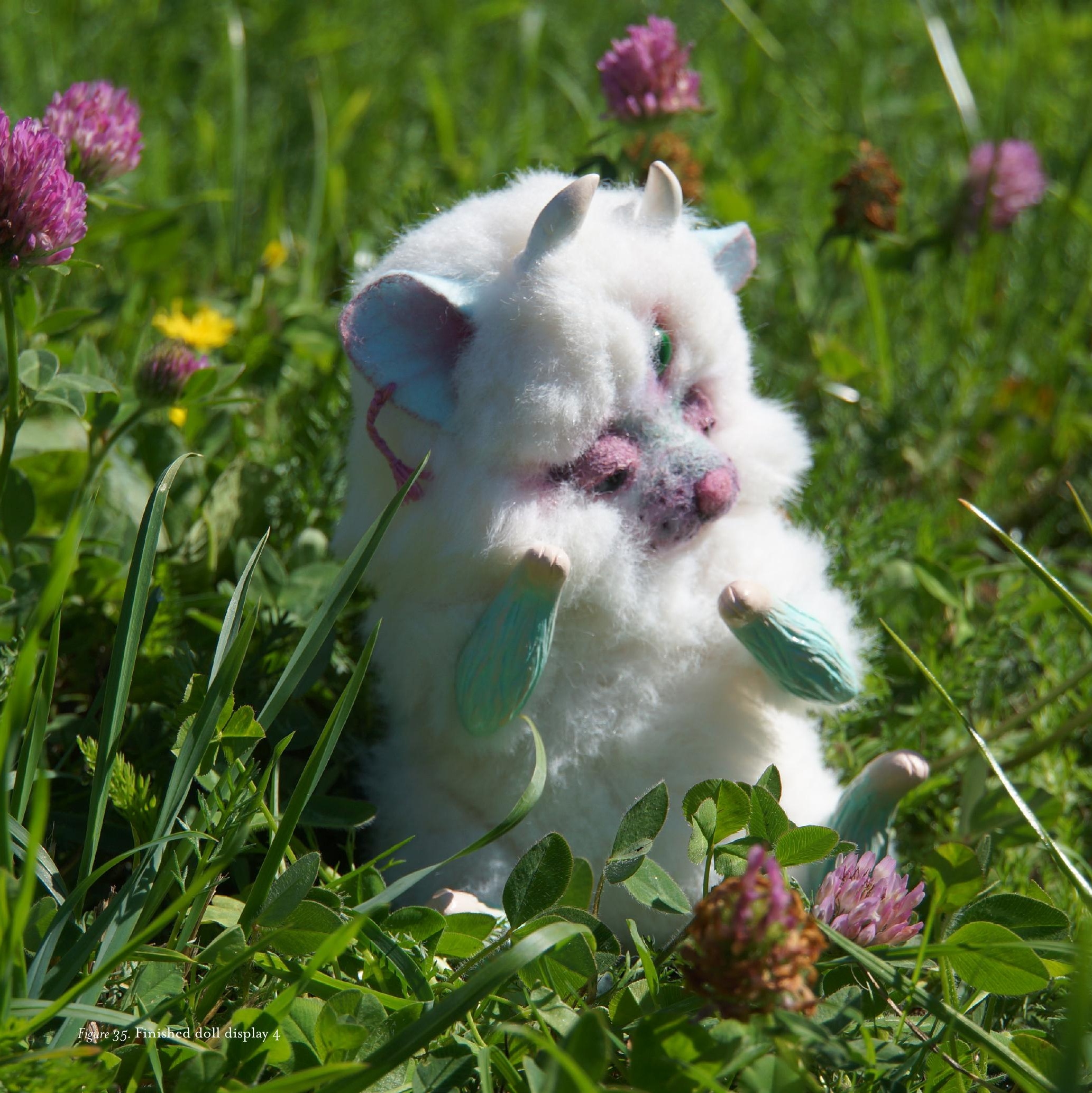




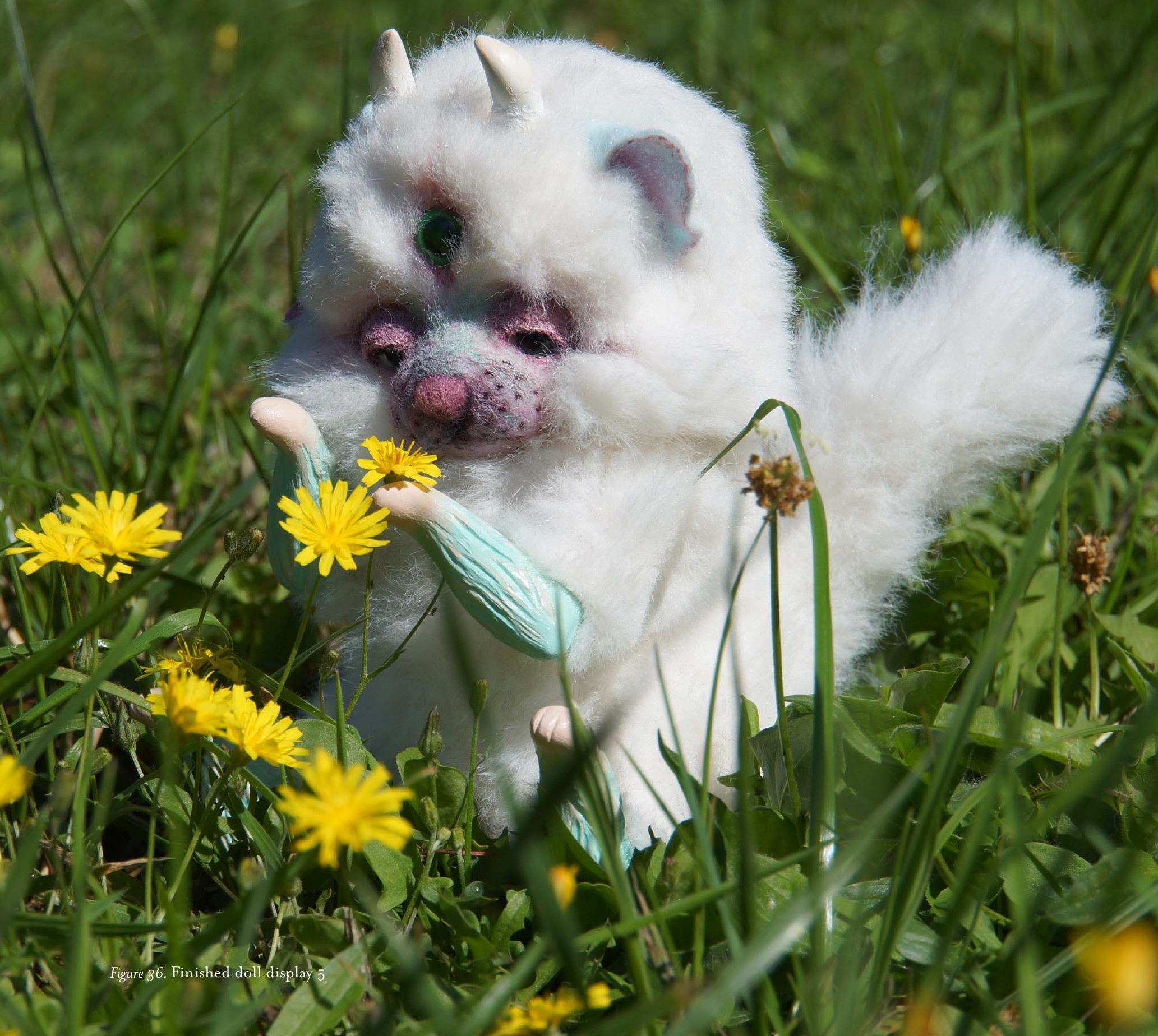




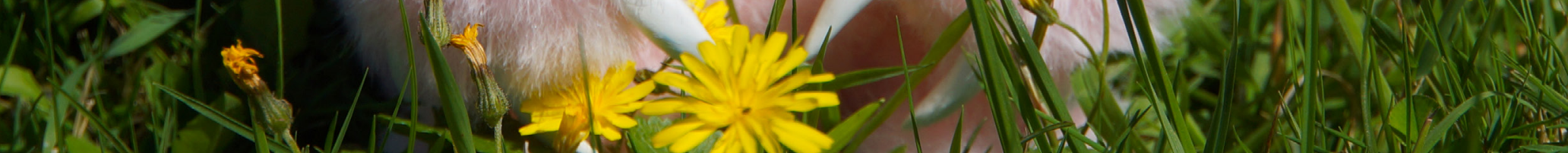
wathes 2)

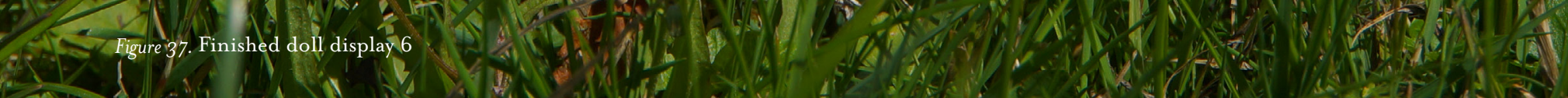
25e- 


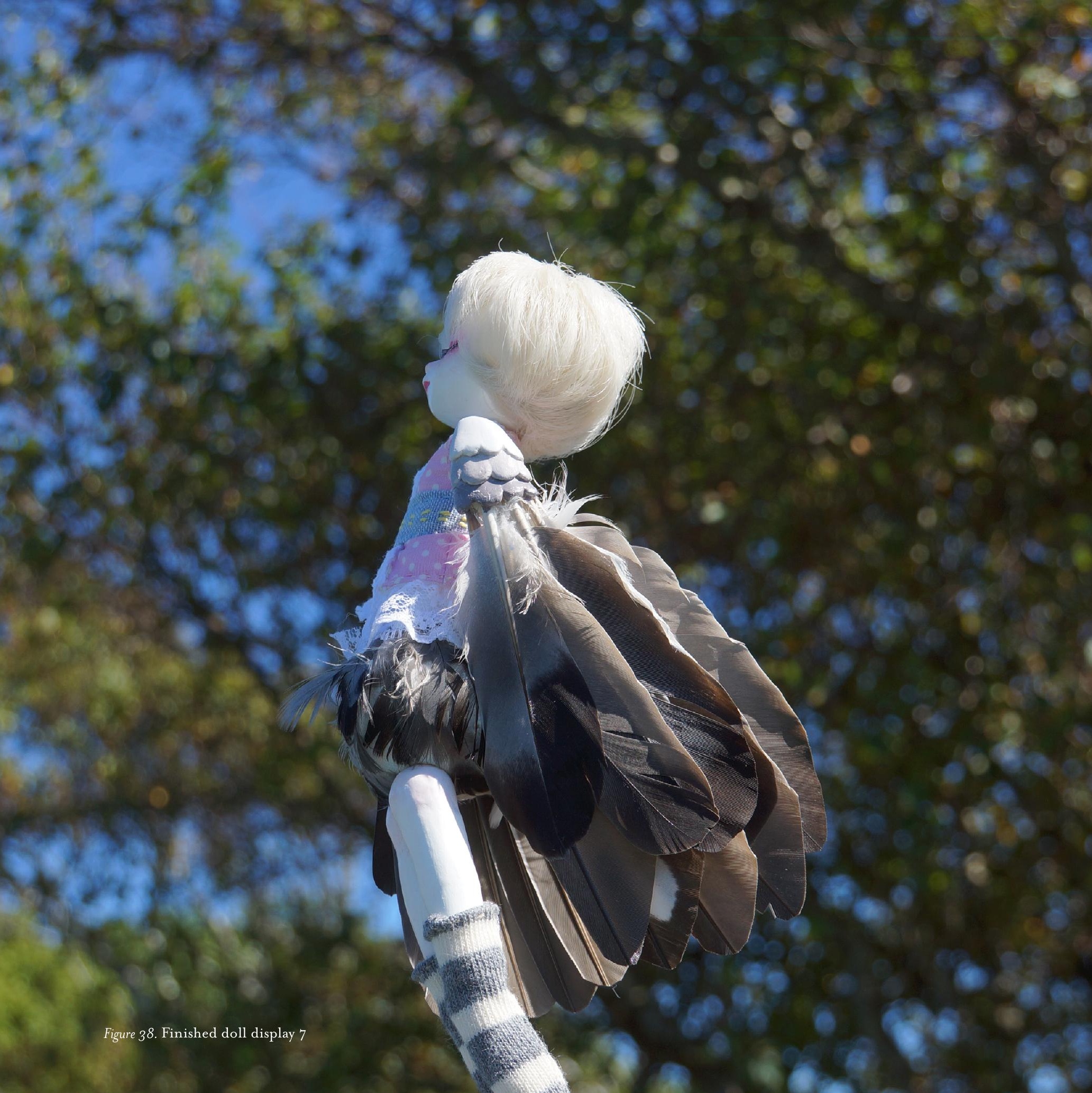


3

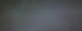

$+$
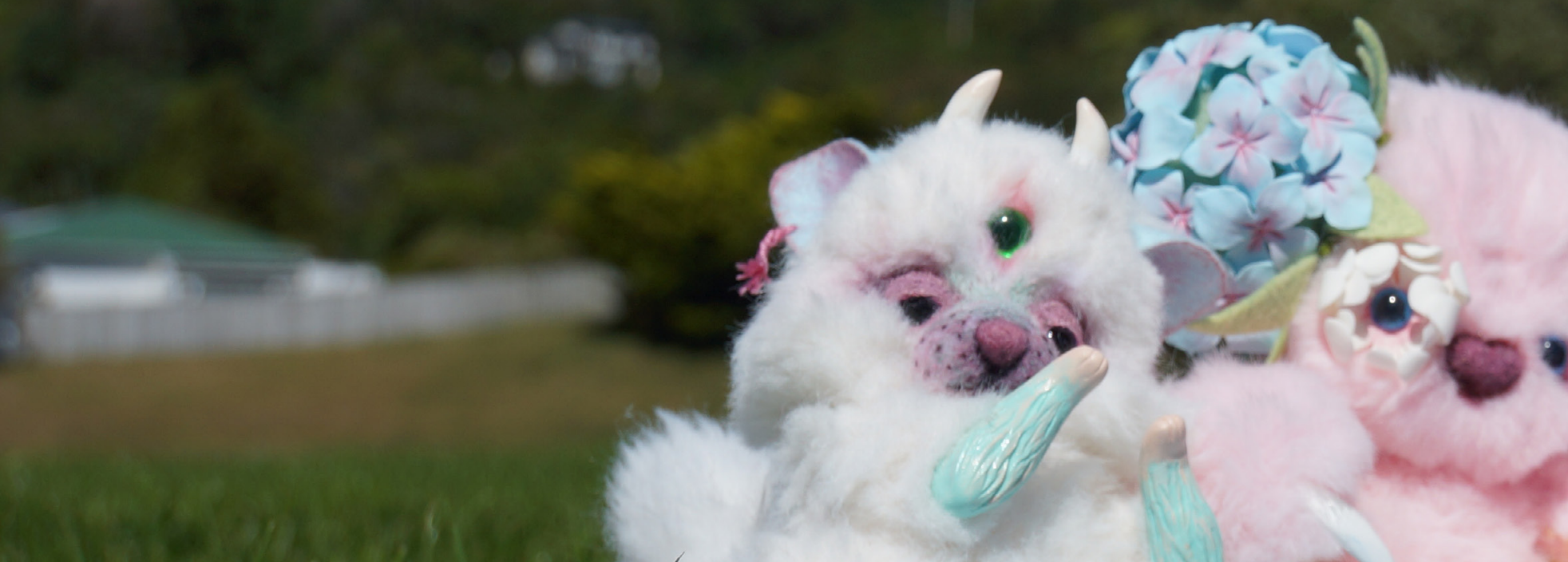

(10.)

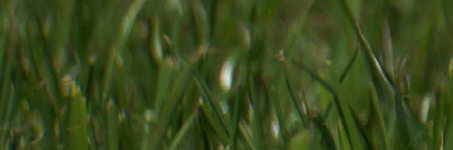

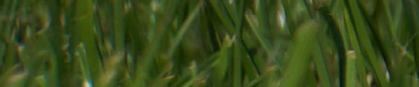

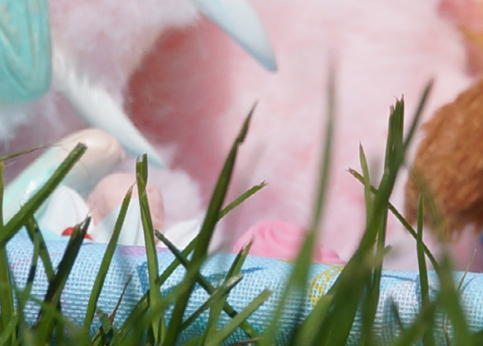




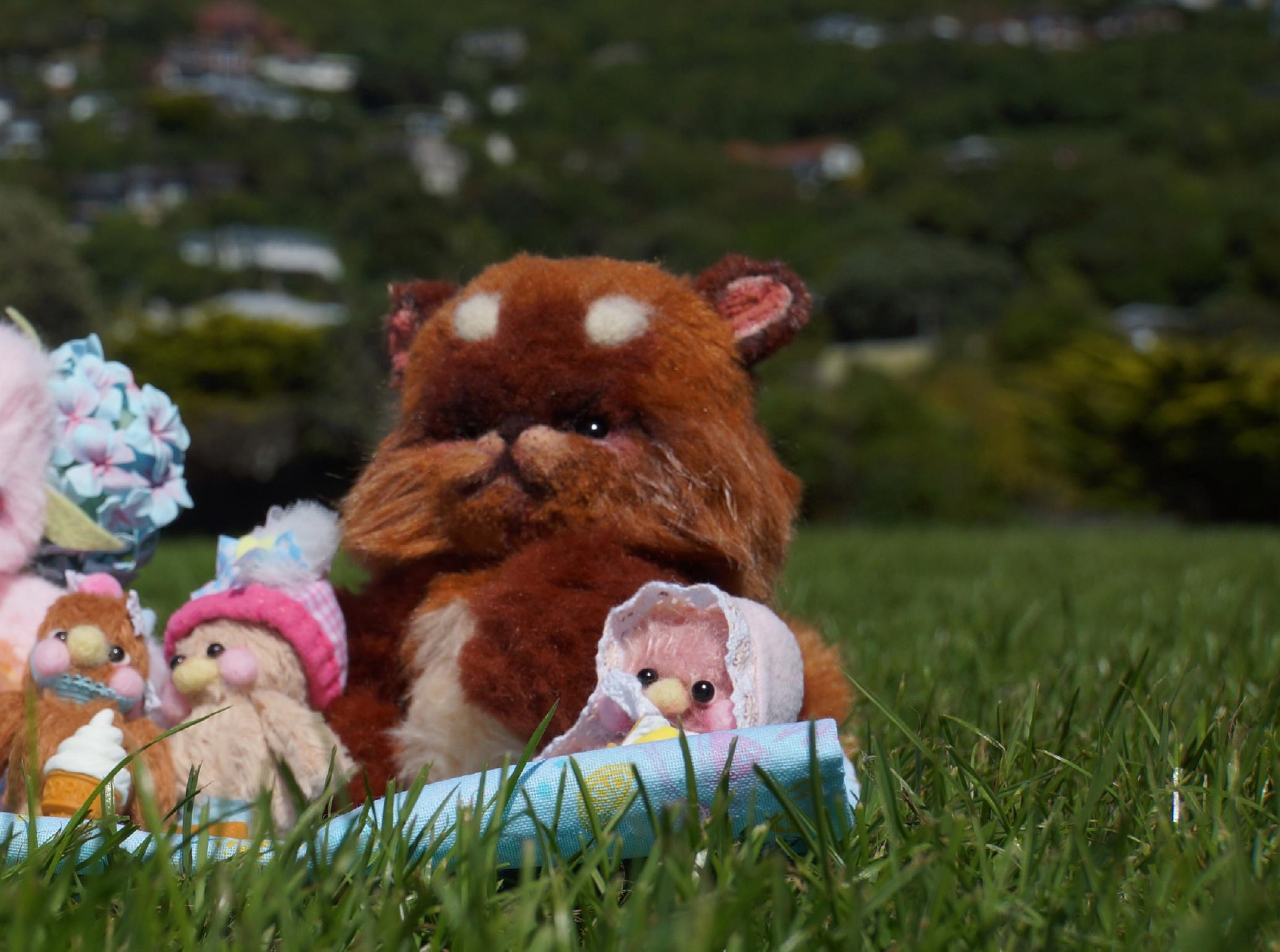



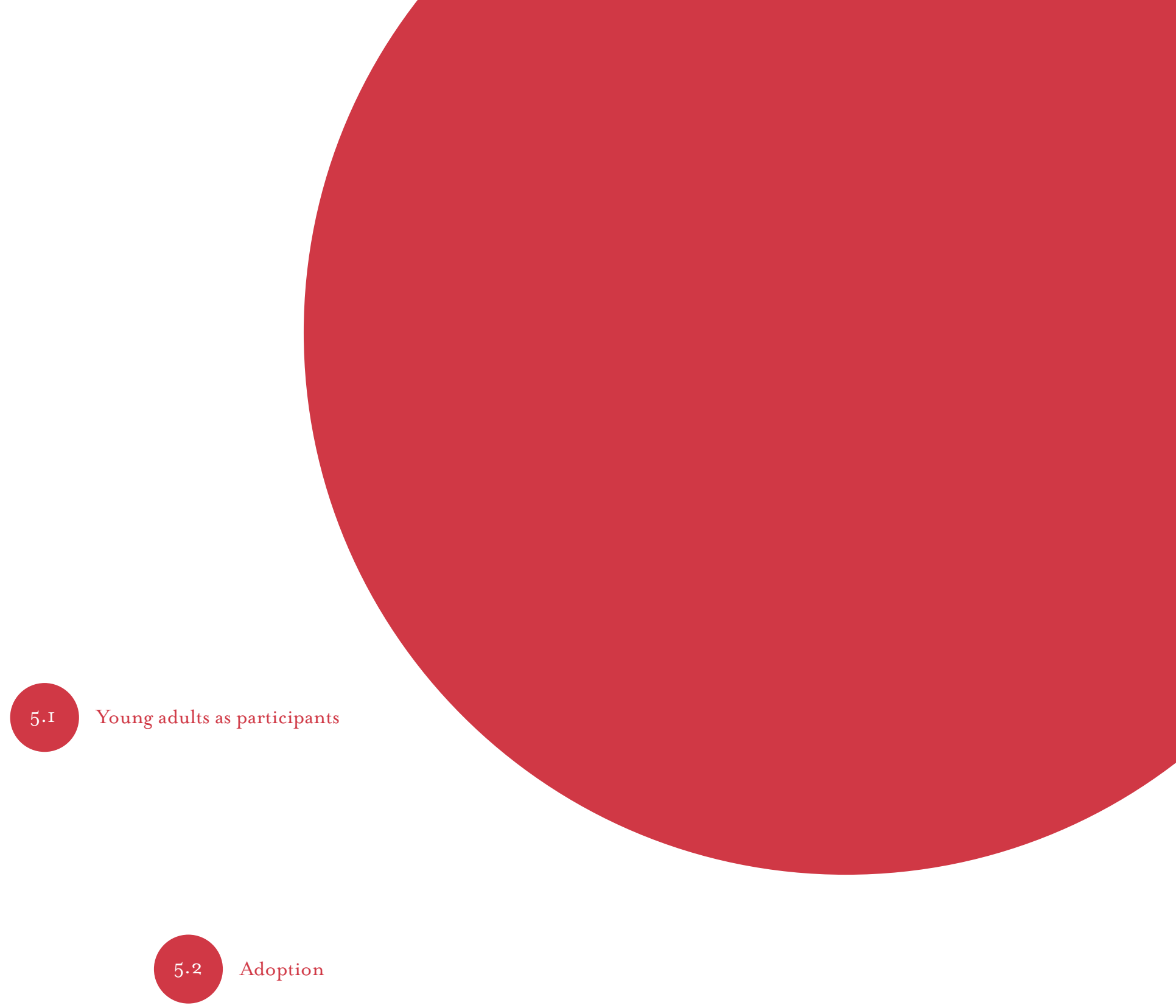

5.3 Interaction 
5. Connecting with the spirit of the doll 


\section{Connecting with the spirit of the doll}

In this research, the purpose is more than documenting the experience between the doll and the participant. It is to explore the relationship between dolls and young adult collectors, and the story which they create. Thus, it allows us to imagine and create what is yet to come. The interaction of both of their past shapes the narrative of their relationship, and it will continue to influence the stories and the character of the doll that we tell.

\subsection{Young adults as participants}

Over time dolls became toys for children as well as works of art valued for their beauty. Recently, young adults collecting dolls have become a subculture (Phoenix, 2006). According to Heljakka's research adult collectors appreciate the value of dolls more. They do not regard themselves as players, but collectors or hobbyists (Heljakka, 20I8). Therefore, the relationship adults have with their doll is beyond the activity of playing.

What they are looking for is not just ownership but a creative narrative. Nieuwenhof (20I2) found that adult collectors, especially young adult collectors are more willing to conduct activities and share the narrative of their collections. They often attach their original narrative to the doll and share the story. Through those activities, dolls become their special friends or family member. Today, designer dolls are more popular among young adult collectors who see companionship with them as special partners.

\subsection{Adoption}

As a doll maker, I always consider the doll I create by hand as my child. Each of them is one of a kind. They are born at different times and have different experiences. The birthday card that I provide is also the proof of their existence. When I send them to the participants, I always consider that as the process of getting them to the new parents. They are going to the people that can actually take care of them and going to have a new life. Thus, I call it adoption.

In order to make participants get better involved in this project, I try to get them to select their favorite doll. After discussion and negotiations, each of them chose the doll they were interested in. I packed all the dolls in gift boxes and sent them overseas. 


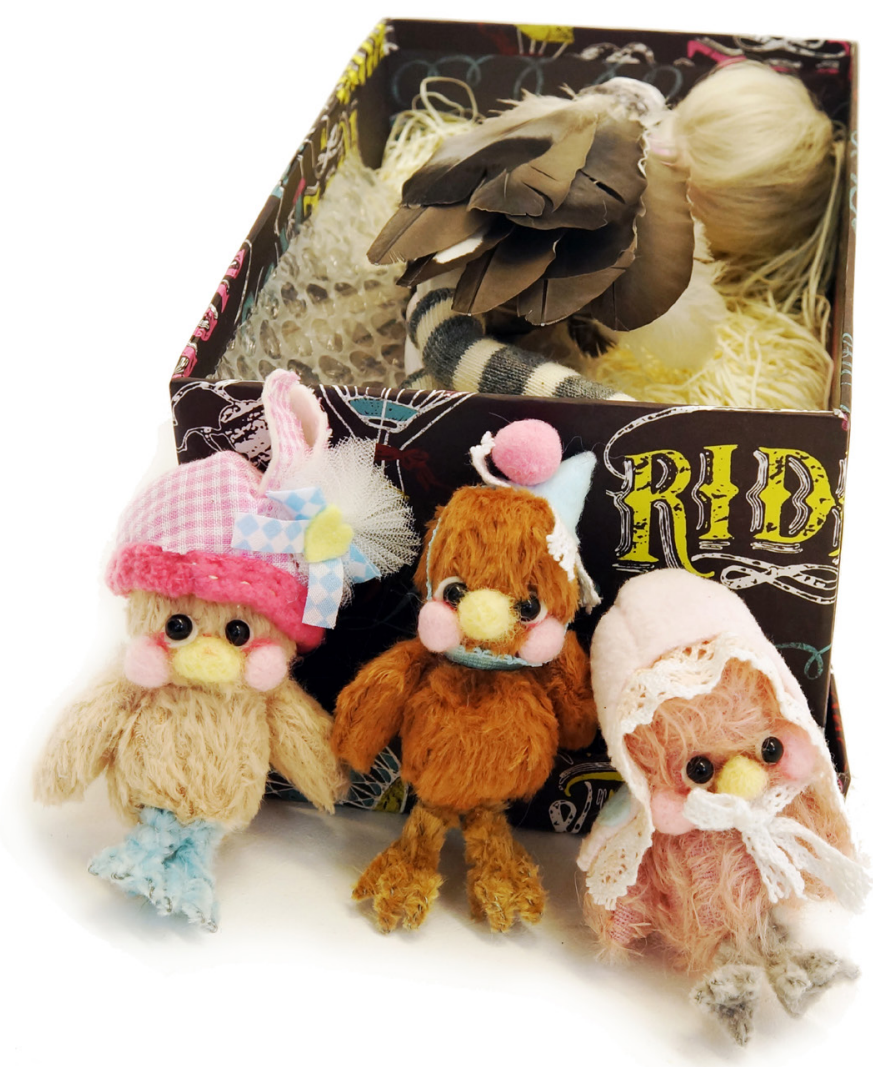

Figure 40.Packed dolls 


\subsection{Interaction}

The concept of wabi-sabi in Shinto belief is not only reflected in the process of production, but also in the process of using and, the process of interacting with people. Wabi-sabi is also inclined to refer to positive impermanence and the noble signs of time. It believes the self-do does not persist over time and things are always more beautiful when forbearing the marks of age and individuality (Ayala-Garcia, 20I7). As time changes, the change in objects is also a part of its existence. In the concept of Shinto, you are not the same person from birth to death and those changes occur over one's lifetime. So the so-called self is a bundle of impressions, consisting of many things, such as the body, memories, and even labels that are imposed on the self by others. In the eastern culture the impermanence and operation of life from nature and feel the beauty of natural variation and the feeling of sorrow, so the natural time series always affects the unique thoughts of people (Prusinski, 2012). Therefore, the existence of the matter could be like a piece of chain, where you follow the timeline of one particular set of links, new links are created then added to the chain. Thus, identities of the objects are formed and maintained through the interaction with others entailing the processes of identification through exchange and confirmation.

Especial for the dolls' creator and collector the object's meaning has changed to become part of a collection. Greating or changing objectives is a way in which objects can become part of the extended self (Nieuwenhof, 20I2). Resultantly, the traces of time are among them, which produce the emotion and memory generated by the interaction with nature and the interaction between people and objects. 
86 


\section{I.2 Analyze and create new stories}

6.I.I Answer from question cards

6.I Collecting and clustering 
6.Visual narrative 


\section{Visual narrative}

Stories are what our life is made up of, and stories are how we remember people and things. For participants and the dolls, these stories are the memories that they recalled from the interaction during this one-month period. The dolls designed according to Youkai stories and Shinto beliefs are not just a toy or object. They are born for stories. Stories affirm who they are and give their life meaning. Using the information gained by four participants through the question card initiated the last section to create a visual narrative. This is the way visuals represent them, and it is visuals they will project their life experience.

\subsection{Collecting and clustering}

\subsection{1 answer from question cards}

After one month, I received the question cards from the participants. The information I received was based on the participants' explanation were having dialogue scenes and a narrator is inherent. In order to gain the participants' thoughts and feelings directly, I decided to let them utilize their first language (Chinese). However, the participants of all of the young adults and the language they are using is not a traditional formal language. So, some of the vocabularies used are new and have only appeared in recent years, like slang words common amongst the younger generations. Therefore, no same words have a formal English translation.

In order to display that information in detail and reorganize it, I decided to tell the story visually rather than relying on dialogue because visual language is a unifying language that surpasses boundaries of linguistics and global boundaries (Tufte et al.,I998). A visual narrative can provide us with more information in the same amount of time and visual story capturing and communicating experiences in a more nuanced and interpretive way.

\subsubsection{Analyze and create new stories}

Stories are fundamentally chains of cause and effect wrapped around the truth (Cohn, 20I3). Those stories could lead one on a journey to discover the development of the character that I designed for the dolls and the relationship between dolls and participants. The stories I received from the participants are their own stories and experiences. They plot what they said and the description of the events on the question card is unique to them, but some experiences are universal. 
To interpret their world to a general audience, I decided to use comic books as a format to visualize their stories. Comics are visual images that embrace all of the senses within it. All pictures, words, different symbols, and everything in between in the comic are all present in a single vision. Comics provide the opportunity to see how the answers from question cards to translate to new stories and spread these stories to new audiences.

\subsection{Narrative structure}

Stories need an architectural structure that is often unnoticeable even once you read the story. With the invisible structure, the information transferred from personal memories of participants to the sharing of audiences. Having a clear theme is the basis of the comic book. The theme is the message that I gained from the participants which are their own stories because most of the people are the audience do not have those experiences, but they can relate to the blissful, pleasure and all the type of universal understanding of the story. To organize the story, I collected and clustered the answers from the question cards and started with making the panel of each story. 


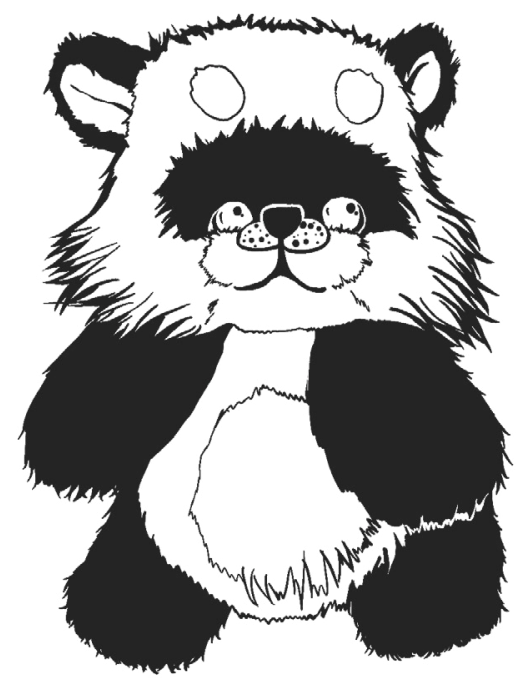

Participant: Raincoat Occupation: Graphic Designer Collection type: teddy beer Location: QingDao, China 


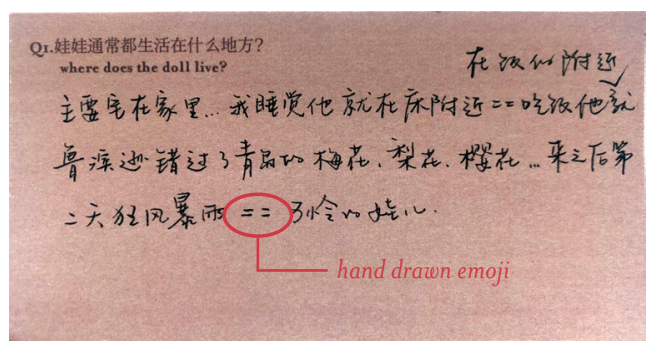

Q2. 你认为你和娃娃的关系是什么? (朋友/亲属/其他) Mother, describe the close what is your relationship with the dorl? relationship with mother 亲属，感觉我是他娘后烺的那种 亦或是俎姐？(不想把自己整老了…) 鲁滨逊和其他孩子们是见策关系

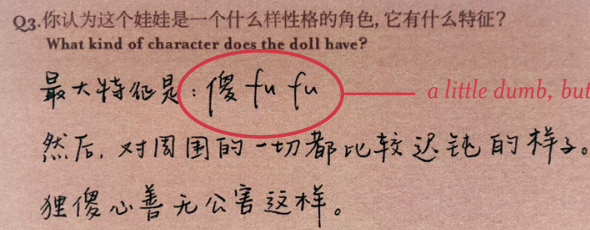

Q4. 你平时都是如何和它玩要的, 你们通常都在一起做什么事? What do you do together?

每天晚上和他的兄剙问一起盘踞在沙发上看电視， 是他的主要日程。偶尔会被投喂一下奥食，吃不 了闻个味心世孙。有时还会和兄弟们一起升会…

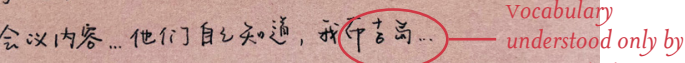
pronunciation

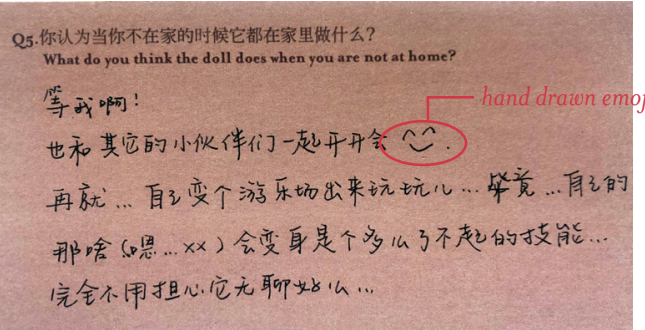

\section{Q1. Where does the doll live?}

Most of the time he lives at home... He is nearby when I sleep = = If I am eating he's near the meal. Robinson missed the plum, pear and cherry blossoms in Qingdao... The next day after the arrival, there was a storm $==$ poor kid

\section{Q2. What is your relationship with the doll?}

Relatives, I think I am his mother...More like stepmother or sister? (Just don't want to sound too old)

Also, Robinson is other kids' brother

\section{Q3. What kind of character does the doll have?}

The biggest character is: a little dumb. And kind like slow reaction to everything around his. His dumb but has a kind heart and harmless to others.

\section{Q4. What do you do together?}

Everyday night, he sits on the sofa with his brothers and watches TV. They know what they are talking about, I don't know.

\section{Q5. What do you think the doll does when you are not at home?}

Of course, he is waiting for me.

Having some meeting with his other friends ${ }^{\wedge}{ }_{-} \wedge$ Or...his might transform into an amusement park... while...he has his youkai superpower, don't need worry he will get bored. 
Q6. Please tell a story about the doll. This can be your imagination or what really happened in this period of time. Or you can expand on previous questions.

Robinson Grusoe

My name is Robinson; I'm waking up now. Where am I?

Dark, so dark. Darkness over me, and there was no light in the sky.

So, what happened?

The last thing that I remember is I am with the flower girl, bird girl, and the three eyes Hakutaku.

In theory, at this moment or the next memory should be that I finally crossed the Pacific Ocean in my dream, and get to my new home.

But!!!

What the hell is this?!

Why so dark!

Why so dark...my hands, legs and head still can move.

There was nothing wrong with the straw mattress underneath the except a little moisture absorption in this ghastly weather. Before I left, mum said not to use my superpower too often.

But why can't I use my superpower to become a ship?

There is only darkness so I can't calculate the time....and, inside the box there are no stars and no moon. Inside this in this small box, like a dead body lying on the straw mattress.

I cannot move. Feels like time is so long... so long...long,

Like a piece of chewing gum.

Also...can't sleep.

It feels I'm being moved to a stable place, because the bad not moving anymore, quite...quite...Finally, I can feel the passing of time.

Sometimes I can hear someone is talking, but there is longer time quite like dead.

Even I can count the date, still feel I this time is longer than my whole life, too boring...

Who betrayed my life in prison!!! Aaa!!!

There is something wrong this morning, my box been picked up.

Why can't buy a car? Why motorcycle...

Is it the voice of nock the door, the voice of the door open...

Eh? Who is opening my box? What are you doing? Stop!!!

No!! I got home!! I saw the light!!! I need to stop complaining and pretending I am a cute kid...

New home, freedom, sunshine, I'm coming

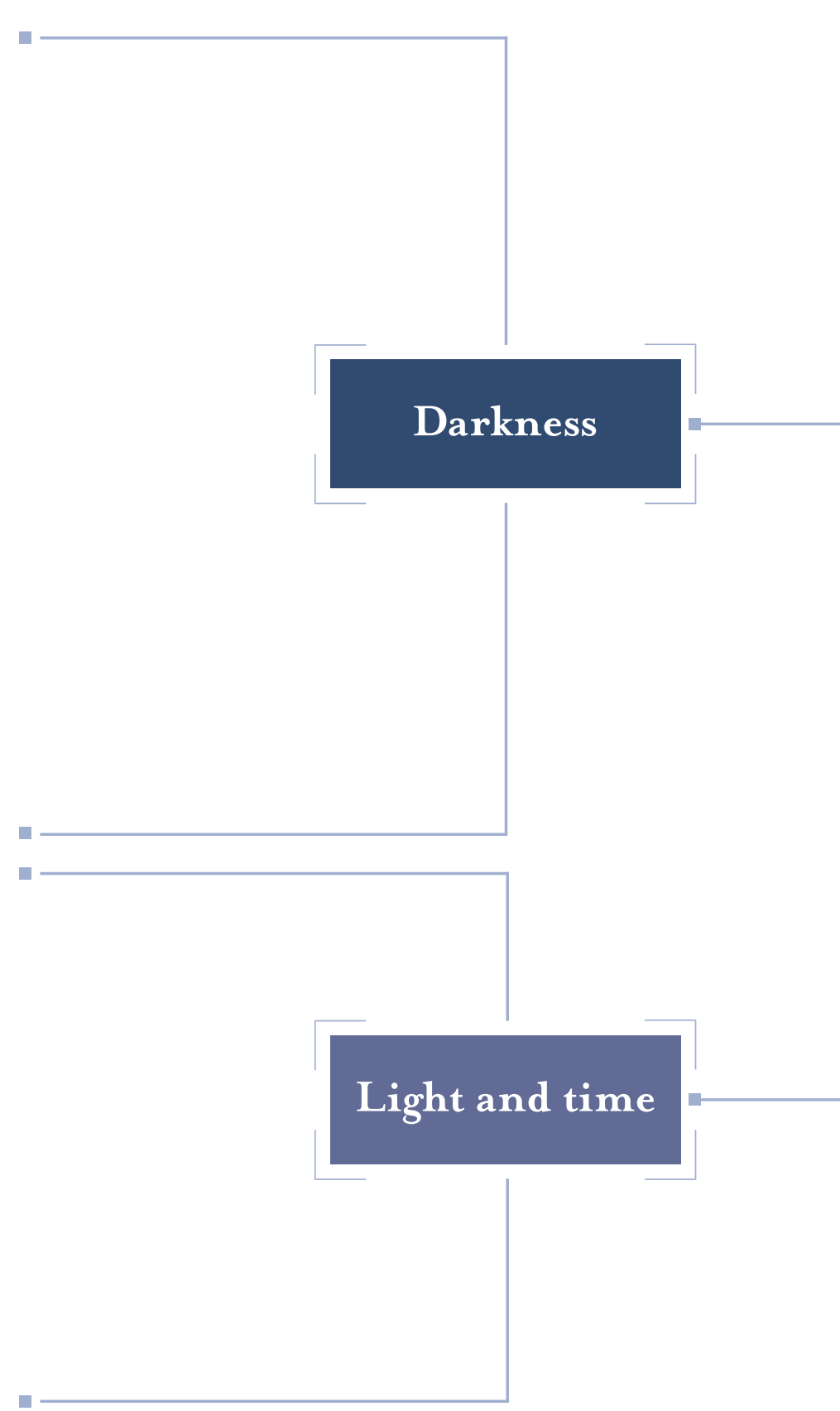


The first half of the story tells the story of The Doll talking to himself in the box. This part of the story takes place entirely in the dark, so there is no image but dialogue.
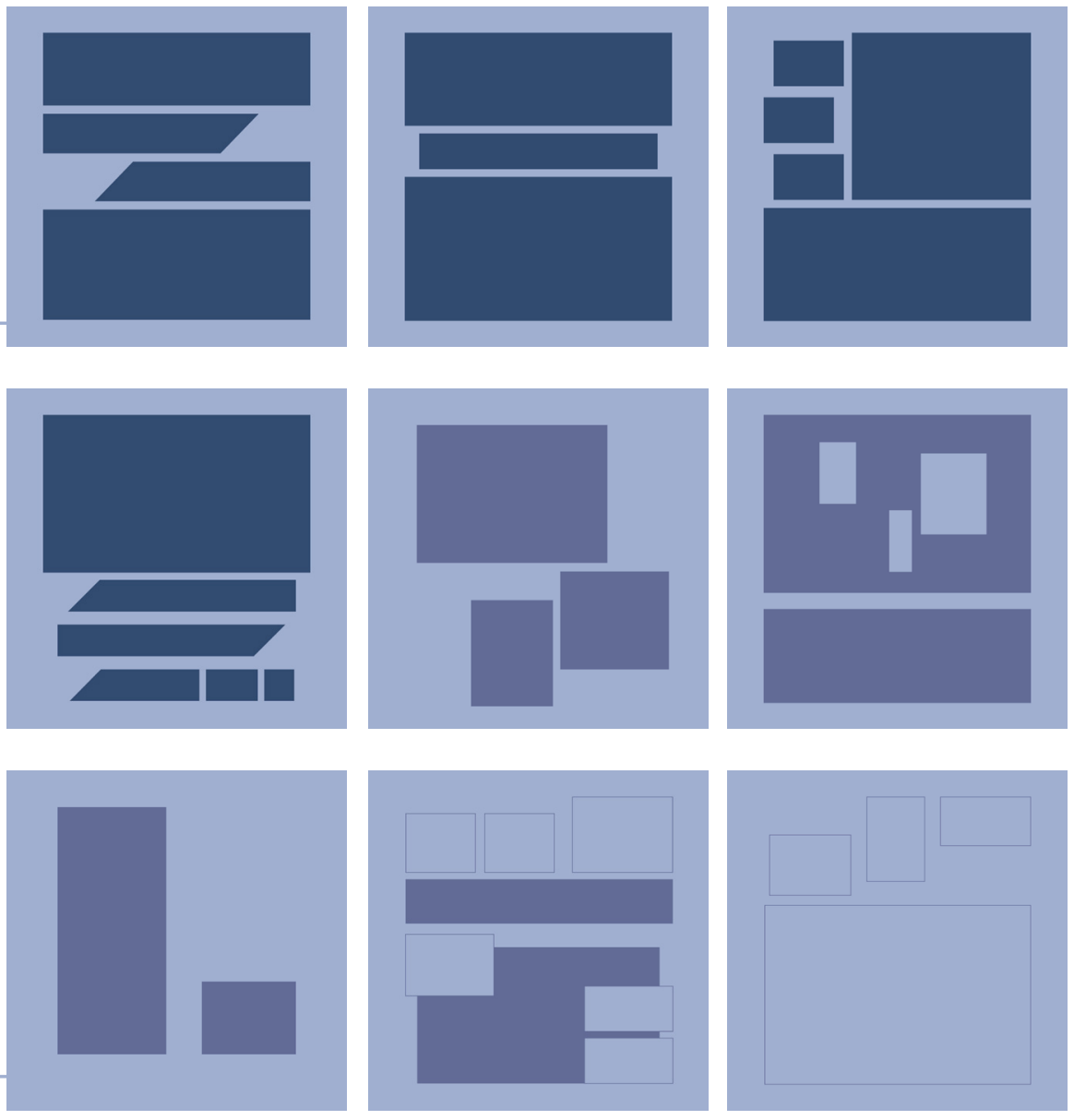

\section{Story 1:}

Title: Robinson Crusoe

The story is about Robinson (Mametanuki) living in the box. Robinson had trouble getting to his new home after a month. Robinson is the main character in the whole story, but he does not appear directly in the story, only shows on the last page.

In the second half of the story, the concept of time gradually came into being, so the color of the background became brighter and more colorful. 


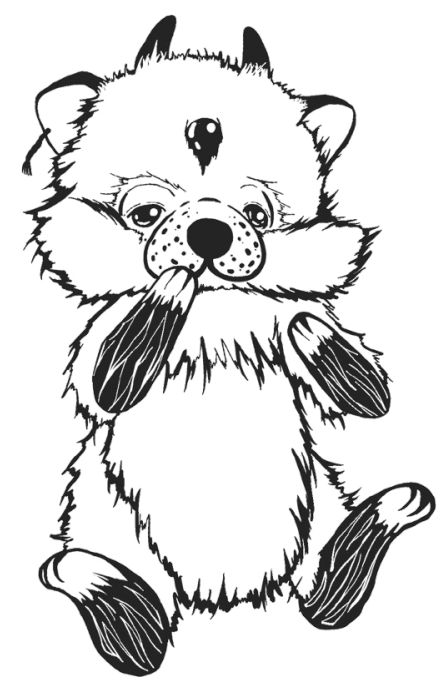

Participant: Aliao

Occupation: Lecturer

Collection type: BJD dolls, teddy beer, figures, animation goods

Location: JiangXi, China 


\section{Q1. Where does the doll live?}

生活在我家

Q2. What is your relationship with the doll?

我是他的姐植-3- hand drawn emoji

Q3. What kind of character does the doll have?

樯樯是一个有点害羞然条的小男骇, 反

应较慢, 性格安静温采很难生气。

感觉有天生的治愈能力, 因为太可爱了

Usually used to describe people as simple as small animals but have their own unique ideas. Usually their language is direct but not intentional to hurt others. Not paying attention to cooperating groups, but very not clumsy

Q4. What do you do together?

抱着他, 喜欢捏他的耳朵还有小爪爪丿

做手工时候, 他陪着我。

给他指照, 放到包包里带他出门! 春天雨

水太多了梳淋湿, 所以期待夏天的外景

\section{Q1. Where does the doll live?}

Living in my home

Q2. What is your relationship with the doll?

I'm his sister. - $3^{-}$

\section{Q3. What kind of character does the doll have?}

Cute character. He is a little shy and naturally dull boy, slow reaction, quiet and gentle personality is difficult to get angry. It feels like there's a natural healing power, because it's so cute.

\section{Q4. What do you do together?}

Holding him, like pinching his ears and claws. $\mathrm{He}$ accompanied me while I was doing the handicraft. Take a picture of him, put it in his bag and take him out. There's too much rain in spring for fear of getting wet, so I'm looking forward to the summer scenery. 
Q5. What do you think the doll does when you are not at home?

在等我回家。会和我的其他的娃㹩一
起玩, 不过樯宝应该不是主动的一方。

Q6. Please tell a story about the doll. This can be your imagination or what really happened in this period of time. Or you can expand on previous questions.

第一眼看到他的时候就喜欢上了, 觉得这是一 个很有灵魂的小朋友, 他䒿营懂懂坚在其他小 朋友旁边好像还没睡醒, 眼神却透露出一种委 屈, 让人想要保护他一辈子。它的第三只眼一 直昫昫有神, 仿佛可以看到别人看不到的世界。 四同初这个的朋友来到我家, 和我家其他宝宝 成当了伙伴。
Q5. What do you think the doll does when you are not at home?

Waiting for me to go home. I will play with my other dolls, but my cute kid might not be the initiative.

Q6. Please tell a story about the doll. This can be your imagination or what really happened in this period of time. Or you can expand on previous questions.

The first time I saw him, I fell in love with him. I think he is a kid who has a soul. He sat beside other children, and he always looks like he hadn't waked up yet. His eyes revealed a kind of grievance, which made people want to protect him for a lifetime. Its third eye) is always shining, and it feels like it could see the world that no one else can see. In early April, this child came to my home and became a partner with other babies in my family.

the characteristics in this story

key points of this story

the third eye and another word 


\section{Story 2:}

Title: The third eye

This is a story about Hakutaku used his third eye let a girl saw a story of his previous life.

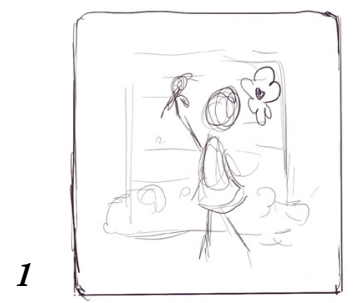

The first day to take the doll home.

2

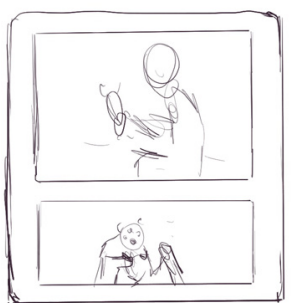

3

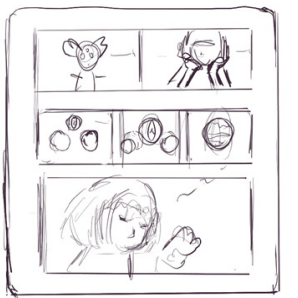

4

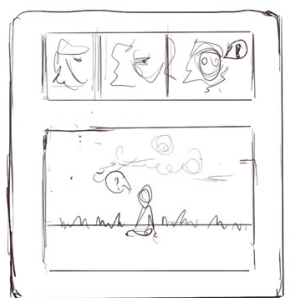
5

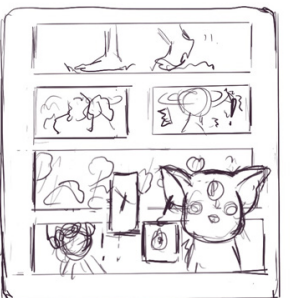

Wake up and find herself in a strange place.

A creature with the same characteristics as

Observing the third eye of the doll gradually lost consciousness and entered the dream. the new doll

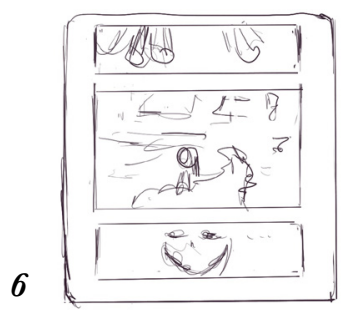

Found out this place is not modern but ancient.

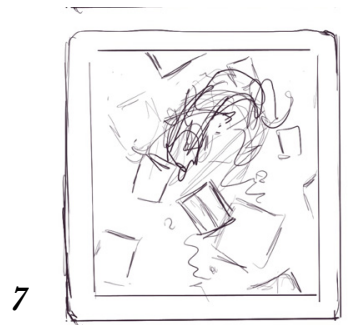

This place is full of memories of the doll's past life.

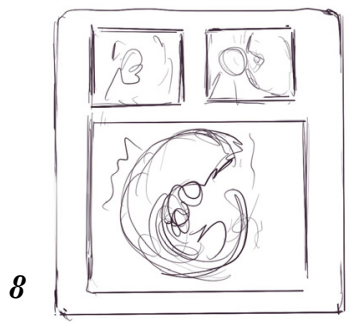

Having learned all the sadness and happiness of the doll's past, the little girl still chose to accept it.

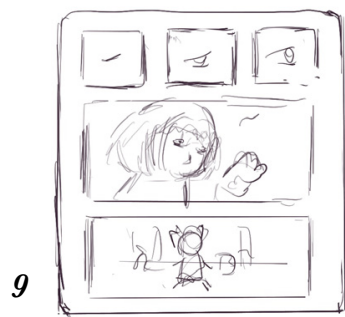

The little girl opened her eyes and found herself go back to her room.

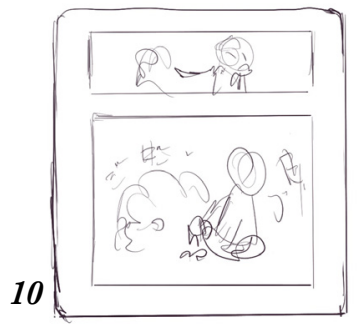

The little girl introduced the new doll to other little friends and told the story of the dream. 


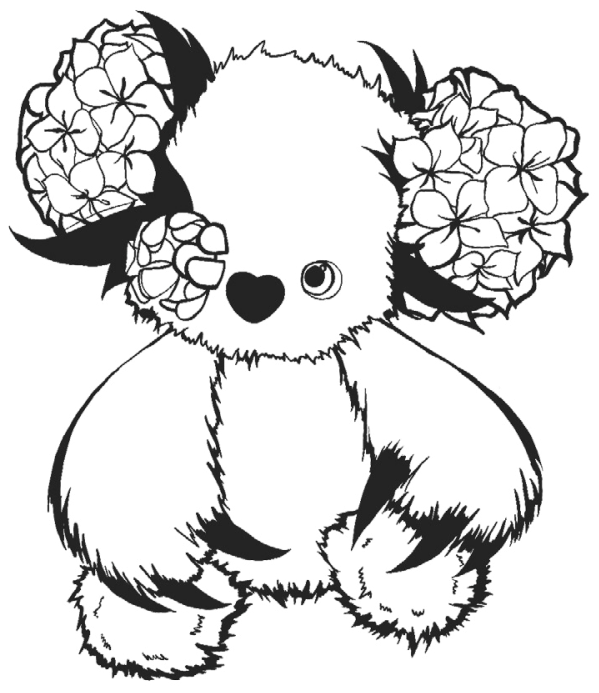

Participant: Summer

Occupation: Housewife

Collection type: figures, animation goods, stuffed toy Location: Singapore 


\section{Q1. Where does the doll live?}

生活在某个充满鲜花・云朵

以及一切美好事物的地方。

\section{Q2. What is your relationship with the doll?}

$$
\text { 亲属 }
$$

Usually used to describe people who are not close to others, often say no and mean yes. They are not good at expressing their feelings, but they are pure and kind-hearted.

\section{Q3. What kind of character does the doll have?}

可能是一个有点儌娇的软胡妹子亲近人 类. 如果不理她的的话会闹小脾气, 然后 需要花一些时间哄好她。

Usually used to describe a girl as gentle and kind

\section{Q4. What do you do together?}

平时会跟她对话, 脑补她的反应来跟自己 互动。会拿生活中的道具跟她摆报。会想 买得合娃㹩尺寸的迷你家具。

\section{Q1. Where does the doll live?}

Living in a place full of flowers, clouds and all the lorely things<smiles>C1CCCC1</smiles>

The environment and background of the story

Q2. What is your relationship with the doll?

Relative

\section{Q3. What kind of character does the doll have?}

Maybe it's a kind like a cat person, a lovely girl, who is close to human beings and will be short-tempered if she's ignored. Then it takes some time to please her.

\section{Q4. What do you do together?}

Usually, I will talk to her and imagine her reaction to my interaction. I used the stuff that come from daily life and take photos with her. I also would like to buy mini furniture in doll size and play with it. 
Q5. What do you think the doll does when you are not at home?

她会在家里跟其他娃挂愉快的玩要, 但 是到了晚上的时候就会坐好好等我回家。

Q6. Please tell a story about the doll. This can be your imagination or what really happened in this period of time. Or you can expand on previous questions.

我认尚每一个娃㹩都是有灵性的, 好果经常跟 它说话就会觉得它的表情很柔和, 如果有一段 时间没有理它会觉得它的表情有点不满。几乎 是每一个㹩㹩只要拿到手里就会和它互动, 并 且会拿着它跟周围亲近的人互动。
Q5. What do you think the doll does when you are not at home?

She would play happily with other dolls at home, but at night she would sit well and wait for me to go home.

Q6. Please tell a story about the doll. This can be your imagination or what really happened in this period of time. Or you can expand on previous questions.

I think every doll is spiritual. If you talk to it often, you will feel its expression is very soft. If you ignore it for a while, it will feel a little dissatisfied with its expression. Almost every doll interacts with it as soon as it is in its hands, and it interacts with people close to it. 


\section{Story 3:}

Title: The girls from the garden

The story described Momijigari is a girl who comes from a place full of flower. One day she met a girl who came to the city and took her home.

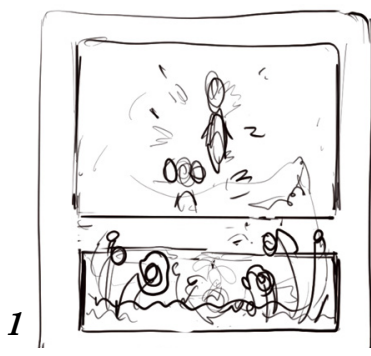

Found the doll in the garden. (blue as the main color)

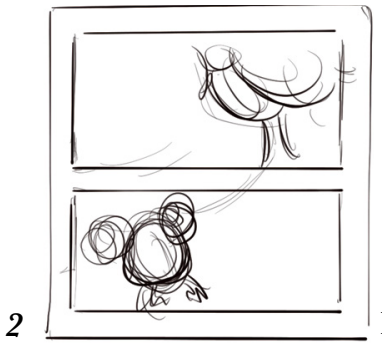

Look at each other

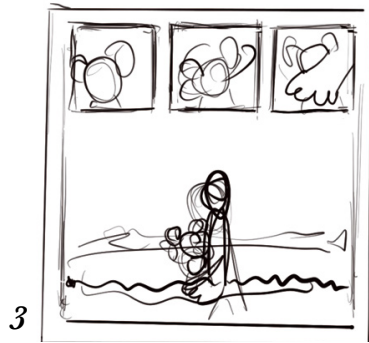

She took the doll home.

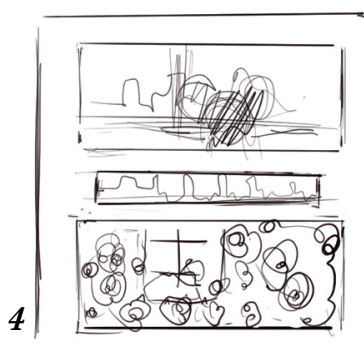

First glance at the city. (Change the main color to yellow)

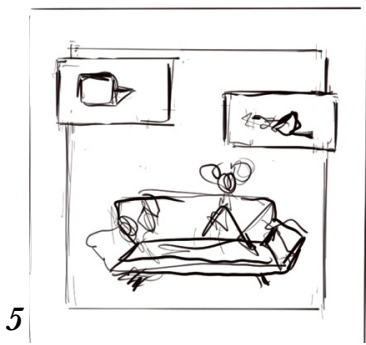

At home, little girls don't always play with dolls.

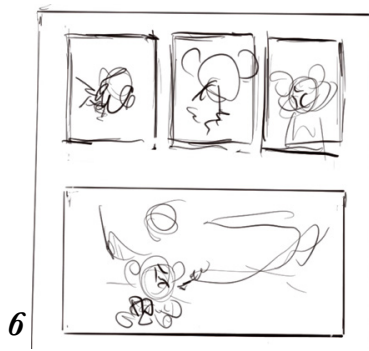

Dolls start to annoy and attract the attention of little girls in various ways.

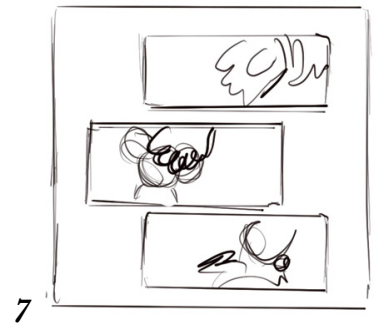

The little girl went to placate the doll.

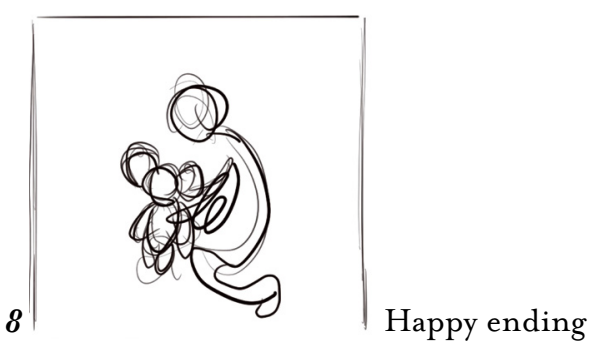




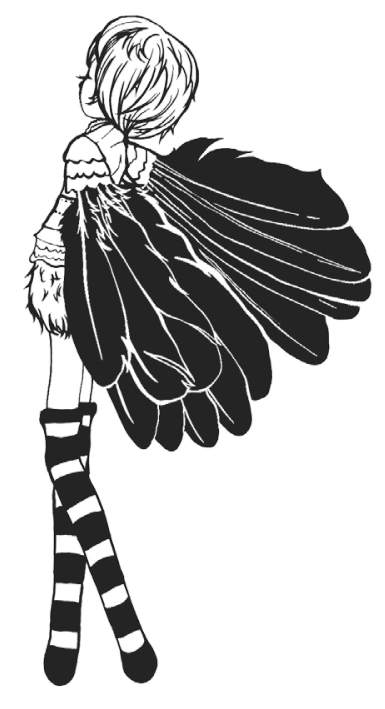

Participant: Vera

Occupation: Marketing and communications Collection type: game goods, stuffed toy Location: QingDao, China 
Q1. 娃娃通常都生活在什么地方？

where does the doll live?

$$
\text { My bed. }
$$

Q2. 你认为你和娃娃的关系是什么?（朋友/亲属/其他）

what is your relationship with the doll?

$$
\text { Friends }
$$

Q3. 你认为这个娃娃是一个什么样性格的角色, 它有什么特征?

What kind of character does the doll have?

$$
\text { raughty Characters of the dolls and types of stories (comedy) }
$$

Q4. 你平时都是如何和它玩要的, 你们通常都在一起做什么事?

What do you do together?

$$
\text { Travel or stay at home }
$$

Q5. 你认为当你不在家的时候它都在家里做什么?

What do you think the doll does when you are not at home?

$$
\text { play with herself. }
$$

Q6. 请讲述一件关于这个娃娃的故事, 可以是你的想象也可以是在这段时间里真 实发生的事情。或者可以对之前的问题进行进一步扩展。

Please tell a story about the doll. This can be your imagination or what really happened in this period of time. Or you can expand on previous questions.

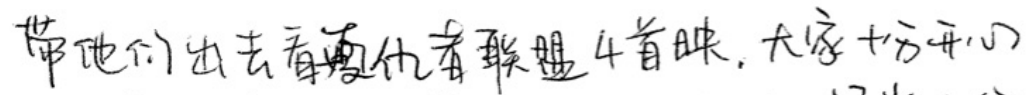

$$
\begin{aligned}
& \text { 并差总去了帽子。后来带他们去台北划, 䠈当地的 }
\end{aligned}
$$

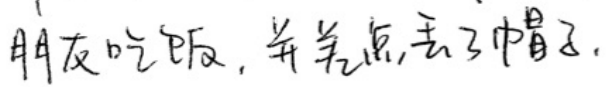

I took them to watch Avengers4 premiere. They all enjoyed.

It's just that they almost lost their hats. key point of the story

Later I took them to visit Taipei. They play and eat dinner with the local

friends. Also, almost their hats.

\section{Story 4:}

Title: Where is my hat?

It tells the story of three birds losing their hats under various circumstances. Every story is short but has a good sense of humour. 


\subsection{Visual narrative}

Story I: Robinson Crusoe

Story 2: The third eye

Story 3: The girls from the garden

Story 4 : Where is my hat? 


\section{Robinson Crusoe}

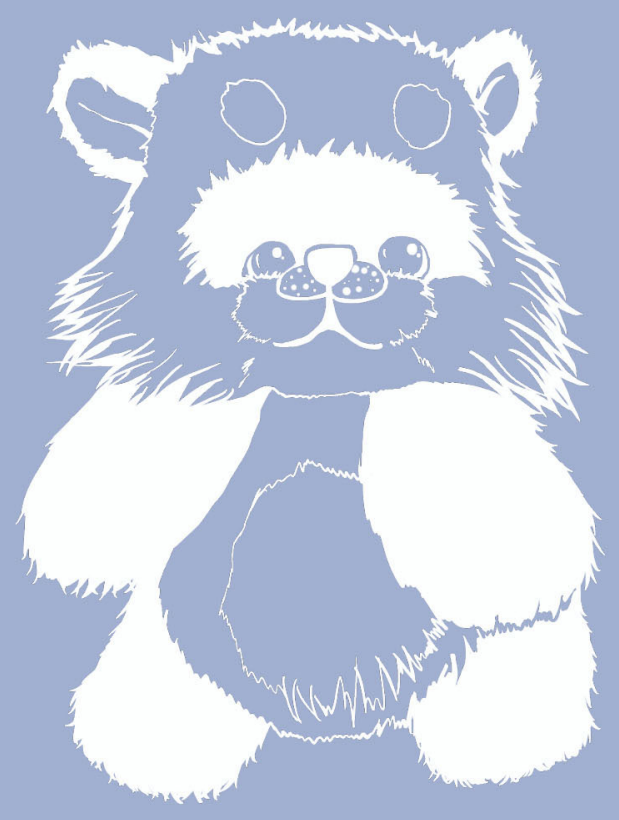


My name is Robinson

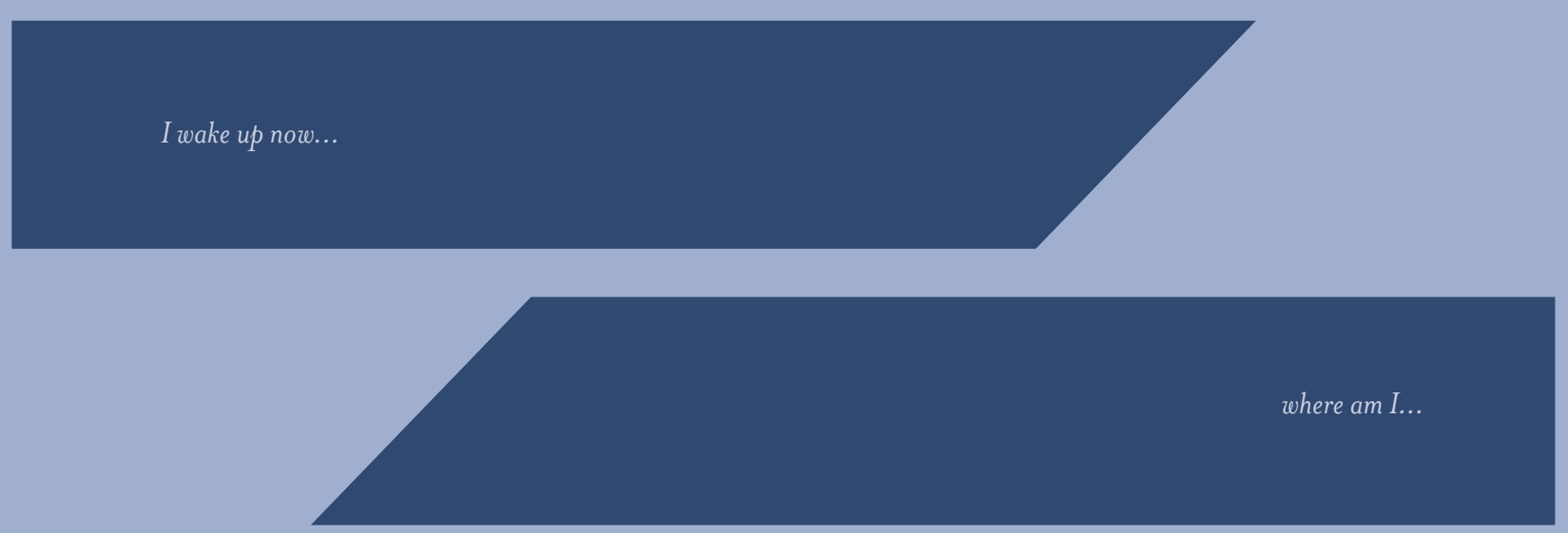

It's dark...

so dark...

Darkness hung over me, and there was no light in the sky. 
So, what happened?

The last thing that I remember is I am with the flower girl, bird girl and the three eyes Hakutaku.

In theory, at this moment or the next memory should be that I finally crossed the Pacific Ocean in my dream, and I get to my new home. 
Why so dark...

My hands, legs and head still can move.

What the hell is this?!

There was nothing wrong with the straw mattress underneath the except a little moisture absorption in this ghastly weather.

But!!!

Who can tell me why? At this time...This moment! Me! Still!

Lying on the mattress! Still!

Why so dark!

Before I left, mum said not to use my superpower too often. But why can't I use my superpower to become a ship. 
There is only darkness so I can't calculate the time... and, inside the box there is no stars and no moon. Inside this in this small box, like a dead body lying on the straw mattress.

\section{I cannot move.}

Feels like time is so long... so long...long...

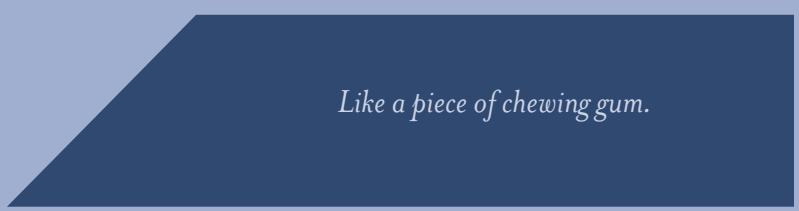

Also...

can't sleep 

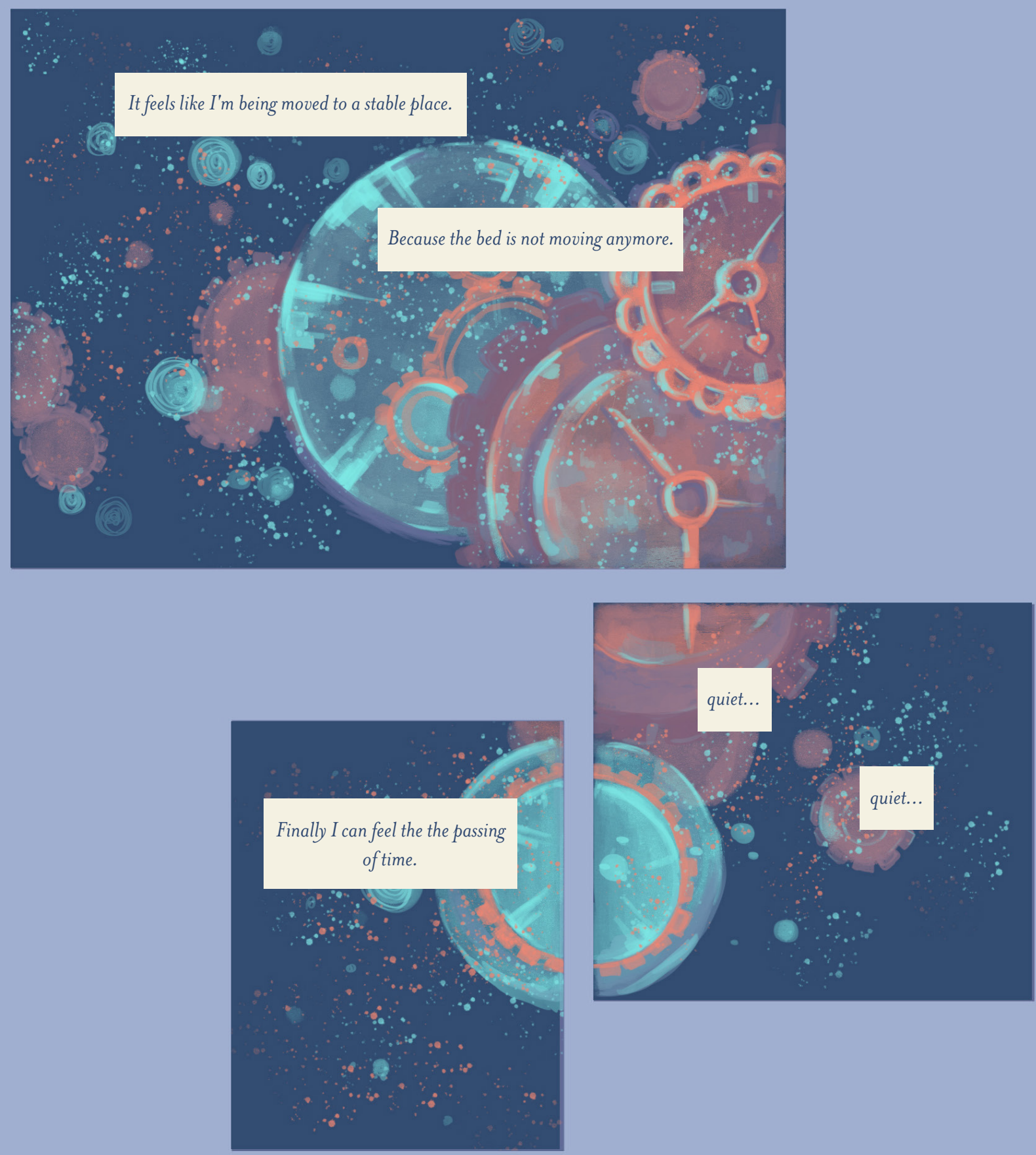

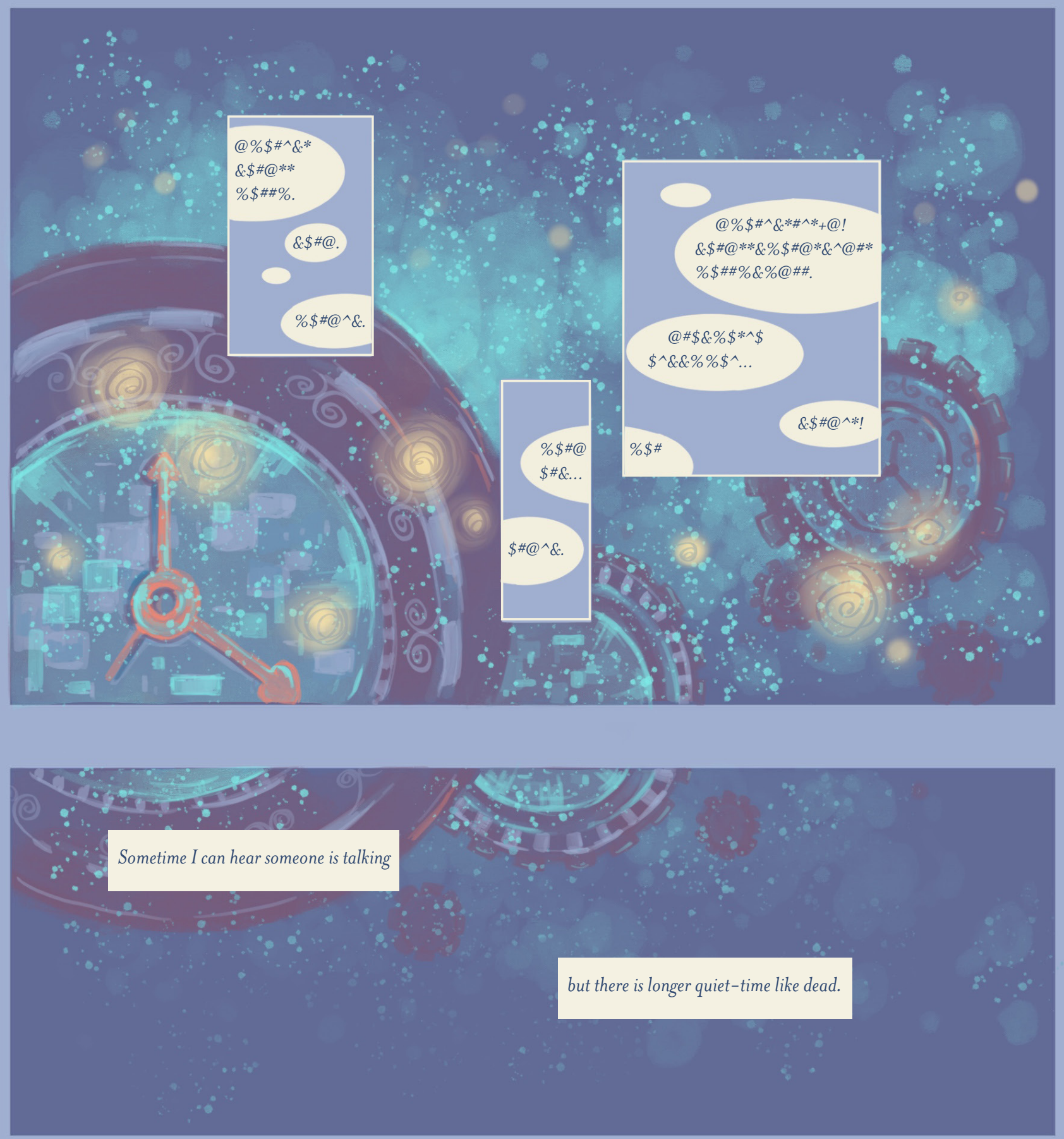


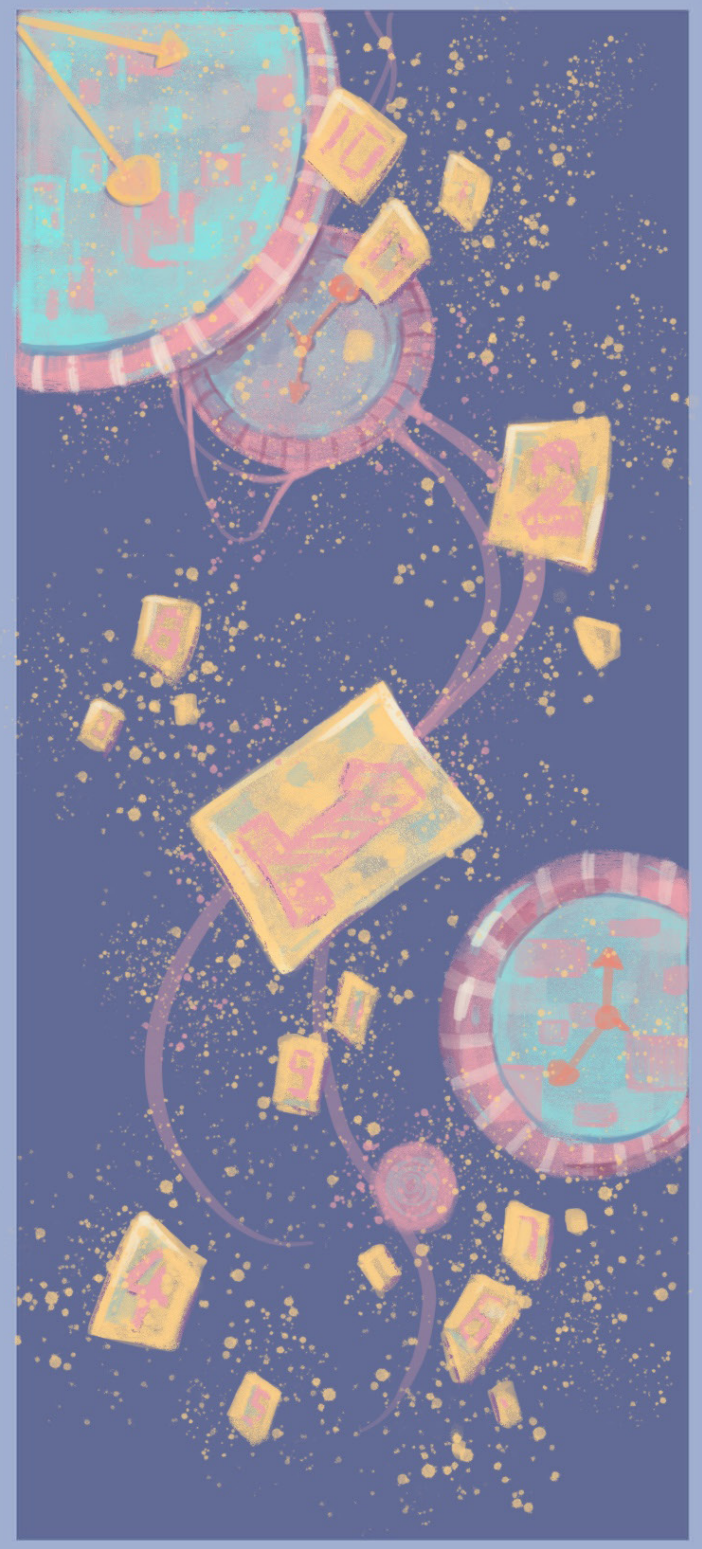

Even I can count the date, still I feel this time is longer than $m y$ whole life.

Too boring...

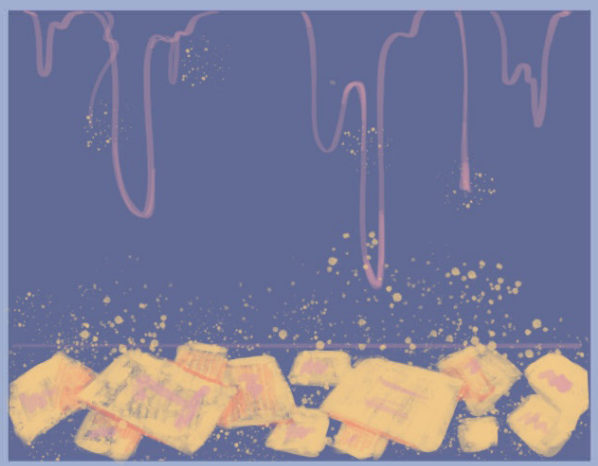



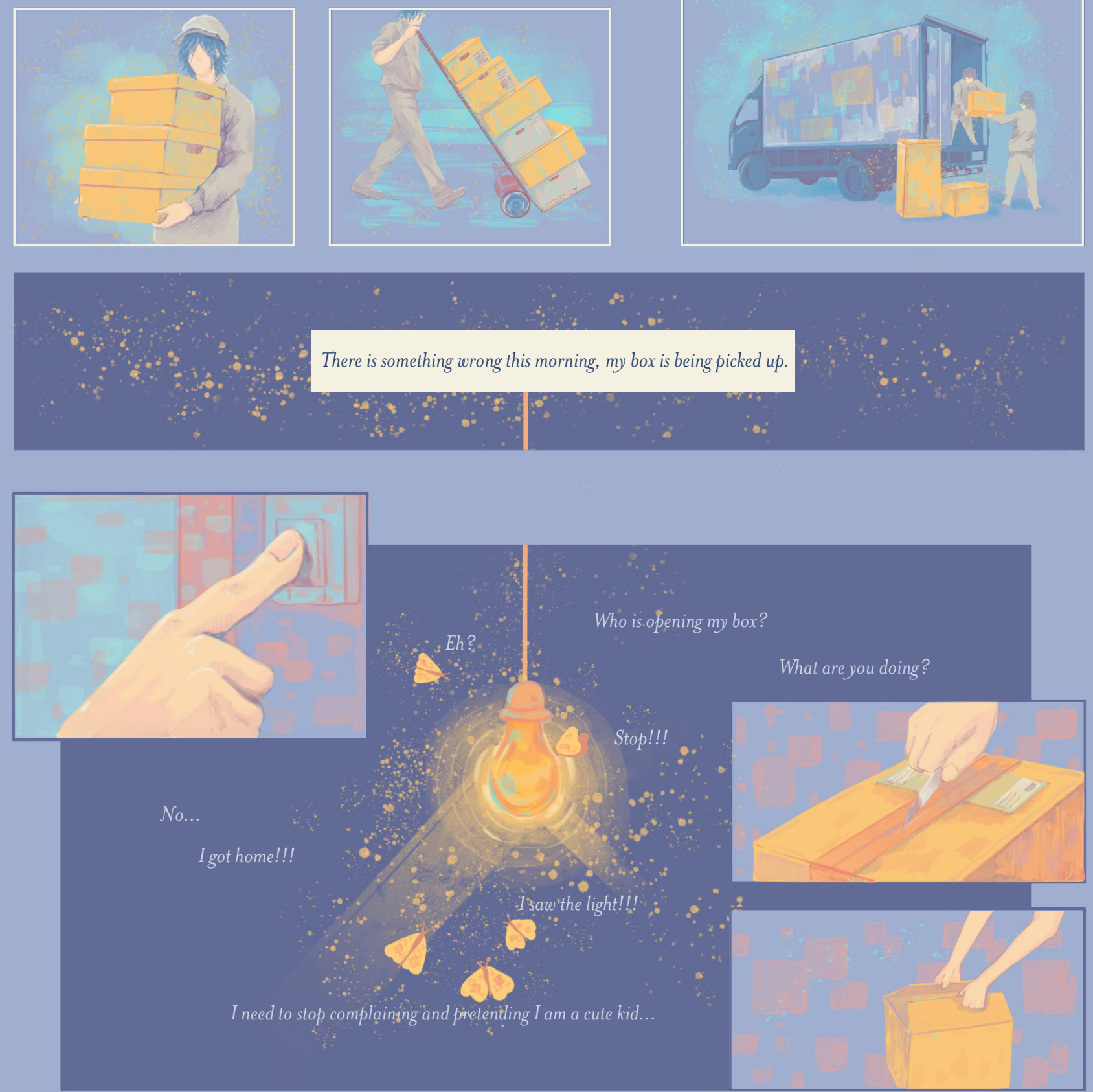


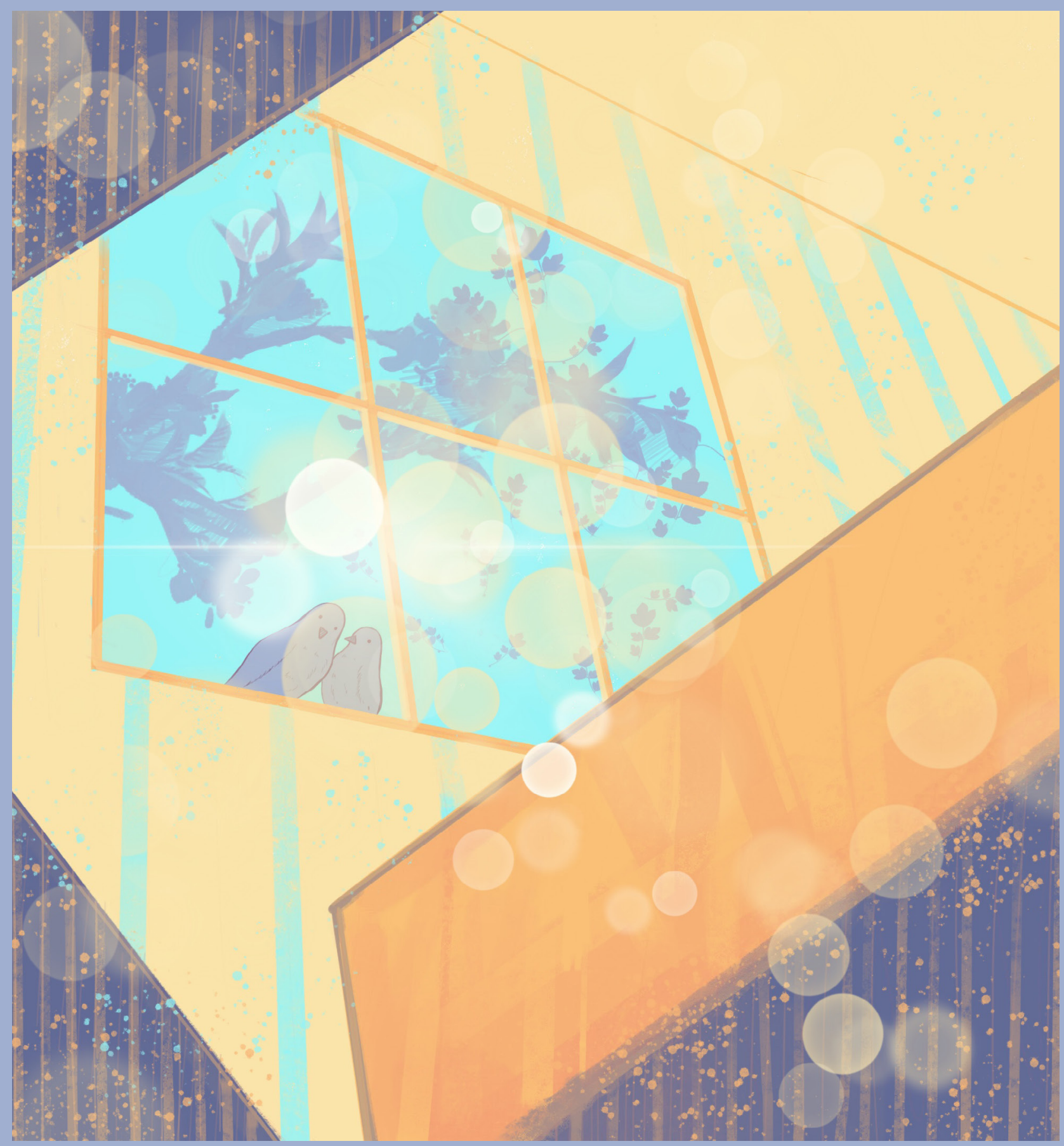


New home,

freedomavel,

sunshine...
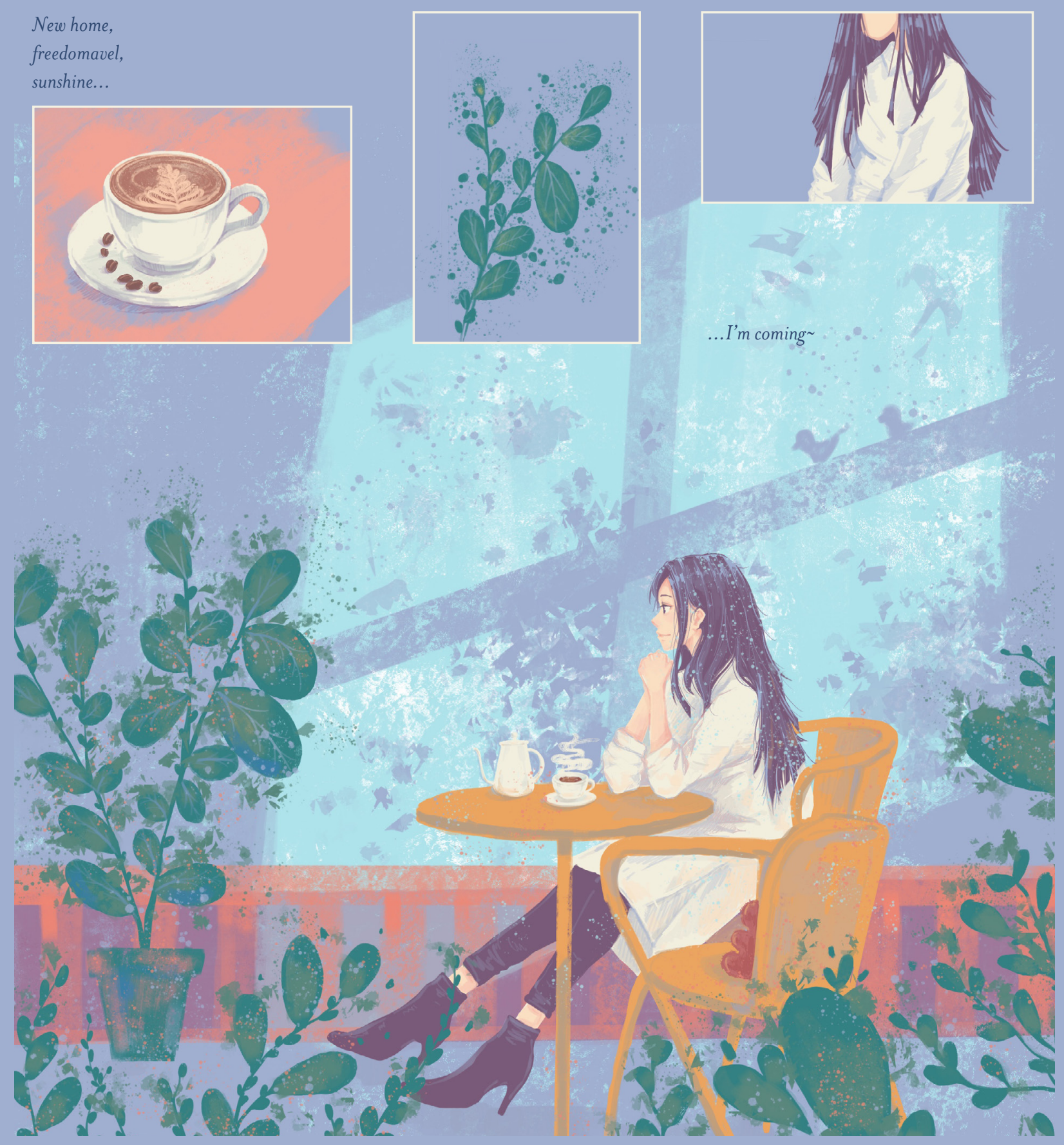


\section{The third eye}

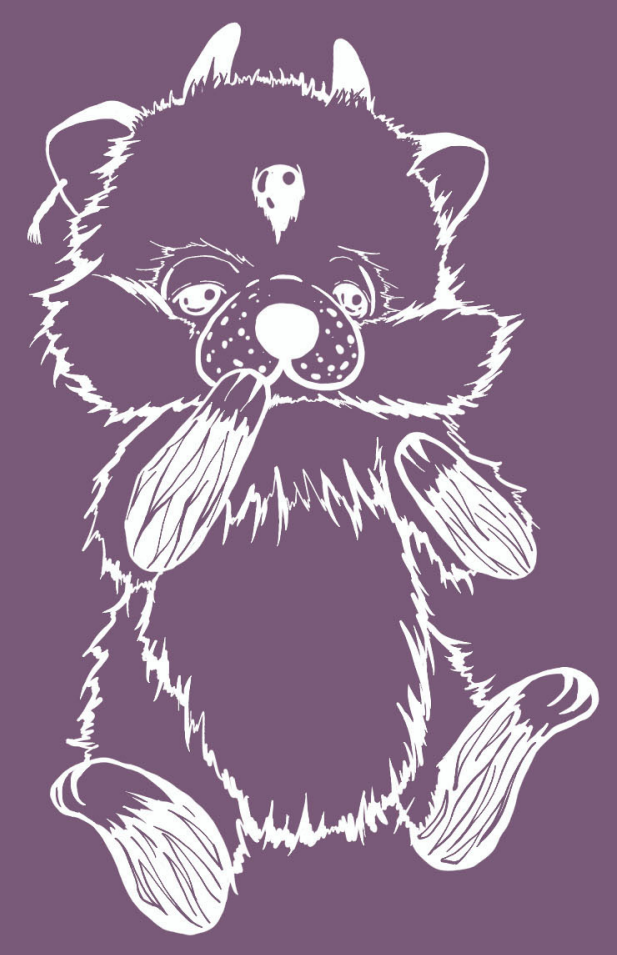




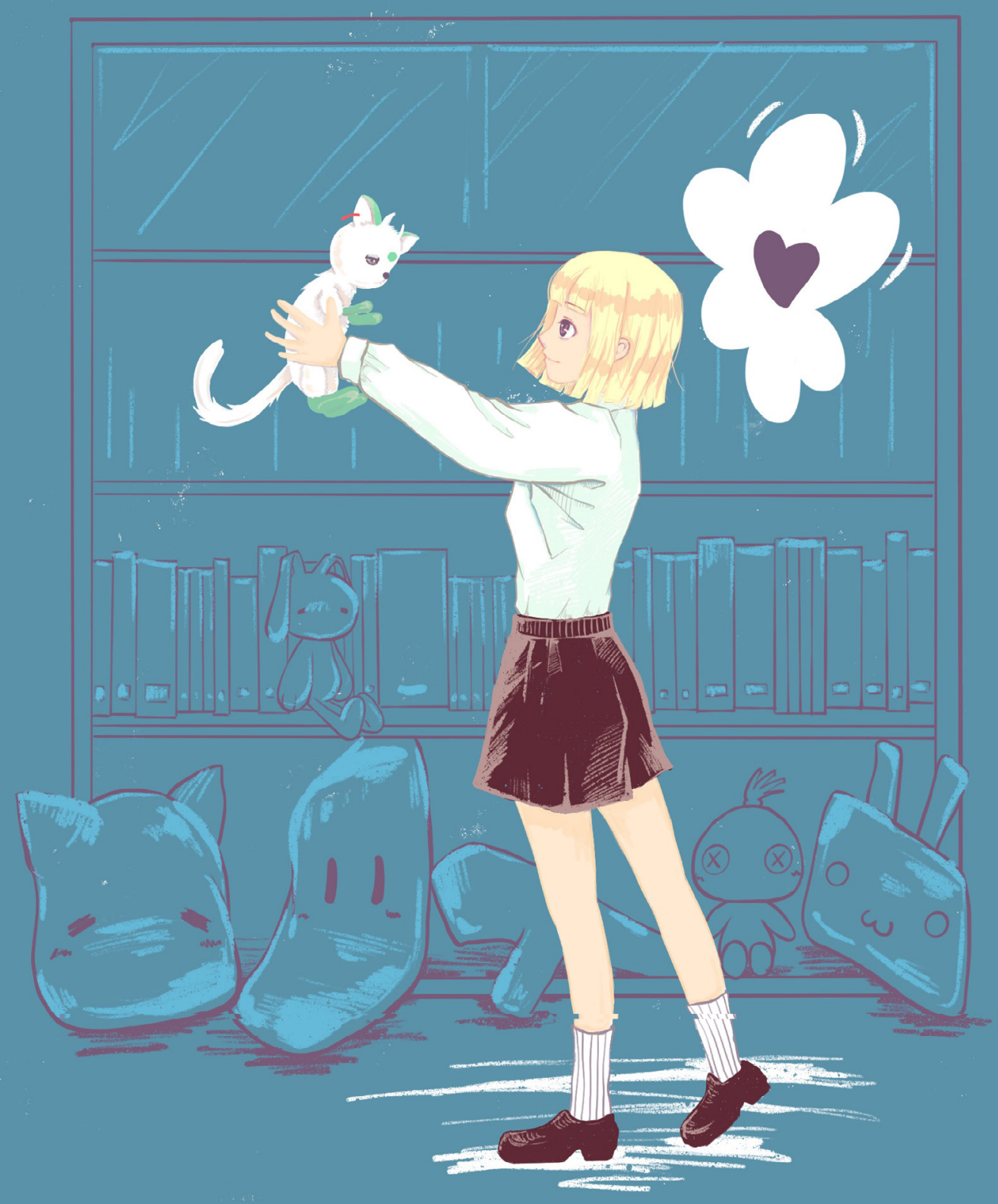



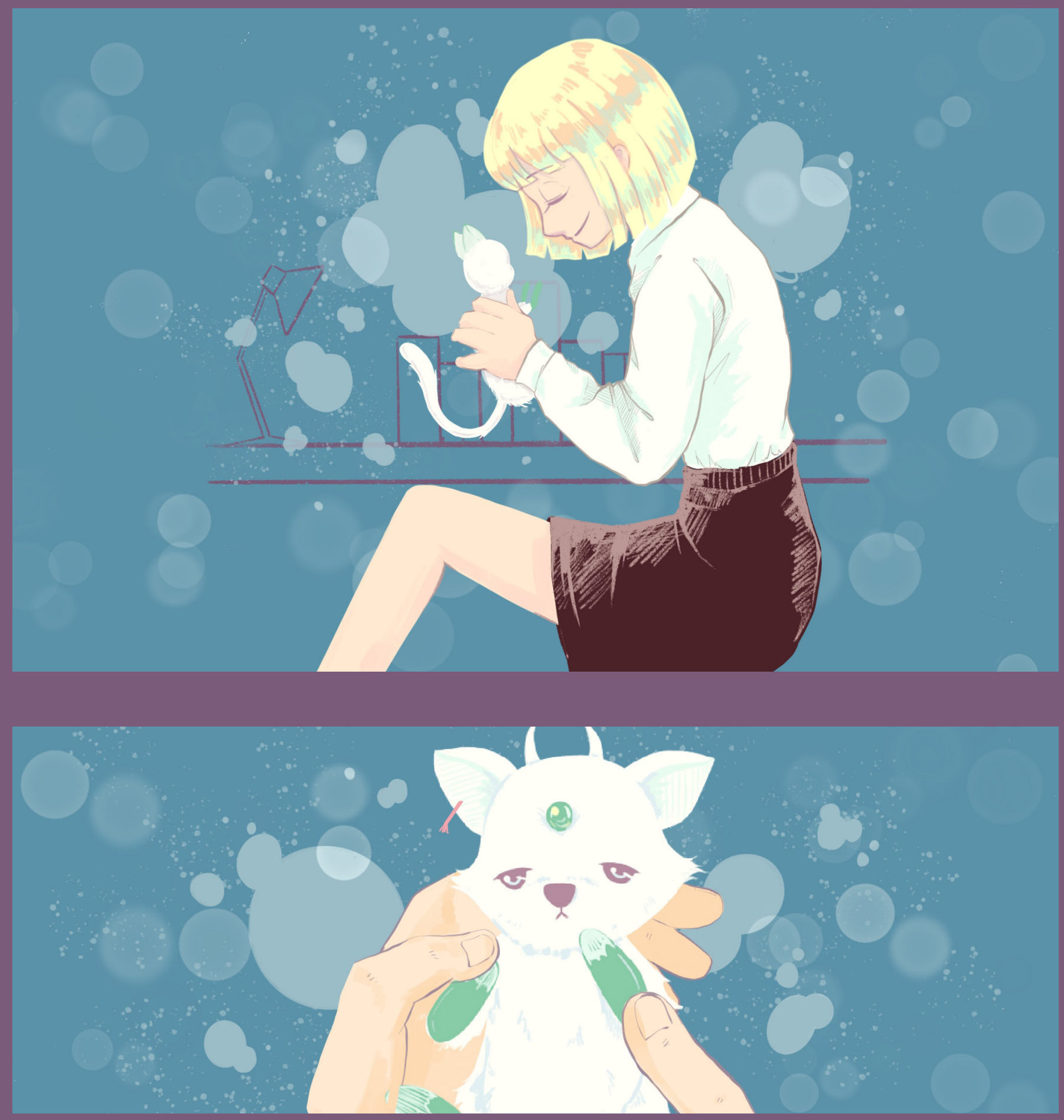

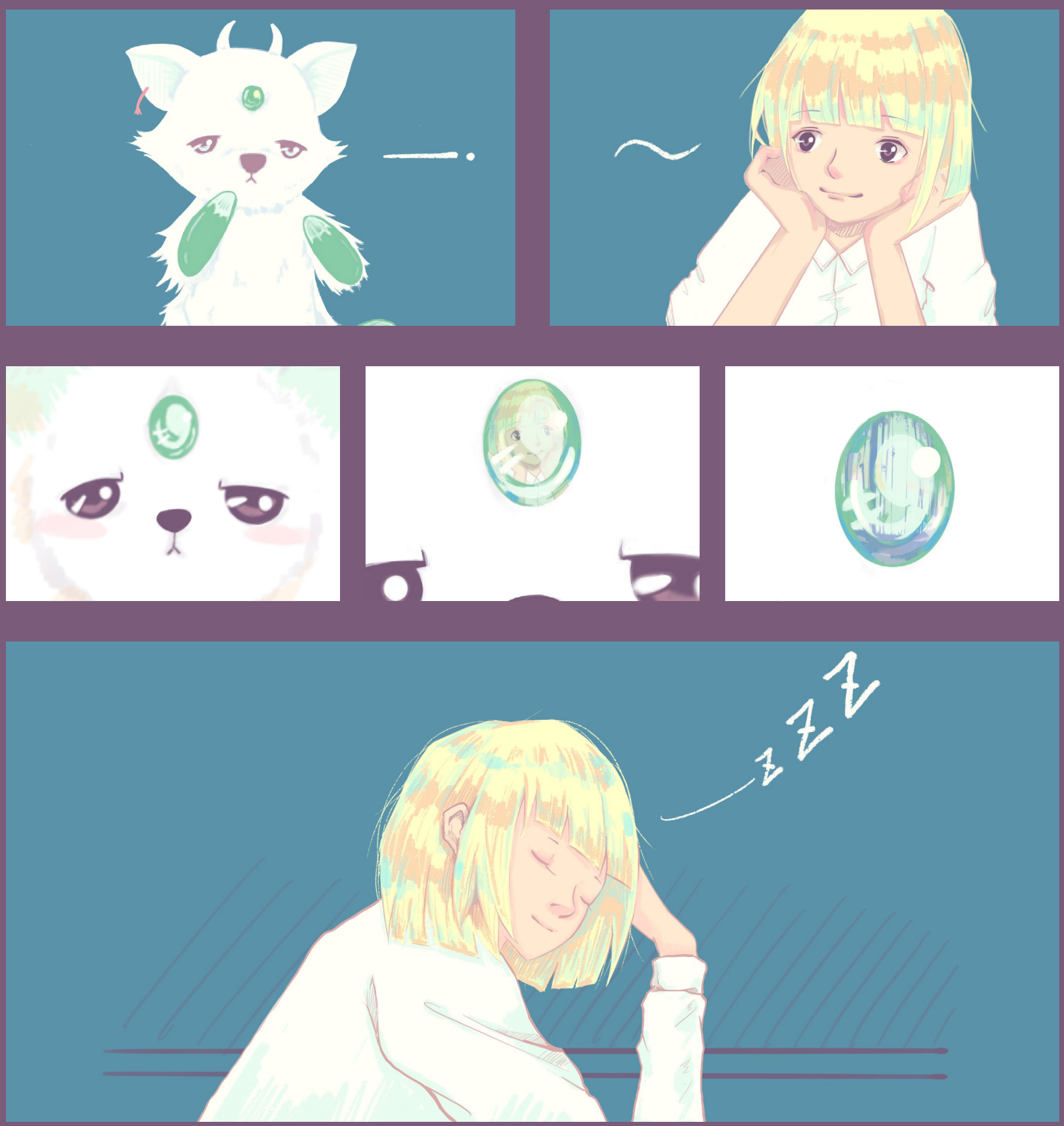

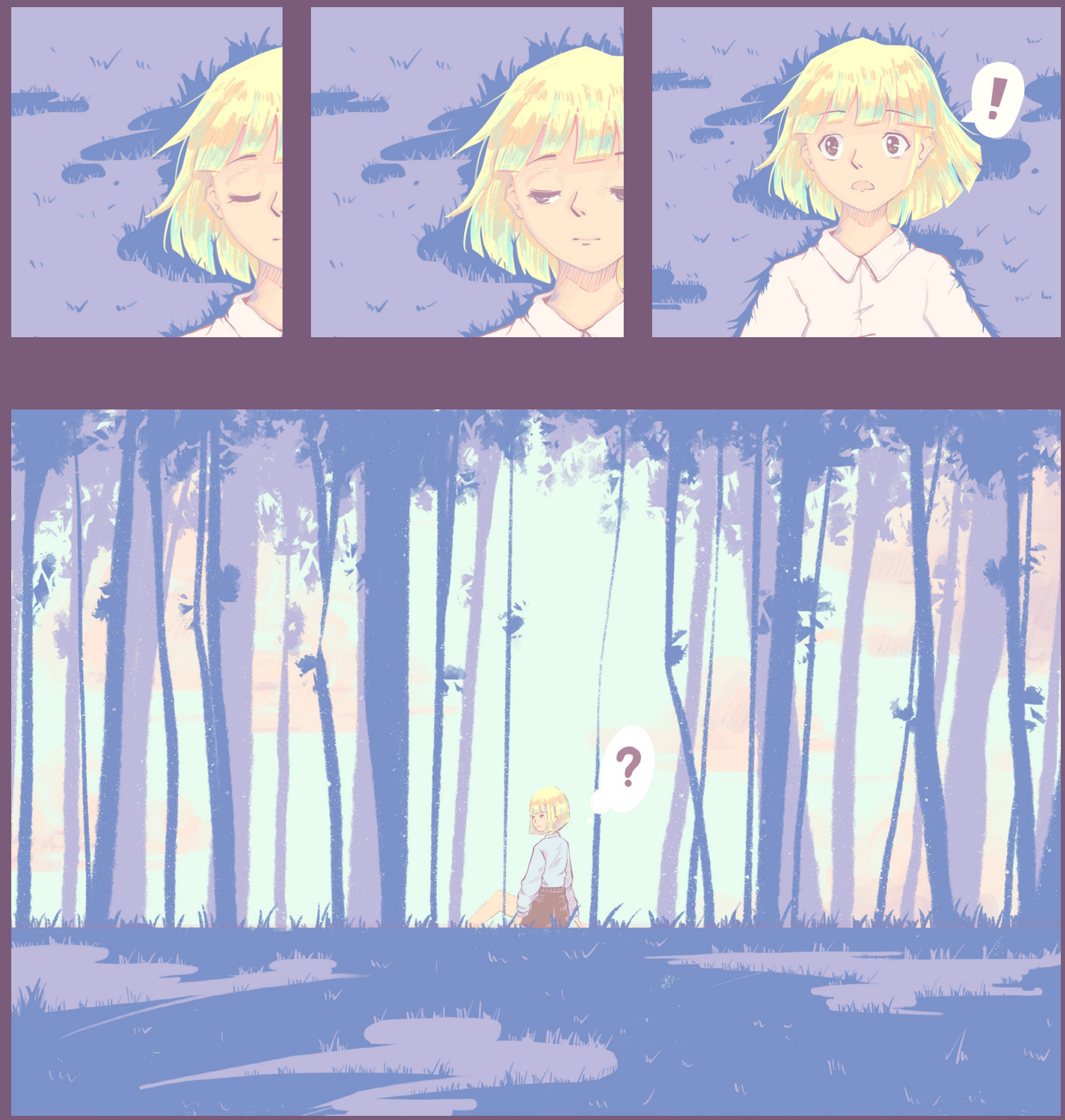

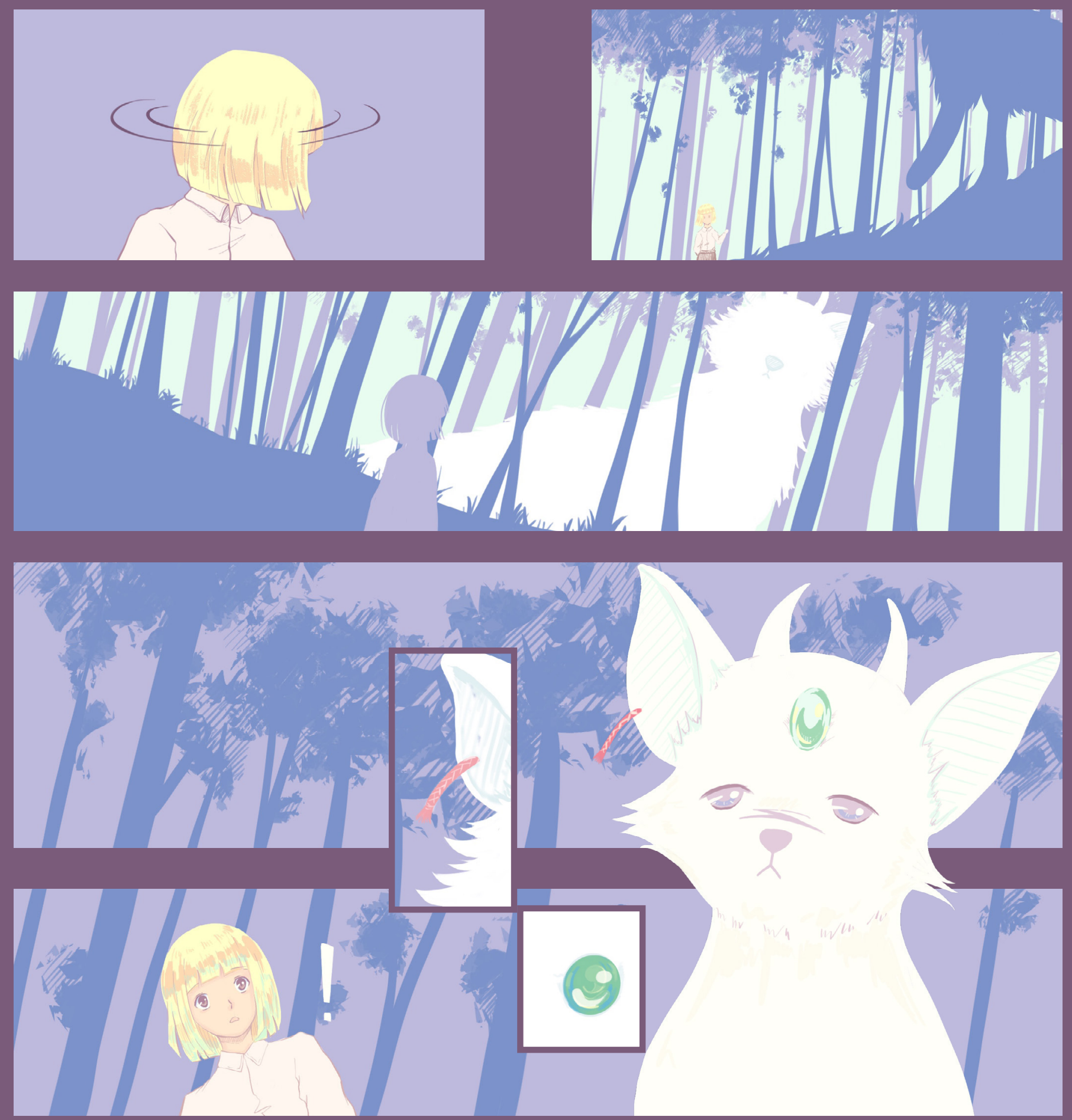

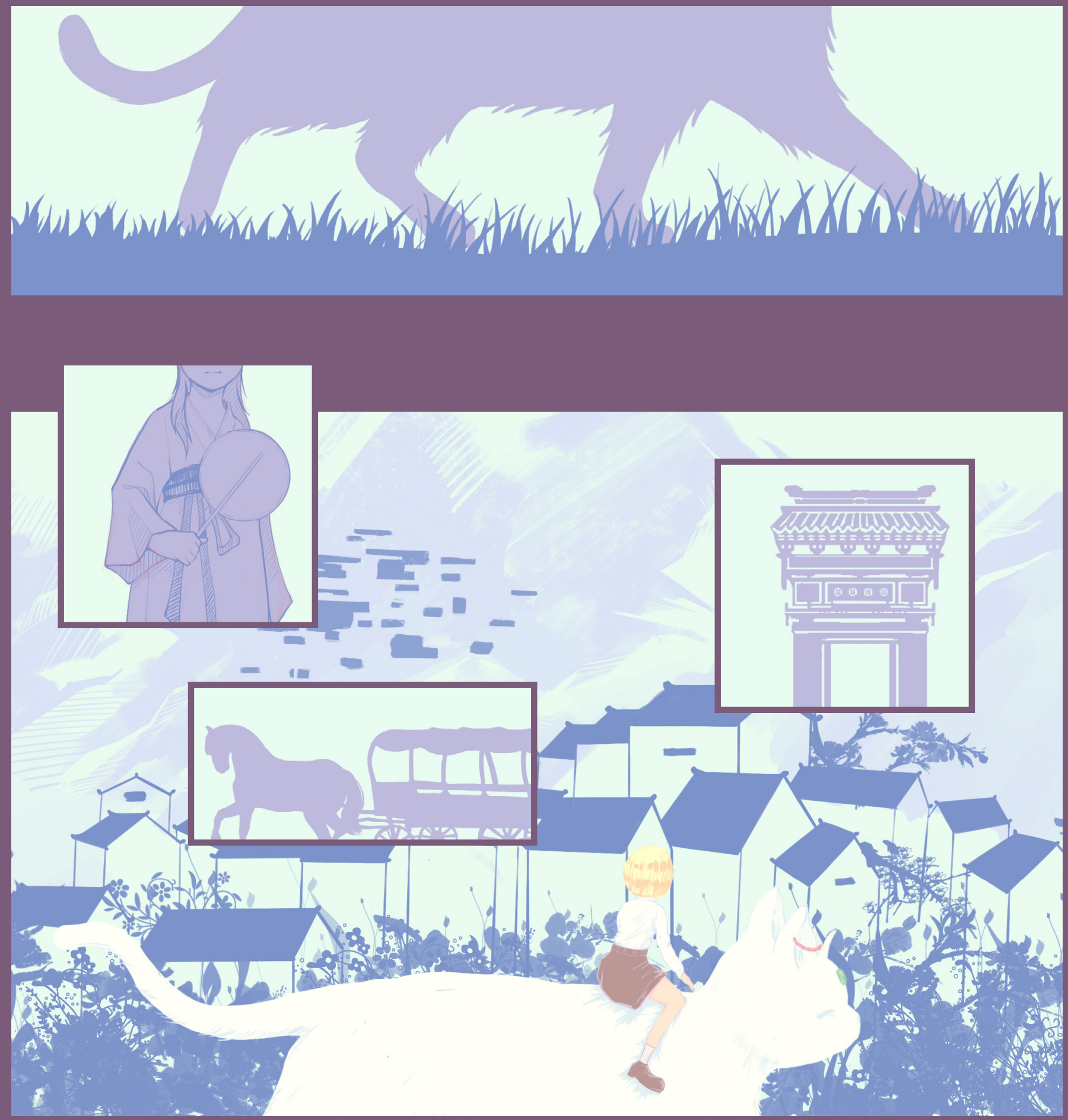


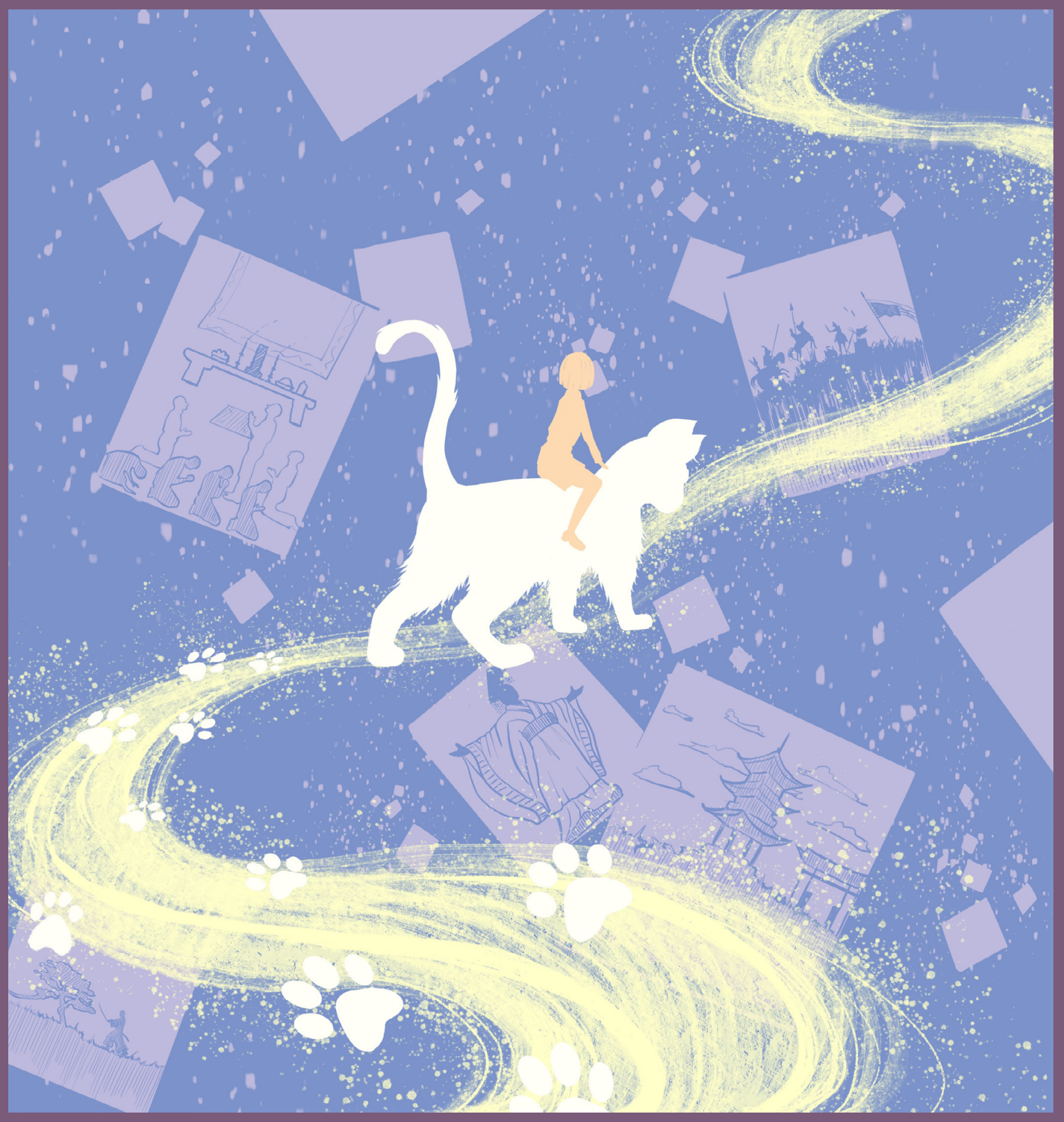



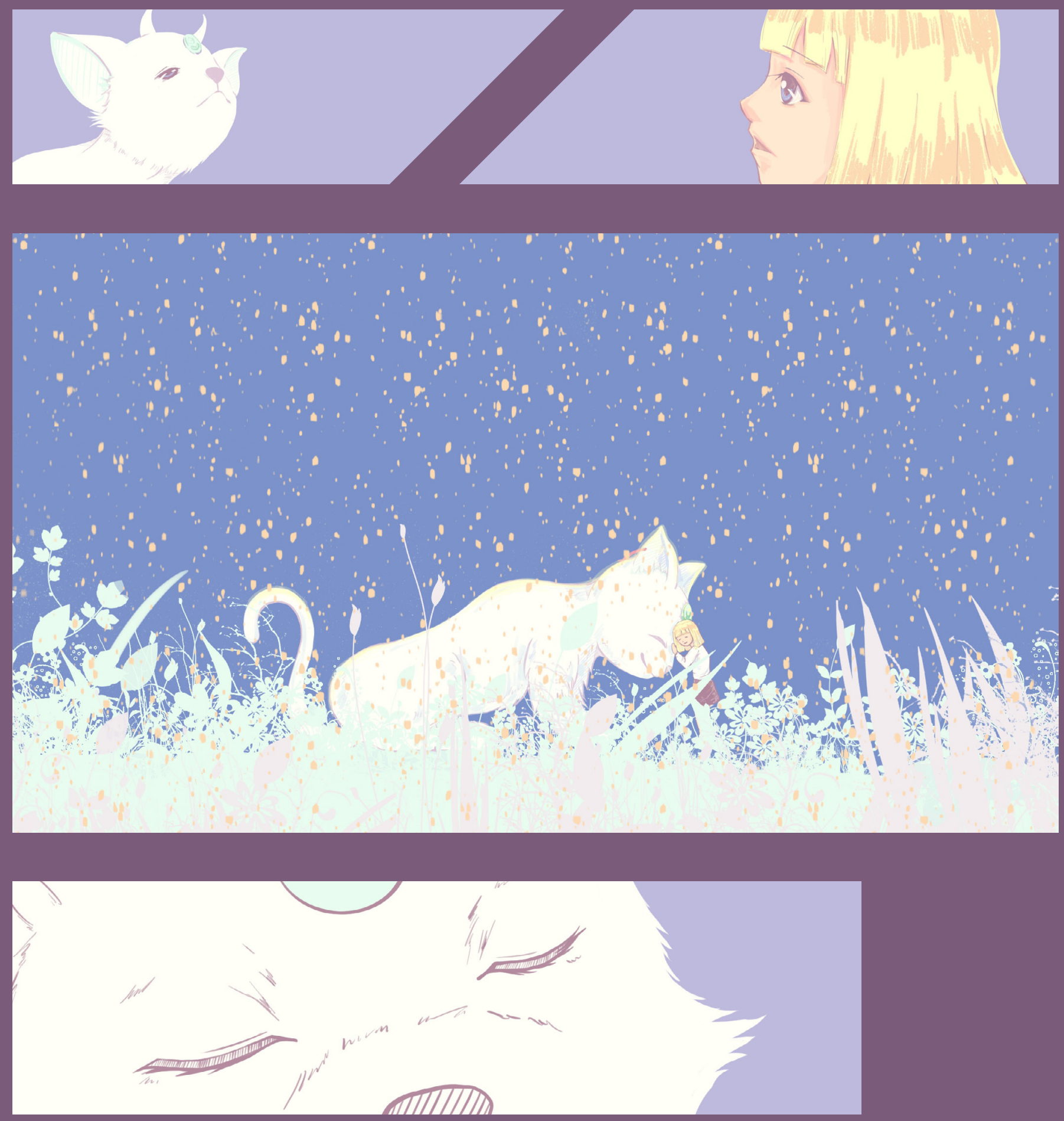

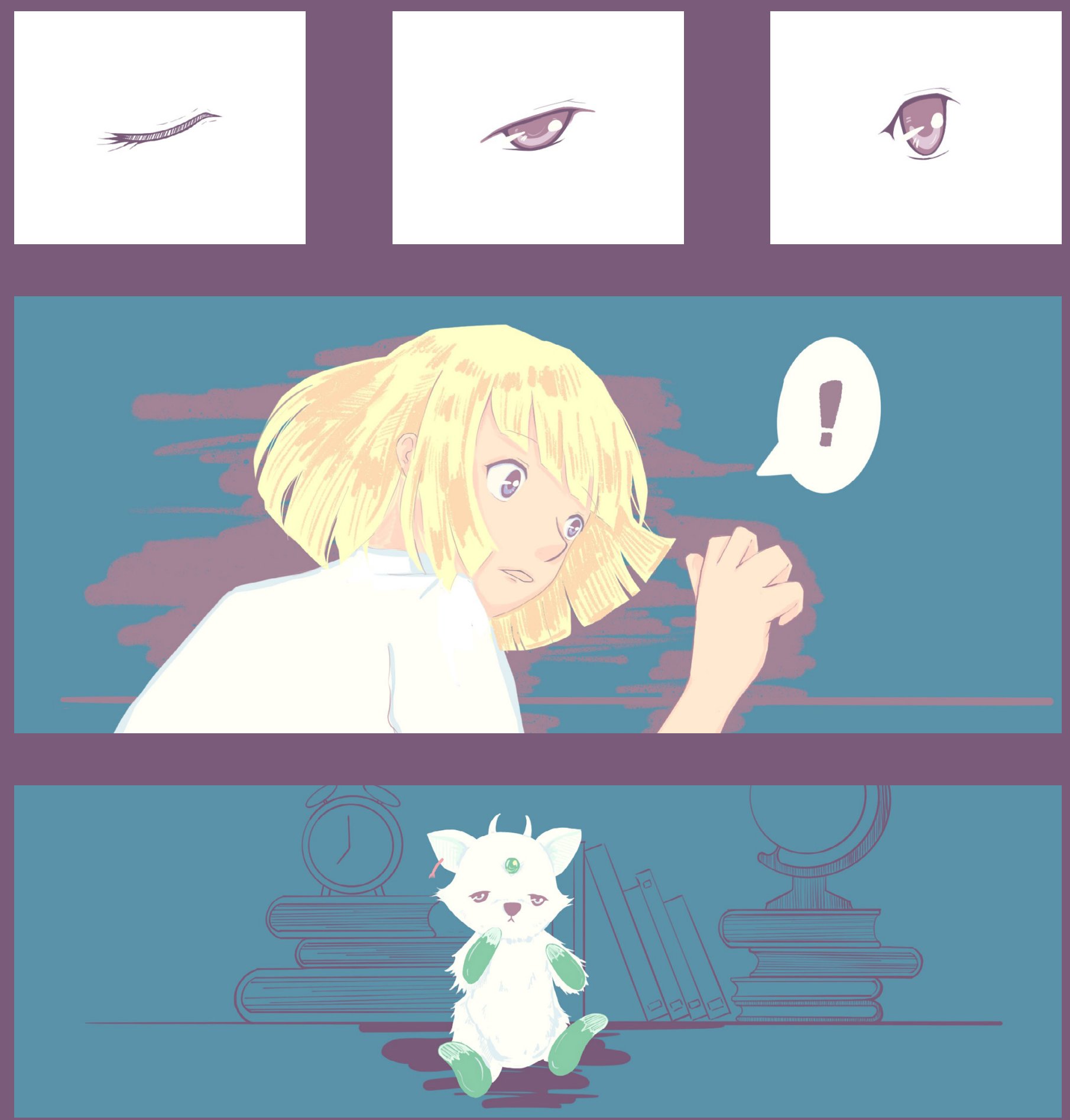

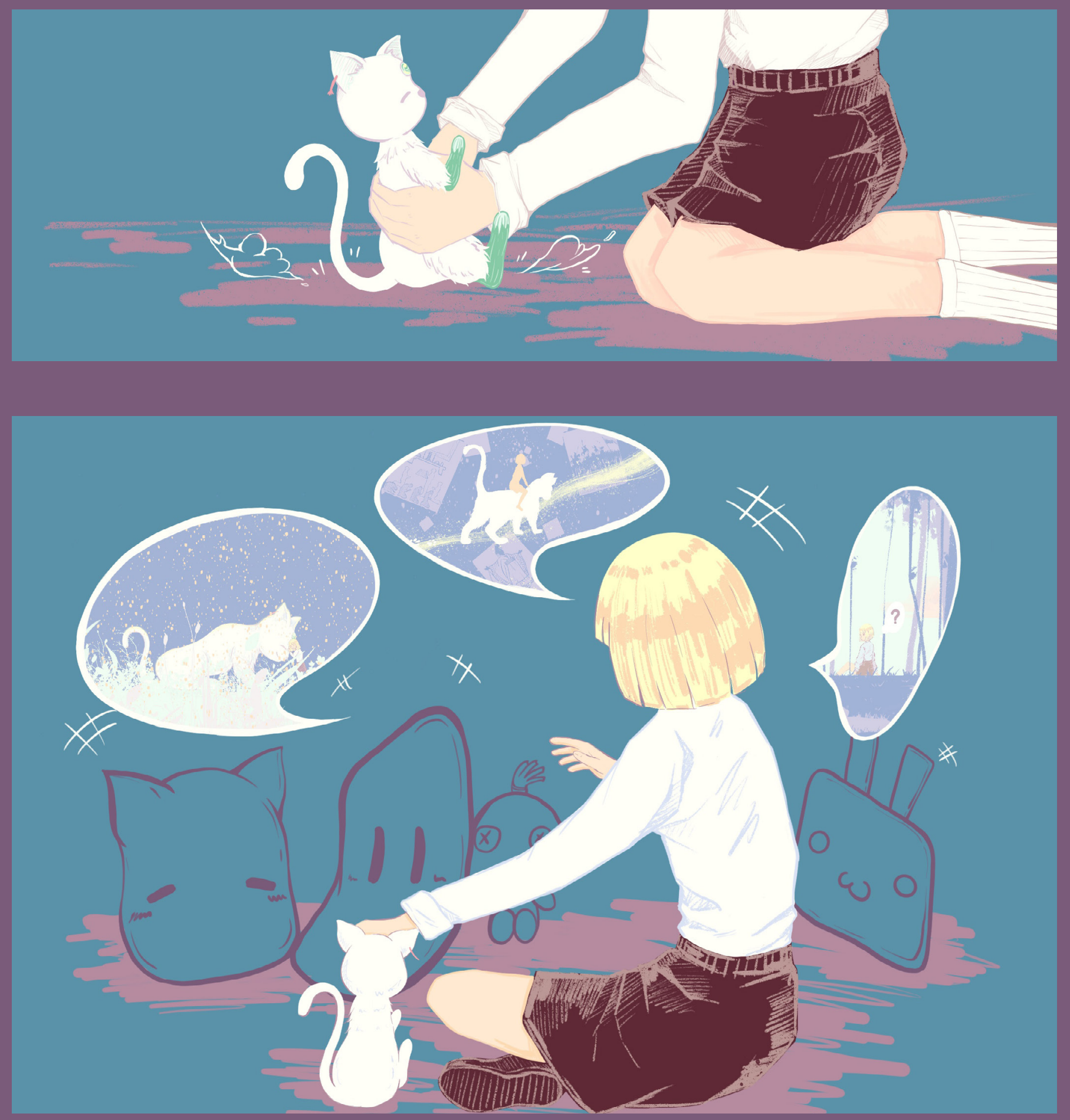


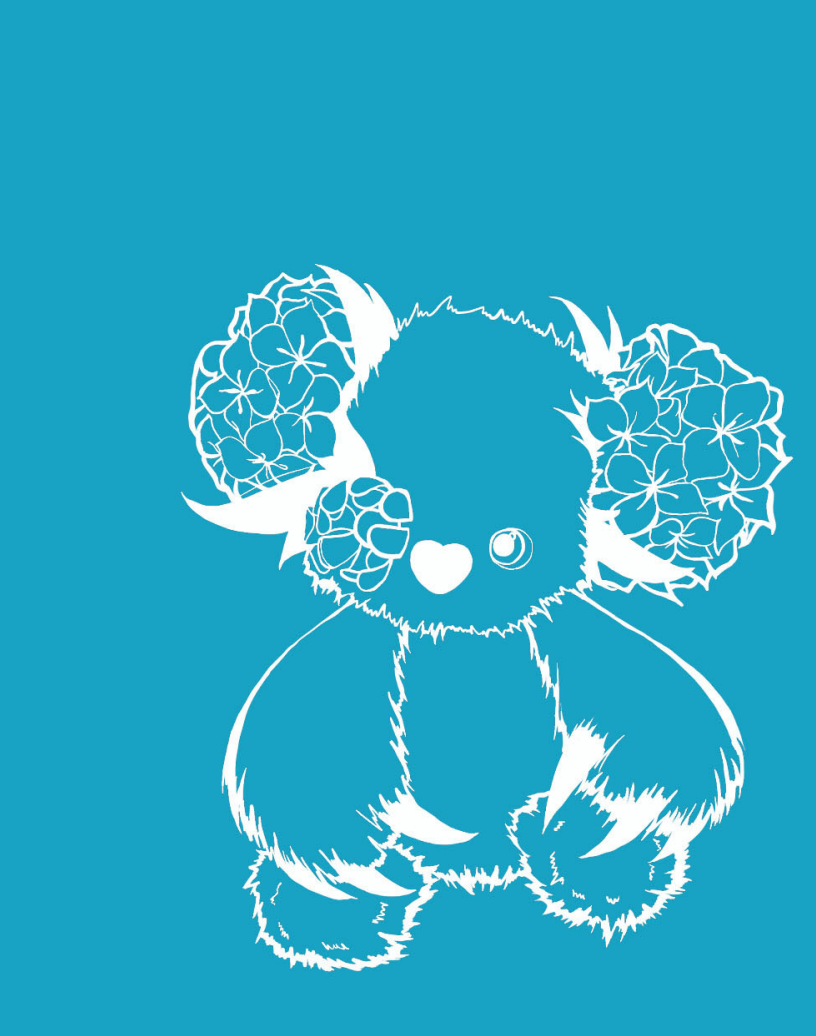

\section{The girls from the garden}

The girls from the garden

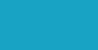

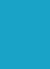
$x^{2}$

.

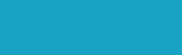

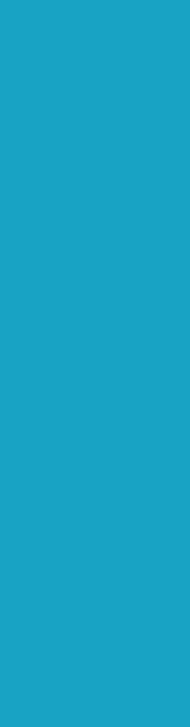

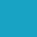

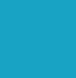

(n) 

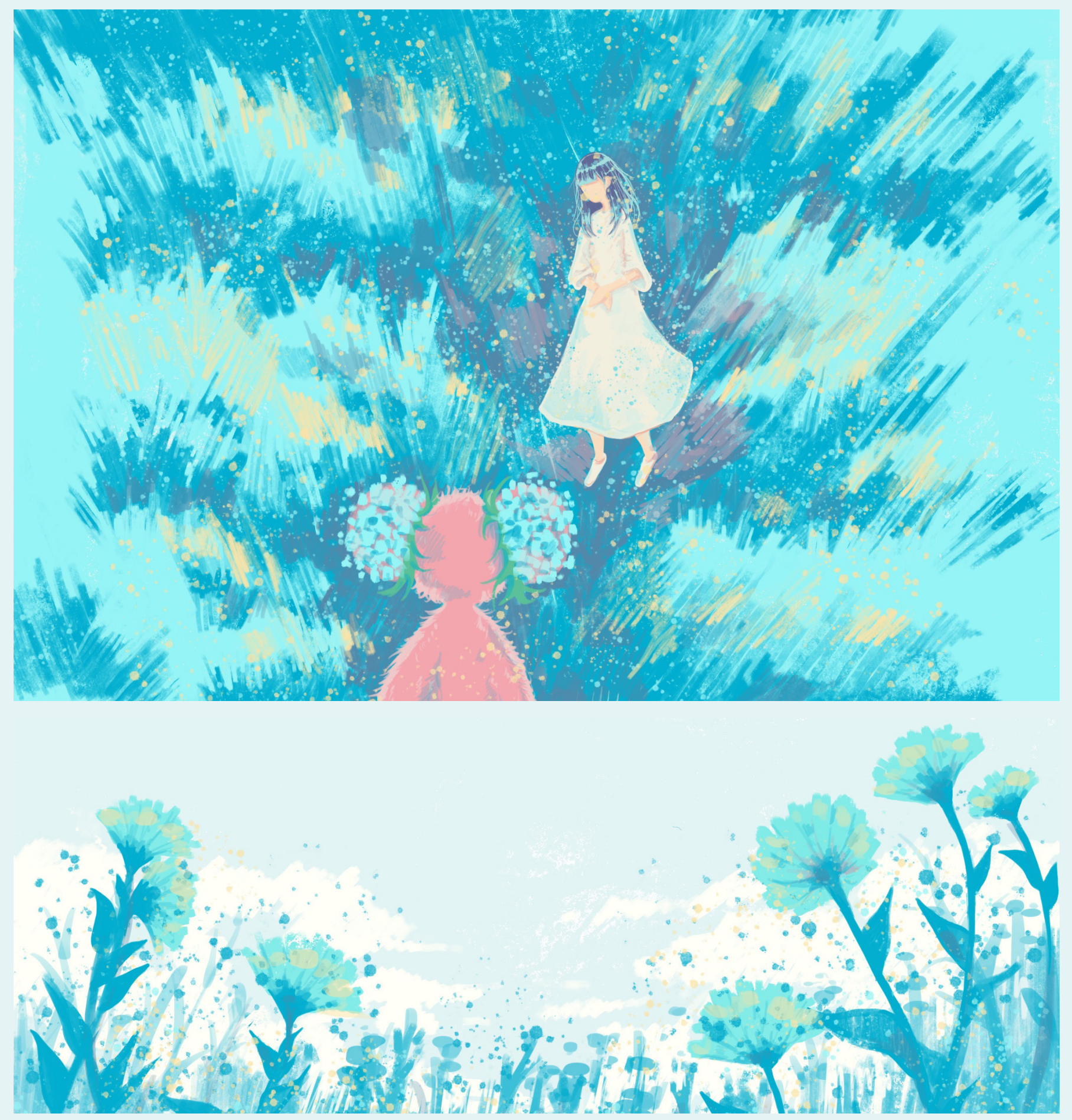

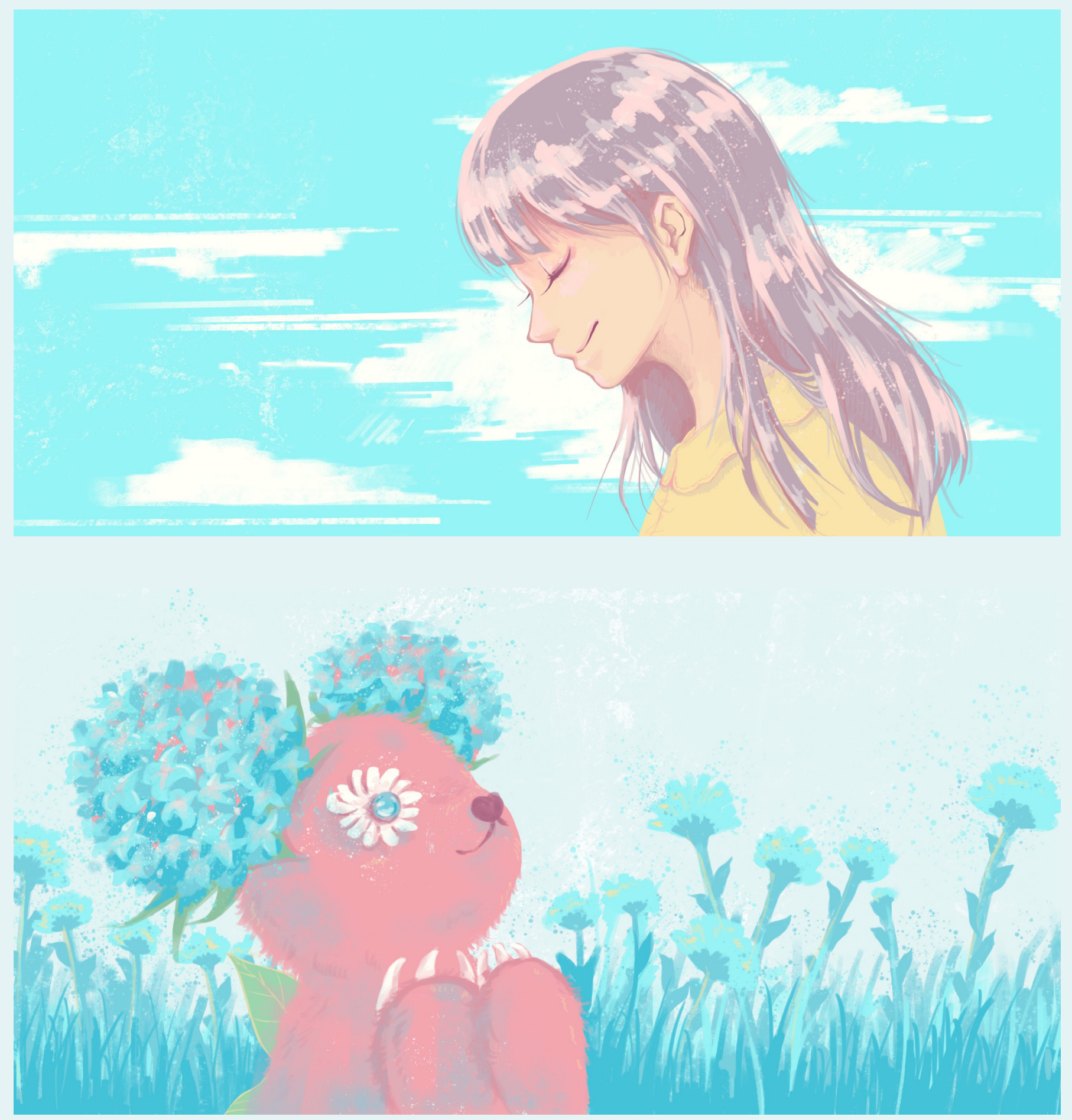


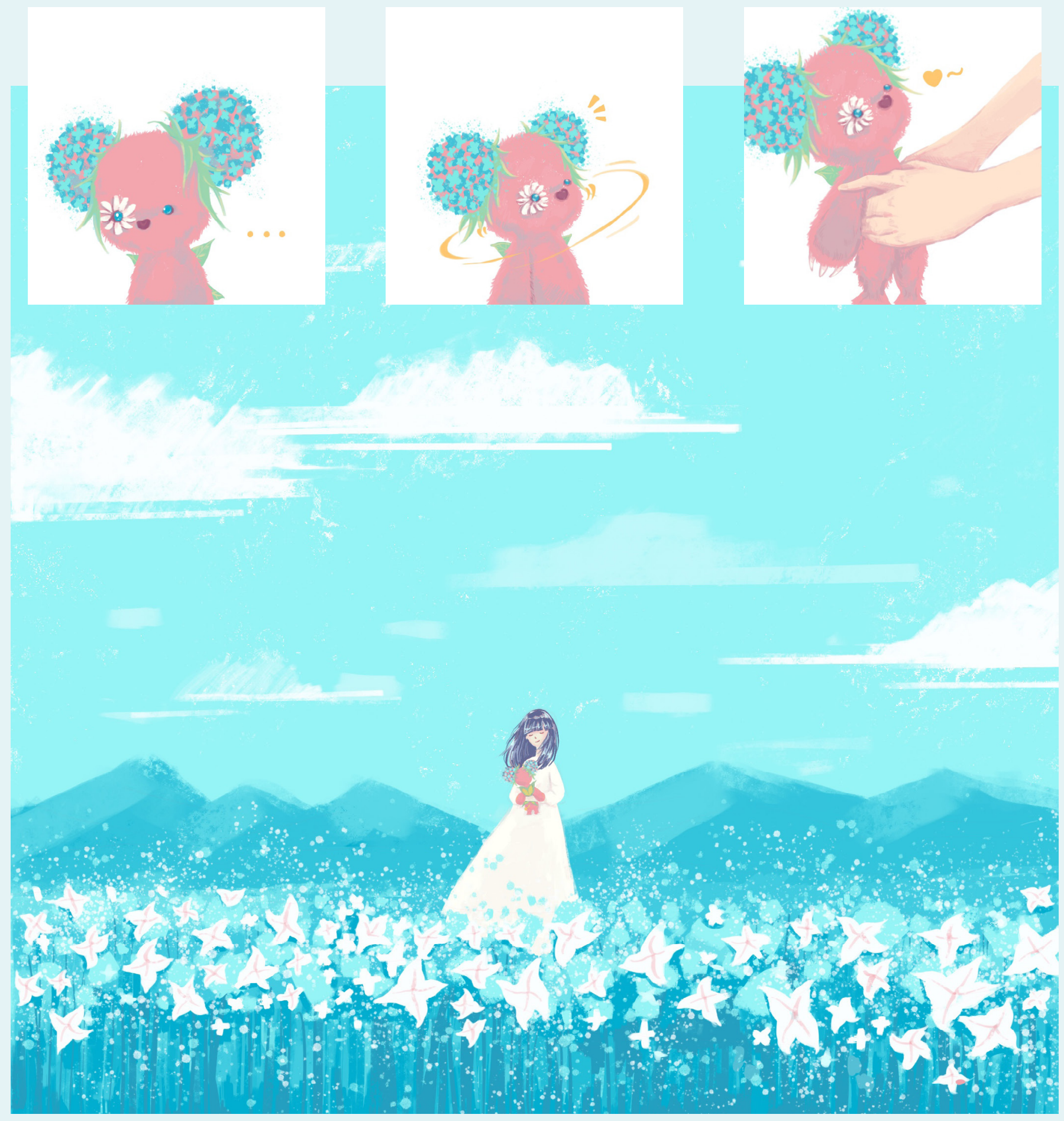



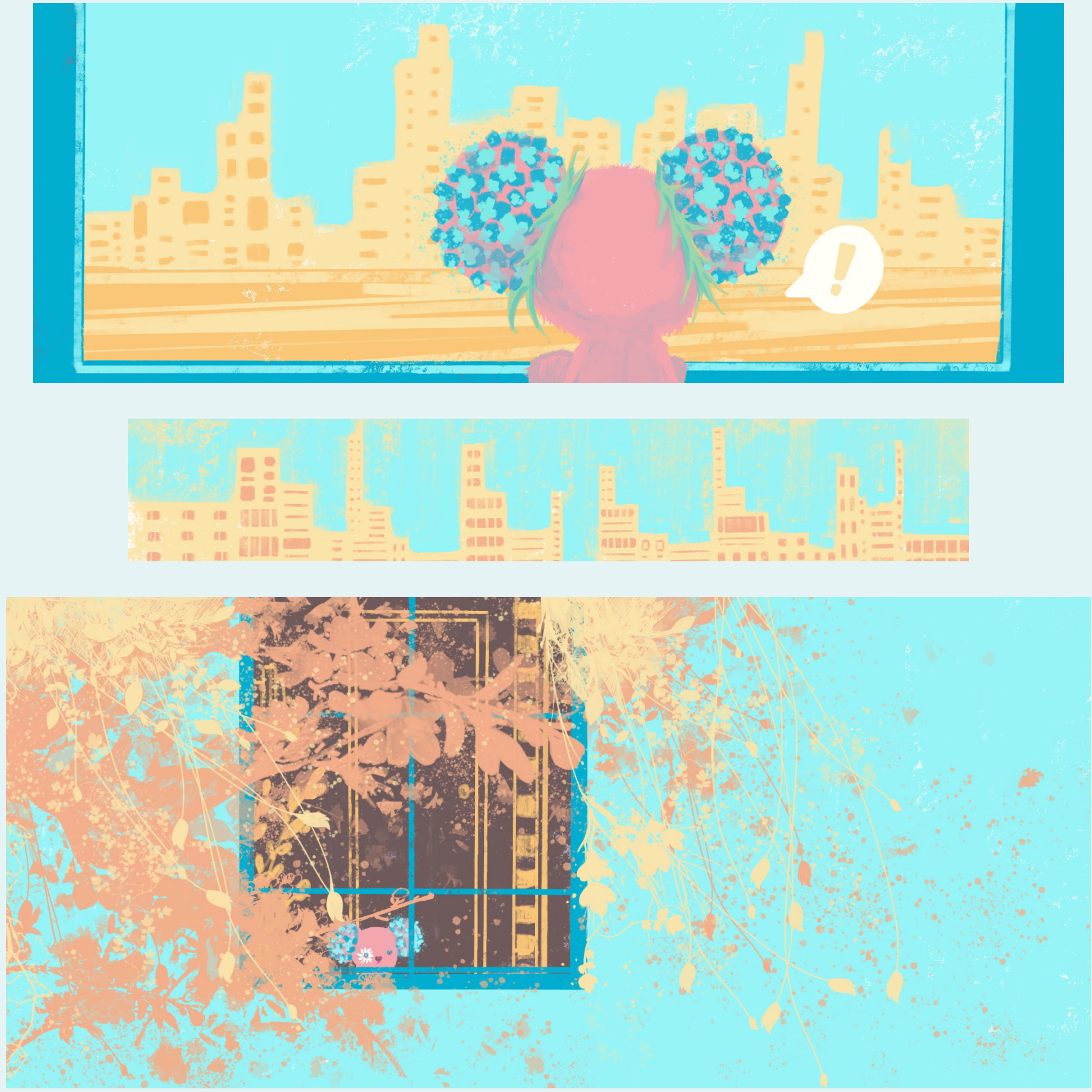


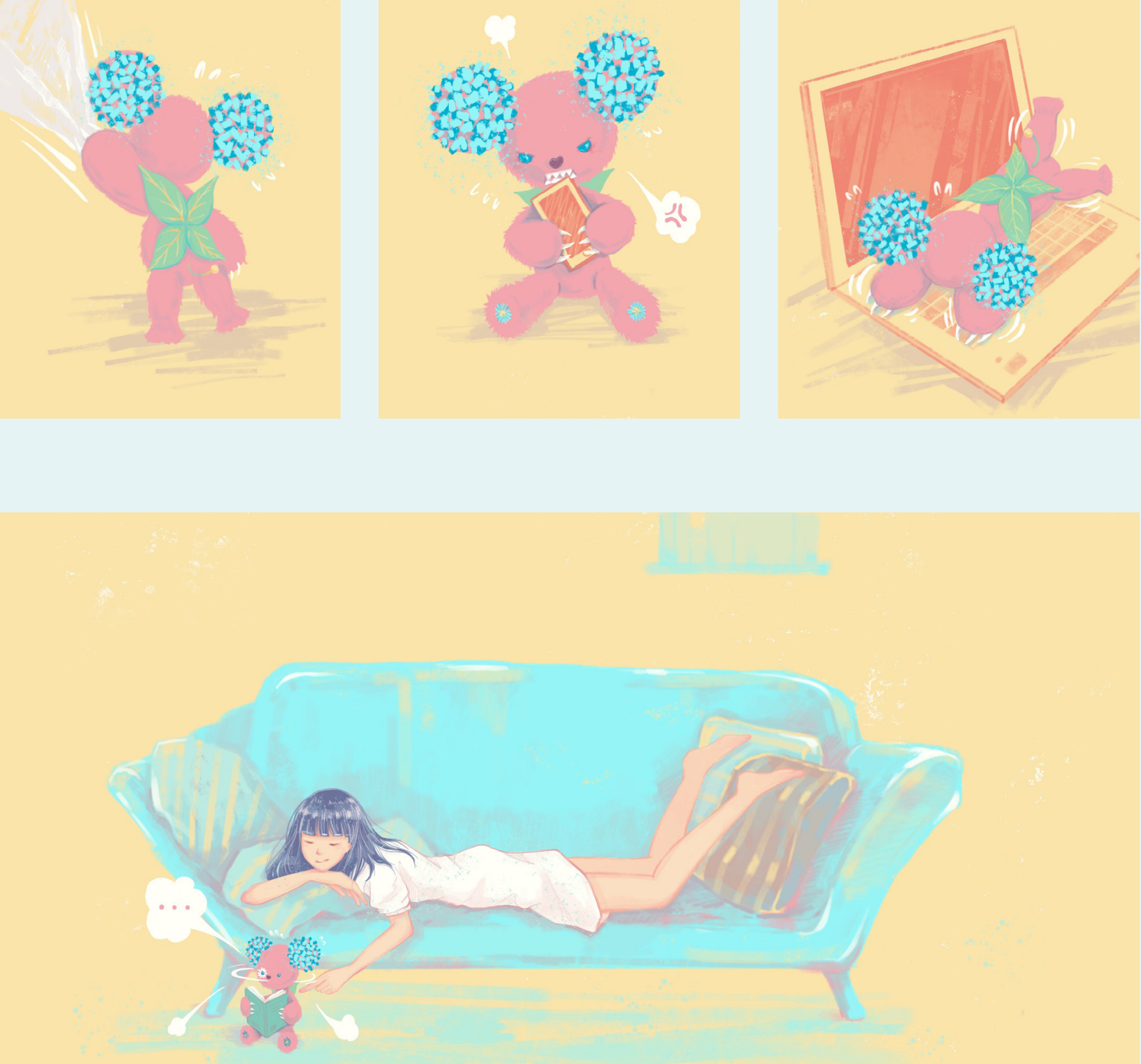

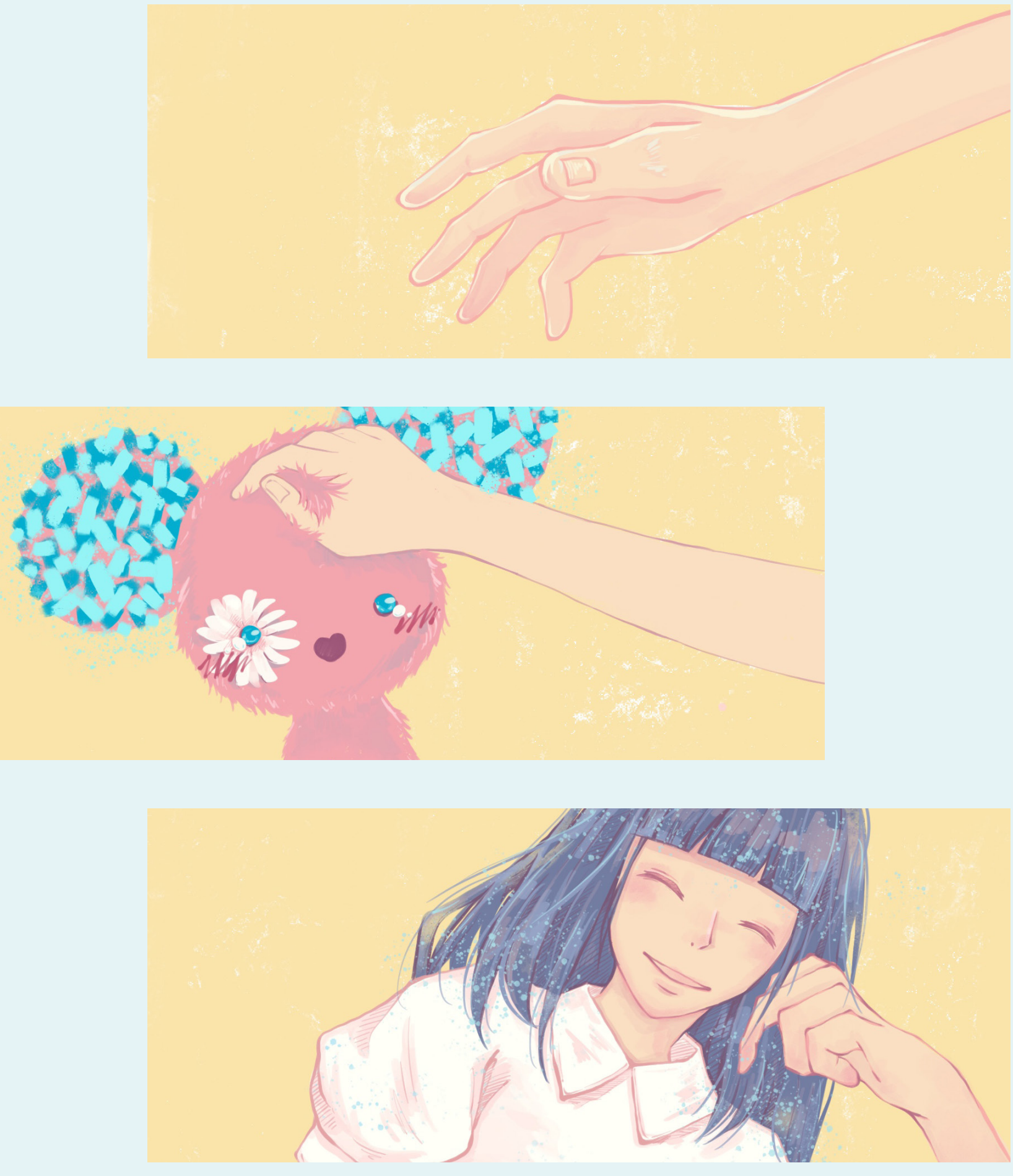



\section{where is my hat?}

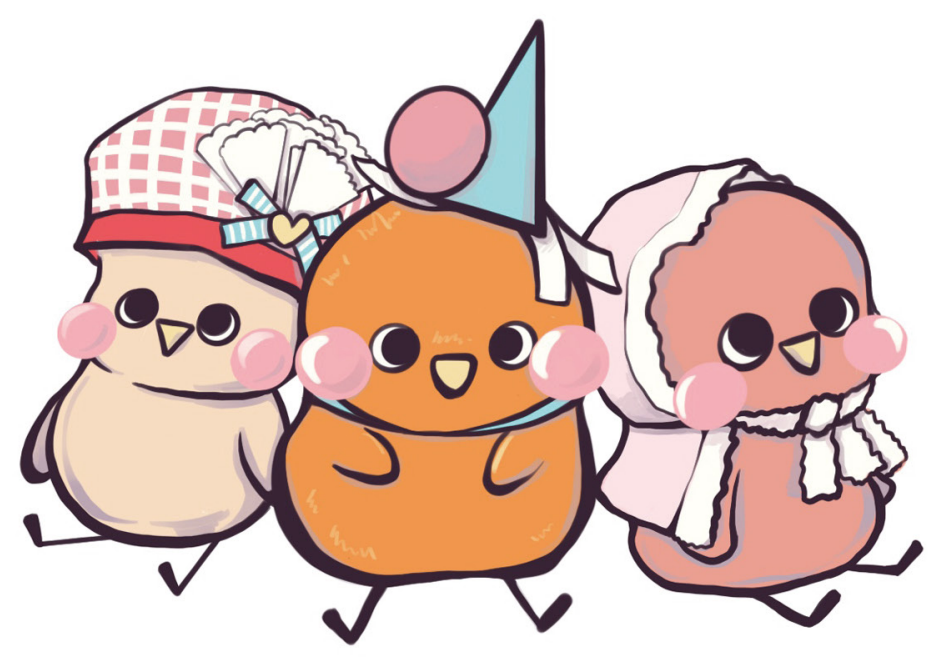



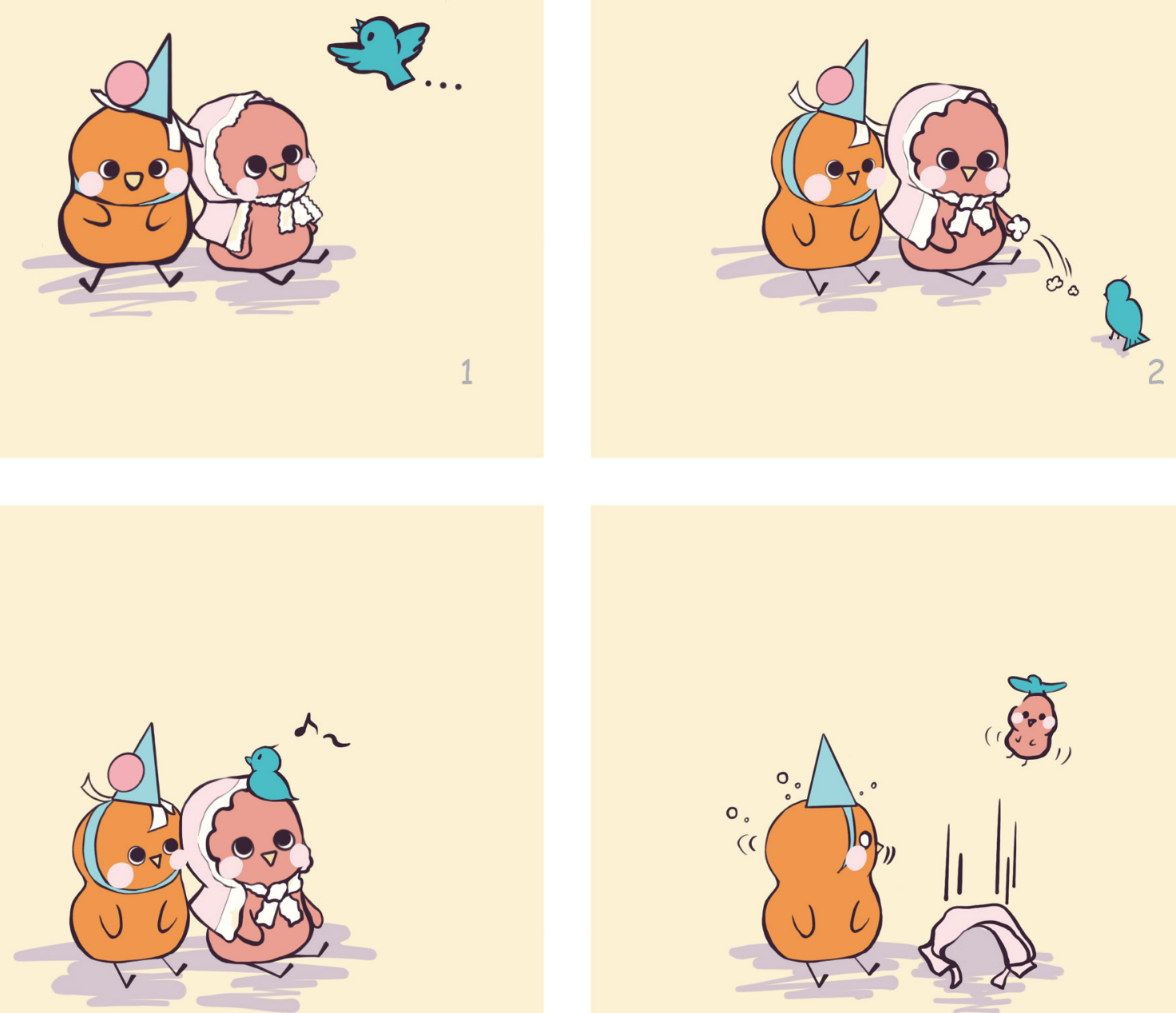


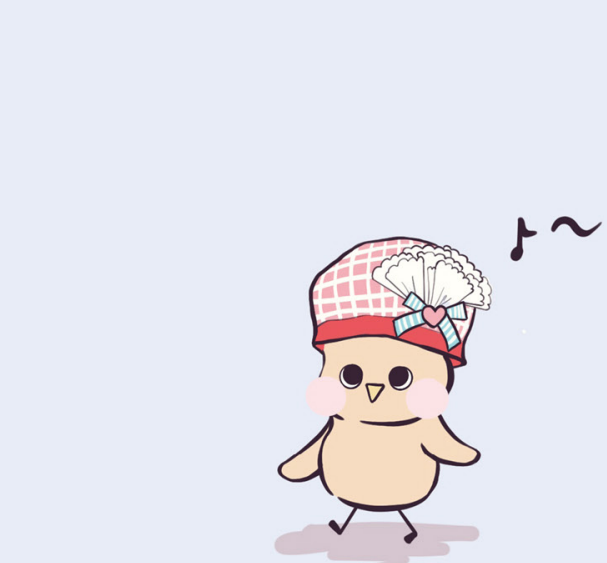

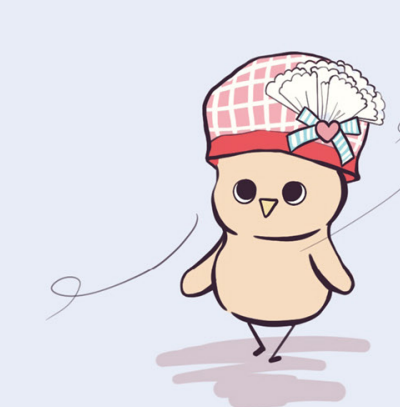<smiles>O/C=C\C12CCCC(CC1)[As]2</smiles>

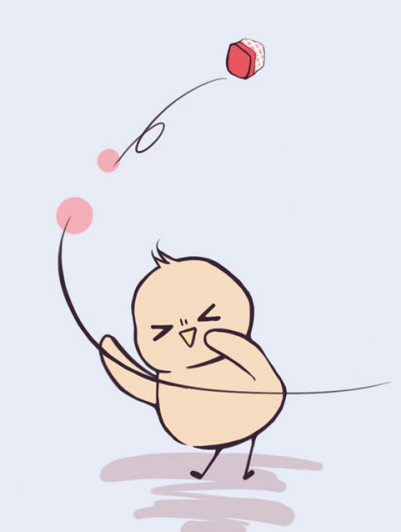



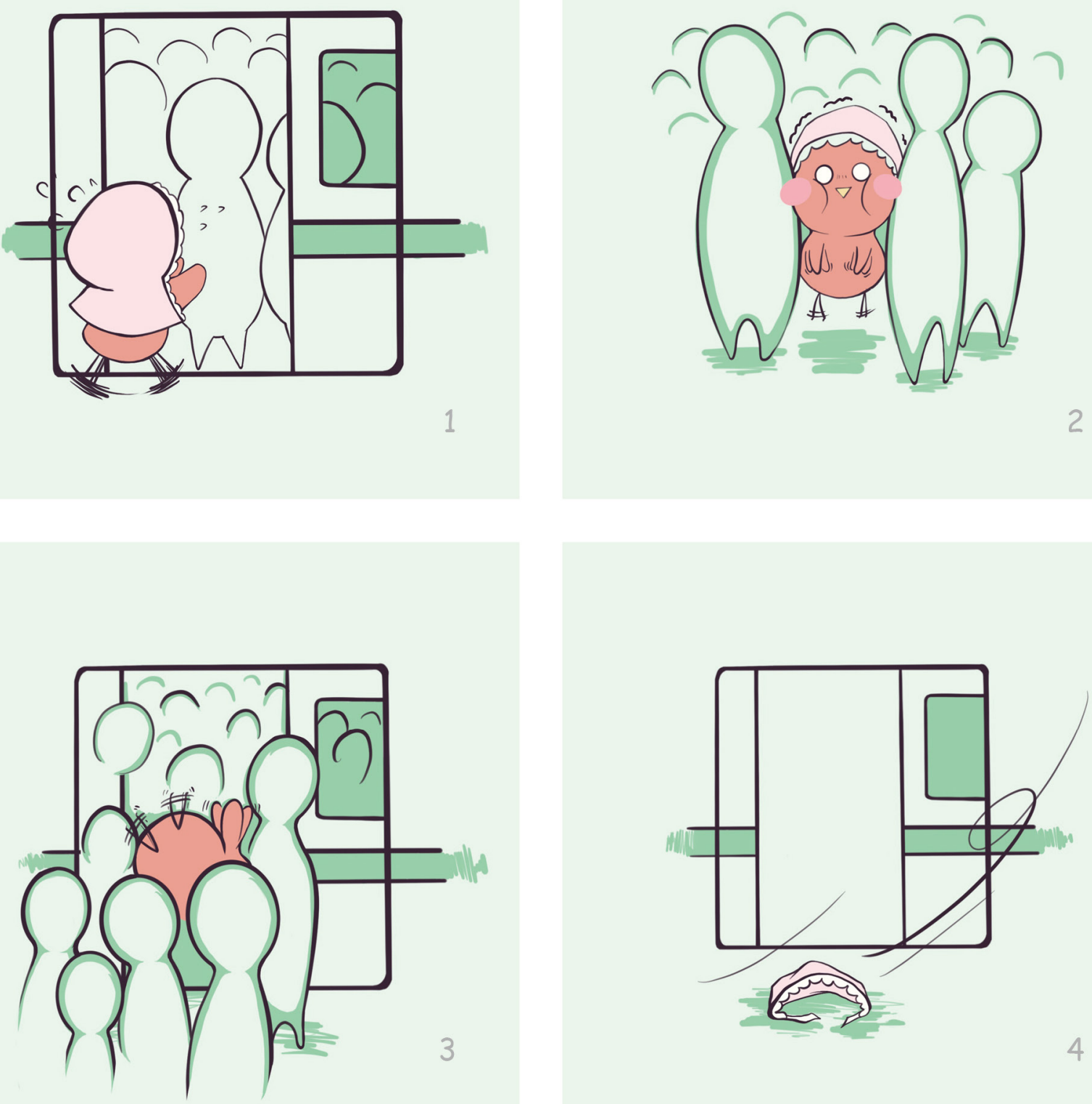
7.Evaluation 


\section{Evaluation}

After I finished, the dolls started their own journey with their new parents. This research enabled the stories of the dolls, and the spirit of the dolls exists in Shinto beliefs. When the stories moved from the traditional Youkai stories to the dolls as well as from person to person, it created momentum. Its power multiplies during this process.

In this project, I extracted part of the characteristics from the traditional Youkai story and used new media and technologies to present them within digital media. Essentially, it is a reimagining of the existing traditional Youkai stories in a new way.

Like the original Youkai story does not have authority. The story of the dolls also passed human by human mouth by mouth. Sometimes, telling the story itself becomes entertainment. People started absorbing external influences and then rewriting them to suit their own needs. Because the story has been passed so many times, and constantly updated by non-authoritative authors, we do not know which one is the original, but the power of the story keeps growing. Those anticipations and uncertainties helped a discovered status that made the existence of the doll stronger, unique and more authentic because real life is never static.

During this period, participants enjoyed and played with the dolls in various ways and shared their stories and experiences. They condensed these experiences into answers based on the question cards and agreed it was the best way to document their stories. Their answers on the question cards were far beyond my expectations. One participant started earlier than the expected time. She documented and sent me the message of how anxious she was waiting for the doll arriving and wrote a story about the doll during transportation. Their relationship began before they had met.

After the investigation, I used the same making method for some extra dolls. Drawing on the first production experience, the second batch of dolls became more elaborate. However, these did not affect participants' perceptions of their dolls. They still think that the doll they spend time with is the perfect one.

The people who hold the story also influence the magic of the dolls. According to Gerbert (200I), when collectors project their emotions onto the doll, the doll will function as a mirror which transforms the player into the doll double. During the research, the characteristics of the doll are variable, and it changes as the research steps evolve. The original character of the dolls is based on the Youkai stories, however, their stories gradually developed after the process of crafting and contacting participants. The Youkai stories I chose all have a double side, but the dolls are all lovely characters in the participants' eyes. When they described the doll on the question cards, they all 
used the word "she" or "he." The doll is a close friend or family number for the participant.

Another magic ingredient of the dolls' life is it can invoke wonder. Gaver et al. (2003) found that ambiguity could be a powerful design resource as it encouraged users to interpret designs in the context of their own lives, and engage on a personal level. The answers from the question cards are only part of the experience of the dolls and the participants. That information finally became comics to the public audience through my imagination. Those visual stories captured and communicated experiences in a more nuanced and interpretive way. This inclusive approach provided readers with more wonder. Curiosity and imagination motivate people to participate in and write blank parts of stories. Eventually, all those who pass on reading and passing stories begin to think that they are part of the project.

Also, the content of their stories gradually became inferred or interpreted by this reader, transforming the narrative. When I completed the comic books, I passed them on to different people. When the stories passed to the four participants, the story retains its original meaning, especially for the story of their own doll. For instance, in the first story (Robinson Crusoe), the doll is the main character in the whole story, but he does not appear directly in the story, only shows a little of his legs on the last page. Only the participant who raised the doll found this little secret. Thus, the person who has a stronger relationship to the original story paid more attention to details.
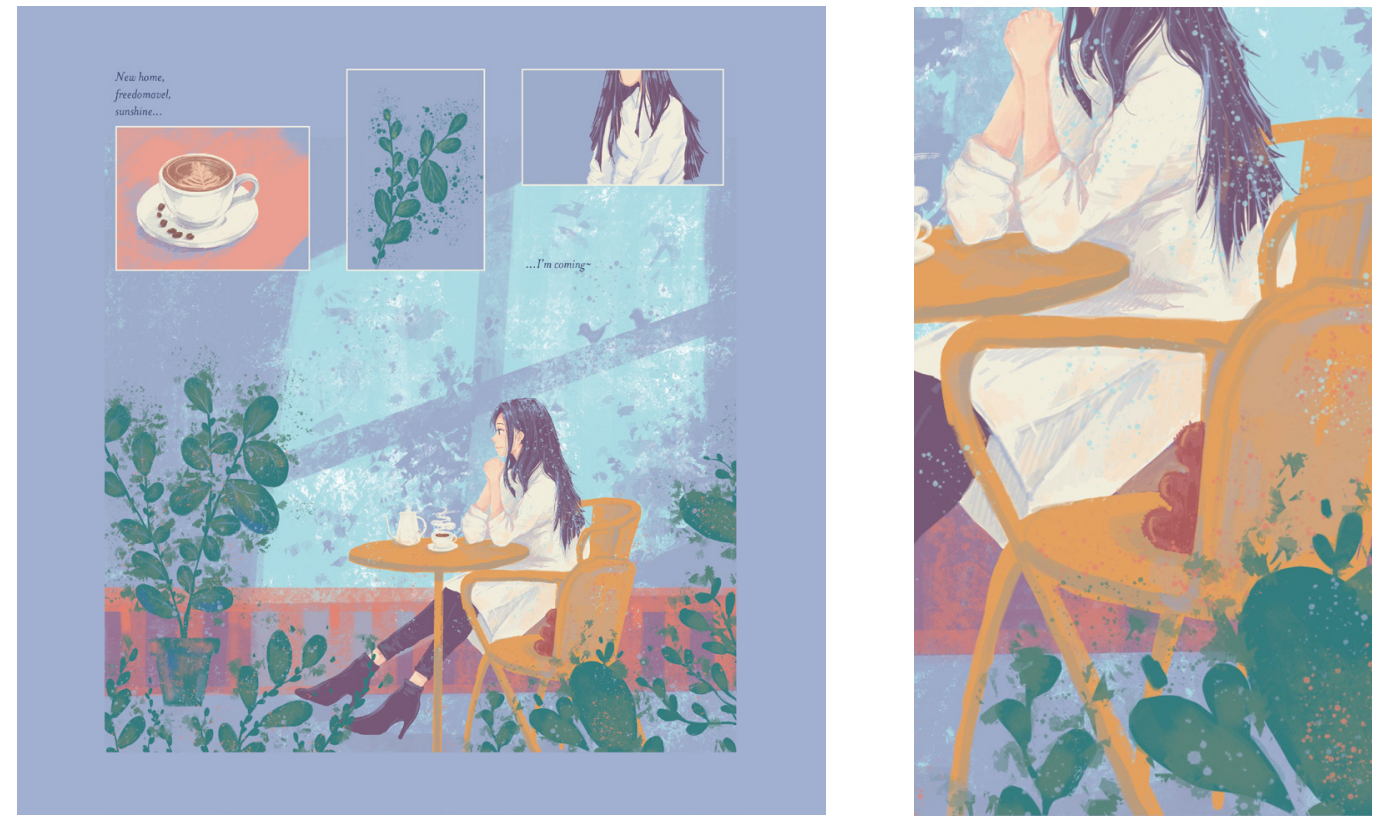
On the other hand, when the story was passed on to someone completely unrelated to this project, they started to turn the story into something with a new purpose, sensibility, or a mode of expression. For example, in the third story ( The third eye), the plot turns in time and space, which gave the reader a place of imagination. People started to give it alternate endings and ultimate beginnings. They added lines to the characters and adding scenarios of their own imagination. This opportunity enables them to explore the stories they want, and the stories are designed for them and by them. It is a reimagining of existing stories in a new way.

As the Shinto belief, everything in the world is spiritual, so does the voice. When we give stories voice, we allow them to resonate in the hearts and minds of people we interact with. When the story has been told, it exists not just in the imagination but the real world of the traditional stories, creator, participants, audience, and the doll itself. In the research, the dolls passed hand to hand, and their stories evolved through word-of-mouth. Thus, those stories created by people have given an attribution of a soul in the dolls. The interaction between human and dolls compose a fantasy world, which is the place that hosts the soul of the doll. The doll as an intersection of that world and reality becomes fascinating and spiritual. 
146 


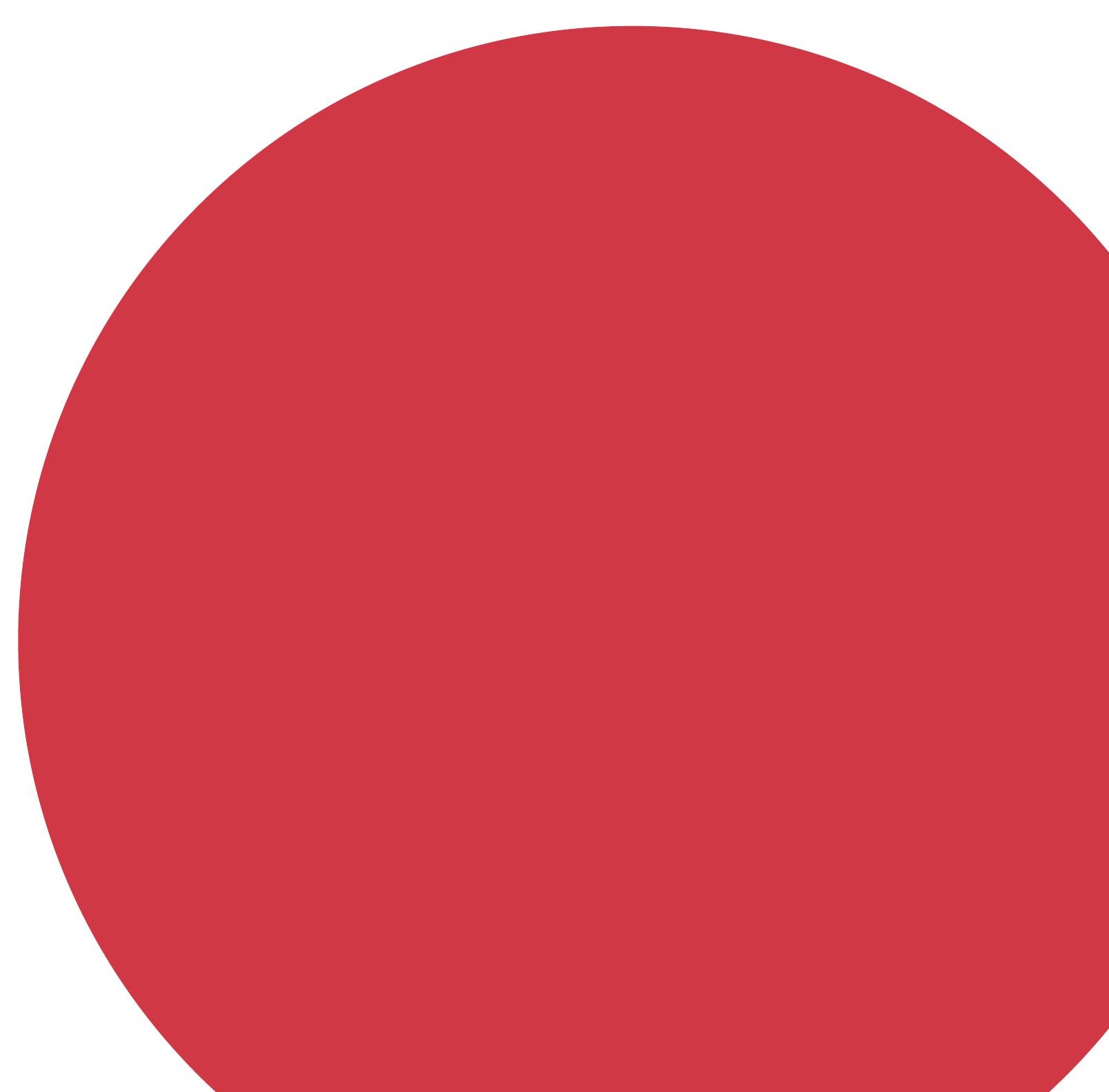




\section{Conclusion}




\section{Conclusion}

Concluding this investigation, I can confidently state the design exploration has been successful in achieving its objectives. The process I have outlined in this thesis demonstrates an approach to designing through and for beliefs of Shinto. Like the original spread of the Youkai stories, the design process followed also moves from person to person, but in addition to words, it incorporates objects and images, and old and new technologies. The spirit of the doll evolves as the story spreads.

Though chasing the dolls' life and study the Shinto belief, it has enabled me to gain a new vision of the approach of the object and design. As a designer, our job is not to master complex skills, but to discover the inner spirit of the thing. Those fancy cover and function can only be satisfied for a moment. The item can result in the long-term as a grand design infused with a soul and enthusiasm under the surface. If you look at them from a different perspective and treat them differently, all objects can share moments of life with you. The Shinto beliefs created a unique companionship with humans and objects, and it illuminated the imaginary story. There is not anything or anyone you could not love once you heard their stories. The greatest story outcome is to make the audience care and become invested. The true value of the thing is captured from the connections between objects and users. That is the thing that cannot be artificially evoked.

The doll from a handcrafted object evolved to an imaginary being through the interaction with the participants and the communicating experiences to the mass audience in a more nuanced and interpretive way through visual stories. These explorations and discoveries in my design research inspired me for further research in this area. For the future journey of the dolls, I am also interested in trying different making methods and using different media to convey their stories. I aim to inspire more people to pay attention to the relationship between humans and objects and reconsider the value of the things.

My doll's journey continues. This is just part of the story of their lives.

I hope that you have enjoyed. 


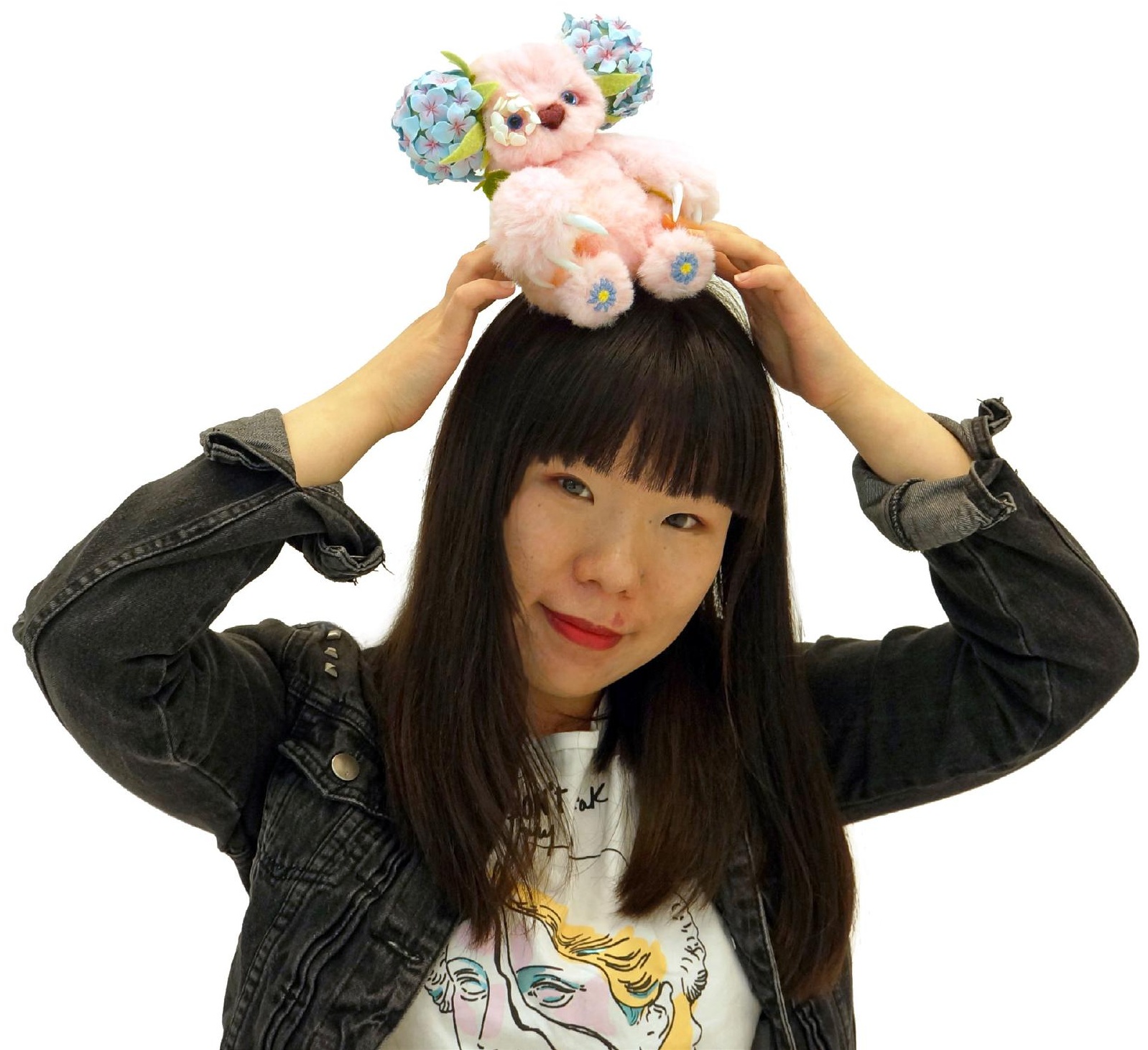




\section{List of references}

Ayala-Garcia, C., \& Rognoli,V. (20 I7). The New Aesthetic of DIY-Materials. The Design Journal, 20(sup I), S375-S389.

Boyd, J.W., \& Nishimura,T. (20।6). Shinto Perspectives in Miyazaki's Anime Film" Spirited Away". Journal of Religion \& Film, 8(3), 4.

Budnitz, P. (2006). I am plastic :The designer toy explosion / Paul Budnitz (pp. 6-7). New York: Abrams.

Budnitz, P. (20 I 0). I am plastic, too :The next generation of designer toys / Paul Budnitz (pp. 7).New York: Abrams.

Cohn, N. (20 I 3). Visual narrative structure. Cognitive science, 37(3), 4I3-452.

Doll Reader. (2009). ENCHANTED DOLL. Doll Reader, 37(2), 50.

Foster, M. (2019). The Book of Yokai: Mysterious Creatures of Japanese Folklore. Berkeley: University of California Press.

Foster, M. (1998). The Metamorphosis of the Kappa:Transformation of Folklore to Folklorism in Japan. Asian Folklore Studies, 57(I), I-24.

Frankel, L., \& Racine, M. (20 I 0, July). The complex field of research: For design, through design, and about design. In Proceedings of the Design Research Society (DRS) international conference (No. 043).

Fujita, H. (20I6). Birth of an Asian Design: Origins of the Chinese word 'sheji'and its relationship with the Japanese word 'sekkei'. Blucher Design Proceedings, 8(2), 8- 14.

Gaver, B., Dunne,T., \& Pacenti, E. ( I999). Design: cultural probes. interactions, 6( I), 2 I-29.

Gaver, W., Beaver, J., \& Benford, S. (2003). Ambiguity as a resource for design. Proceedings of the SIGCHI Conference on Human Factors in Computing Systems, 233-240.

Gerbert, E. (200 I). Dolls in Japan. Journal of Popular Culture, 35(3), 59-89.

Graham, P. (2014). Japanese Design :Art, Aesthetics \& Culture. North Clarendon:Tuttle Publishing

[ebookcentral]. Retrieved from https://ebookcentral.proquest.com/lib/vuw/reader.action?doclD=|767965

Hara, K. (2007). 8 WHAT IS DESIGN. Designing design (pp. 4 I 0-434). Lars Muller Publishers. 
Hara, K. (20 I0). White / Kenya Hara, Emptiness (pp. 35-65), Baden, Switzerland: Lars Müller.

Heljakka, K. (20 18). More than Collectors: Exploring Theorists', Hobbyists' and Everyday Players' Rhetoric in Adult Play With Character Toys. Games and Culture, I3(3), 240-259.

Jensen, C., \& Blok, A. (2013). Techno-animism in Japan: Shinto Cosmograms, Actor-network Theory, and the Enabling Powers of Non-human Agencies. Theory, Culture \& Society, 30(2), 84-I I 5.

Kinser, Maggie. (2002). Toshiyuki Kita. Graphis, (342), 88.

Koskinen, l., Battarbee, K., \& Mattelmaki,T. (2003). Empathic design / edited by Ilpo Koskinen, Katja Battarbee, Tuuli Mattelmaki (pp. 126- I27). Finland: IT Press.

Lupitu, C. (2014) "The night parade". Experiencing the folklore-based Japanese imaginary between wabisabi and the uncanny. Aurelian botica, 37. Retrieved from http://www.emanuel.ro/wp-content/uploads/20 I5/03/3.Lupitu.pdf

Mealey, R. (2016). Japanese 'return doll souls to heaven' in Shinto shrine ceremony. Retrieved from https://www.abc.net.au/news/2016-08-06/japanese-dolls-souls-return-to-heaven-at-shinmeishashrine/76954|4.

Nicolae, R. (20 I2). IN SEARCH FOR CHIMERAS:THREE HYBRIDS OF JAPANESE IMAGINATION. Cogito, $4(2), 1-14$.

Nieuwenhof, D. (20I2). The Collecting Experience:The collector-collected relation and collector interaction of barbie, Blythe, and ball-jointed doll collectors (Master thesis). Leiden University, Leiden, Netherlands.

Phoenix, W. (2006). toys into mainstream Plastic culture : How Japanese toys conquered the world / Woodrow Phoenix (pp. P97). (I st ed.). New York, N.Y.: Kodansha International.

Prusinski, L. (20 I 2). Wabi-Sabi, Mono no Aware, and Ma:Tracing Traditional Japanese Aesthetics Through Japanese History. Studies on Asia, Series iv, 2(1), 25-49.

Rots, A. P. (20 |4). Forests of the Gods: Shinto, Nature, and Sacred Space in Contemporary Japan (PhD thesis). University of Oslo, Oslo, Norway.

Schattschneider, E. (200 I). "Buy Me a Bride": Death and Exchange in Northern Japanese Bride-Doll Marriage. American Ethnologist, 28(4), 854-880.

Schonherr. J., (n.d.) Tokorozawa Doll Memorial Celebration. Retrieved from:

https://www.japanvisitor.com/japanese-festivals/tokorozawa-doll-memorial-celebration. 
Shimazaki, S. (20 I I). The End of the" World":Tsuruya Nanboku IV's Female Ghosts and Late-Tokugawa Kabuki. Monumenta Nipponica, 66(2), 209-246.

Smith, C. P. (2000). Content analysis and narrative analysis. In H.T. Reis \& C. M. Judd (Eds.), Handbook of research methods in social and personality psychology (pp. 3 I 3-335). New York, NY, US: Cambridge University Press.

Spurgiasz, M. (2015). Yokai - Japan Liminal Spirits. Zeszyty Naukowe Uniwersytetu Jagiellonskiego. Seria Religiologica, 48(I), 7I-8I.

Suzuki, C. S. (201 I). Learning from Monsters: Mizuki Shigeru's Yōkai and War Manga. Image \& Narrative, 12(1), 229-244.

Tufte, E. R., McKay, S. R., Christian, W., \& Matey, J. R. (1998).Visual explanations: images and quantities, evidence and narrative.

https://aip.scitation.org/doi/pdf/10.1063/1.168637.

Weishi, Z. (20।6). Analysis on "Blank" Aesthetics of the Suzhou-Style Furniture of Ming Dynasty. Furniture \& Interior Design, 5, 032.

Wilson, M. (2013). Marvels \& Tales, 27(2), 333-335. doi: I0. I 3 I I0/marvelstales.27.2.0333.

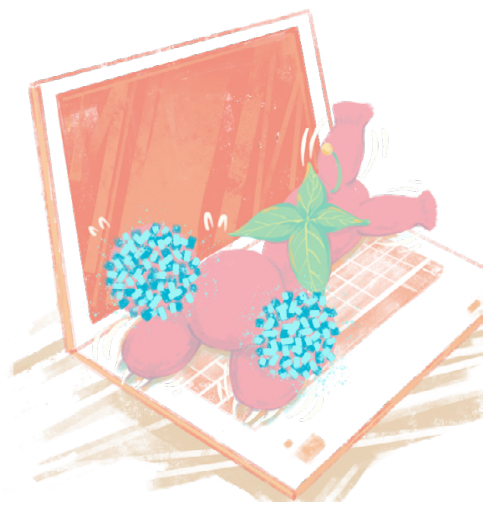




\section{List of figures}

Figure I.Author. (2019). Kappa.[illustration].

Figure 2. Author. (2019). Night parade of a hundred demons [illustration].

Figure 3. Author. (2019). Youkai in five different categories [illustration].

Figure 4. Author. (2019). The common human Youkai [illustration].

Figure 5. Author. (2019). The common plants Youkai [illustration].

Figure 6. Author. (2019). The common animal Youkai [illustration].

Figure 7. Author. (2019). The common object Youkai [illustration].

Figure 8. Author. (2019). The common mythologyYoukai [illustration].

Figure 9. Author. (2019). The common feature crossing all categories of Youkai [illustration].

Figure 10. Author. (2019). Human Youkai [illustration].

Figure II. Author. (2019). Plants Youkai [illustration].

Figure 12. Author. (2019). Animal Youkai [illustration].

Figure I3. Author. (2019). ObjectYoukai [illustration].

Figure 14. Author. (2019). Mythology Youkai [illustration].

Figure 15. Author. (2019). The back of the question cards [image]

Figure 16. Author. (2019). The front of the question cards [image]

Figure 17. Author. (2019). Sketch of the doll with animal Youkai Characteristics-Mametanuki [sketch]

Figure I8. Author. (2019). Sketch of the doll with mythology Youkai Characteristics-Hakutaku [sketch]

Figure 19. Author. (2019). Sketch of the doll with plants Youkai Characteristics-Momijigari [sketch] 
Figure 20. Author. (2019). Sketch of the doll with human Youkai Characteristics-Kokakuchou [sketch]

Figure 21. Author. (2019). Handcraft process [Photograph].

Figure 22. Author. (2019). Mametanuki I [Photographed by Meng Yitong].

Figure 23. Author. (2019). Mametanuki 2 [Photographed by Meng Yitong].

Figure 24. Author. (2019). Hakutaku I [Photographed by Meng Yitong].

Figure 25. Author. (2019). Hakutaku 2 [Photographed by Meng Yitong].

Figure 26. Author. (2019). Momijigari I [Photographed by Meng Yitong].

Figure 27. Author. (2019). Momijigari 2 [Photographed by Meng Yitong].

Figure 28. Author. (2019). Kokakuchou I [Photographed by Meng Yitong].

Figure 29. Author. (2019). Kokakuchou 2 [Photographed by Meng Yitong].

Figure 30. Author. (2019). Birthday card I [image].

Figure 31. Author. (2019). Birthday card 2 [image].

Figure 32. Author. (2019). Finished doll display I [Photographed by Meng Yitong].

Figure 33. Author. (2019). Finished doll display 2 [Photographed by Meng Yitong].

Figure 34. Author. (2019). Finished doll display 3 [Photographed by Meng Yitong].

Figure 35. Author. (2019). Finished doll display 4 [Photographed by Meng Yitong].

Figure 36. Author. (2019). Finished doll display 5 [Photographed by Meng Yitong].

Figure 37. Author. (2019). Finished doll display 6 [Photographed by Meng Yitong].

Figure 38. Author. (2019). Finished doll display 7 [Photographed by Meng Yitong].

Figure 39. Author. (2019). Finished doll display 8 [Photographed by Meng Yitong].

Figure 40. Author. (2019). Packed dolls [Photographed by Meng Yitong]. 
Figure 4I. Author. (2019). Question cards answer from participant I [Photographed by Meng Yitong].

Figure 42. Author. (2019). Panel I [sketch].

Figure 43. Author. (2019). Panel 2 [sketch].

Figure 44. Author. (2019). Panel 3 [sketch].

Figure 45. Author. (2019). The Little Secret in the Story [illustration].

Figure 46. Author. (2019). Liu Yanxiao [Photographed by Meng Yitong]. 


\section{Appendix 1}

\section{Ethical Approval}

Dear Head of School or delegate,

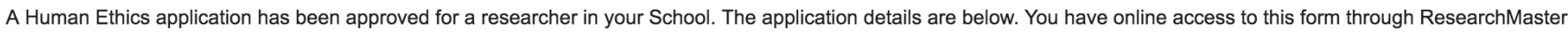
here: https://rme6.vuw.ac.nz/RME6/.

\section{Application ID: 0000026866}

Application title: Designing dolls according to Youkai stories and animism beliefs in Eastern culture

Researcher: Liu

It is best to use either Internet Explorer or Safari to access the system.

Thank you

ResearchMaster

${ }^{* * * * *}$ This is an automated email. Do not reply to this email address ${ }^{* \star * * * * *}$

Queries for the central Human Ethics Committee can be sent to ethicsadmin@vuw.ac.nz

Pipitea Ethics subcommittee queries can be sent to: pipitea-hec@vuw.ac.nz

Psychology Ethics subcommittee queries can be sent to: louise.hamblin@vuw.ac.nz

Information Management subcommittee queries: vanessa.venter@vuw.ac.nz 


\section{Appendix 2}

\section{Visual data from the participants}

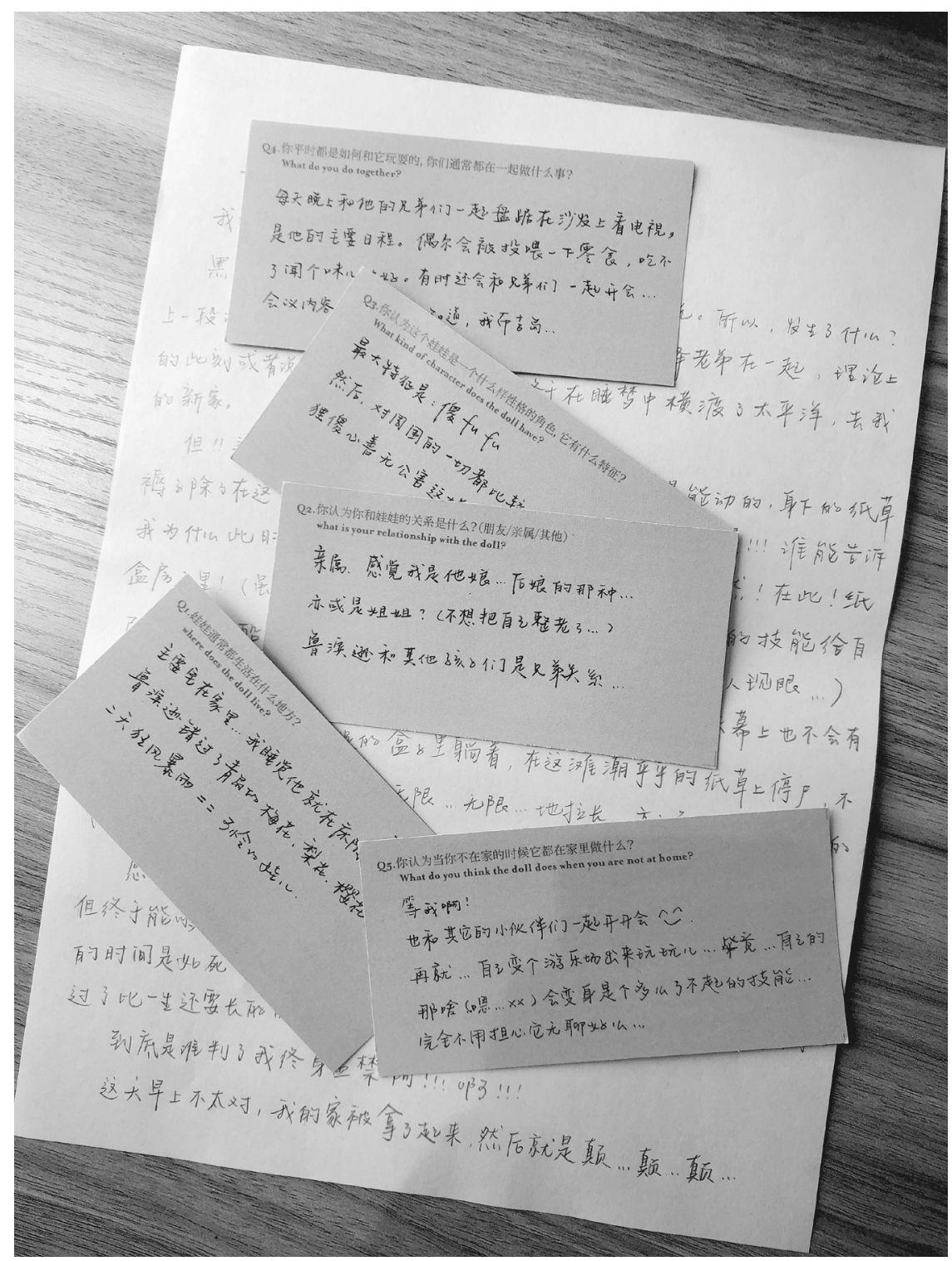



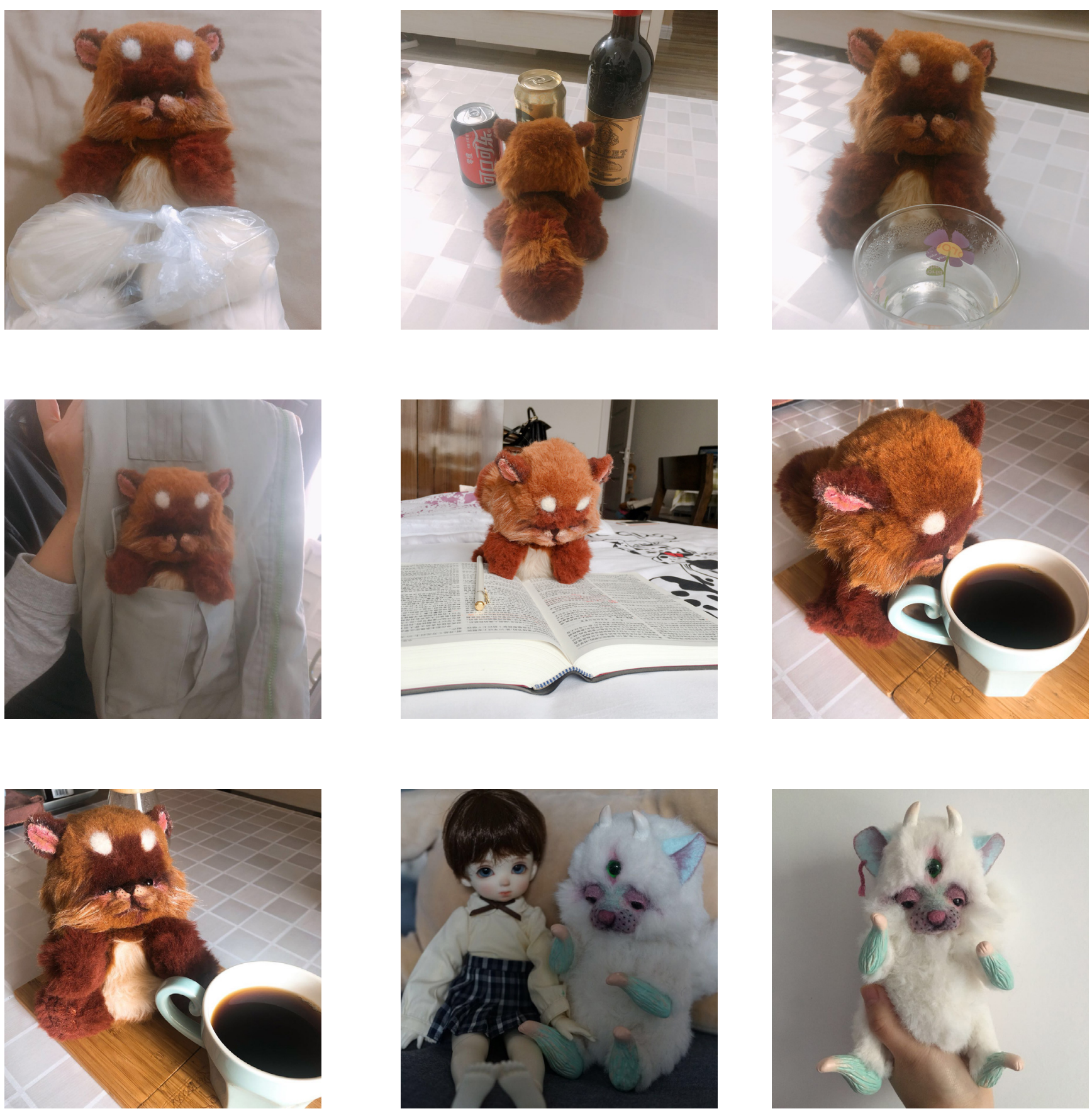

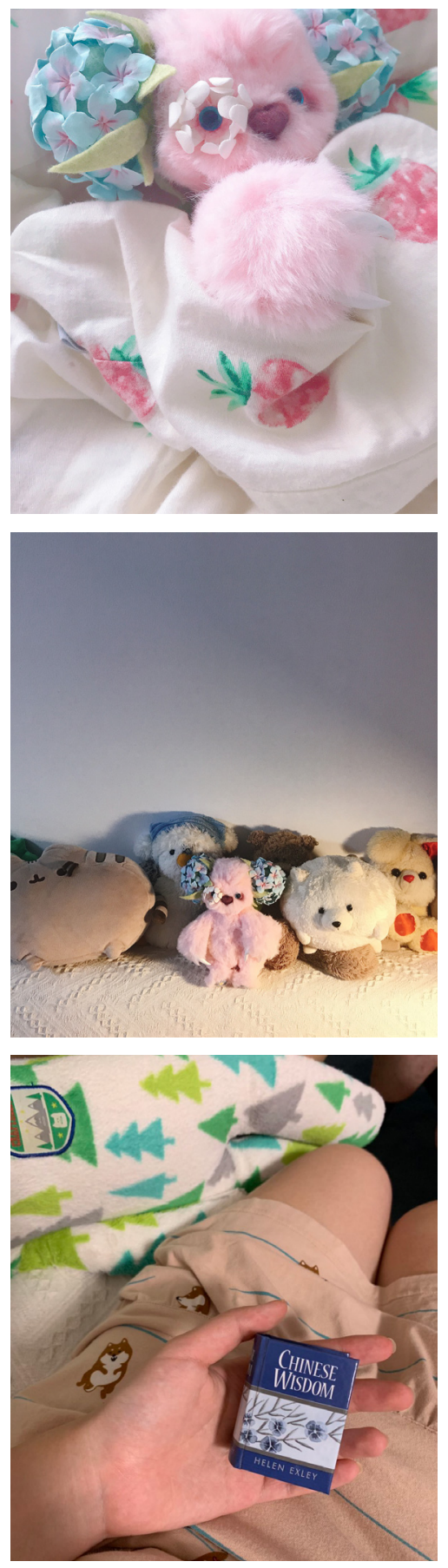
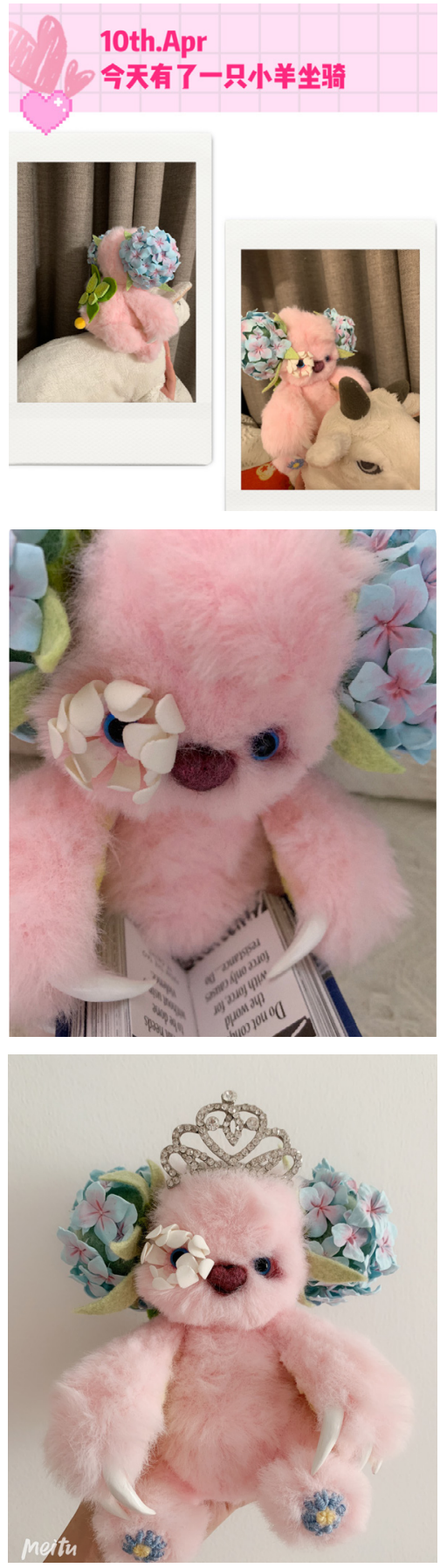
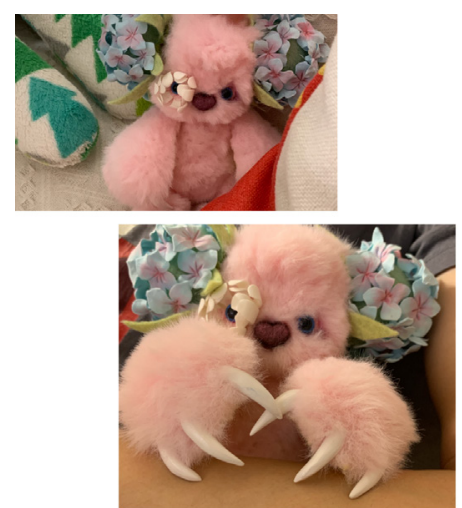

10th.Apr 1 爸爸说我好像小兔吹, 但是人家是小妖怪㕸
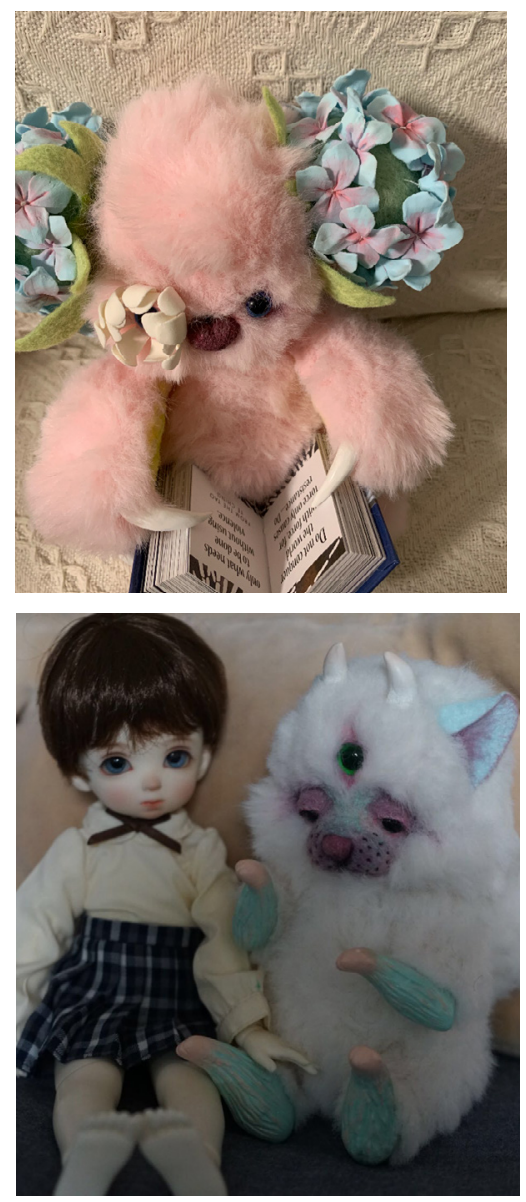

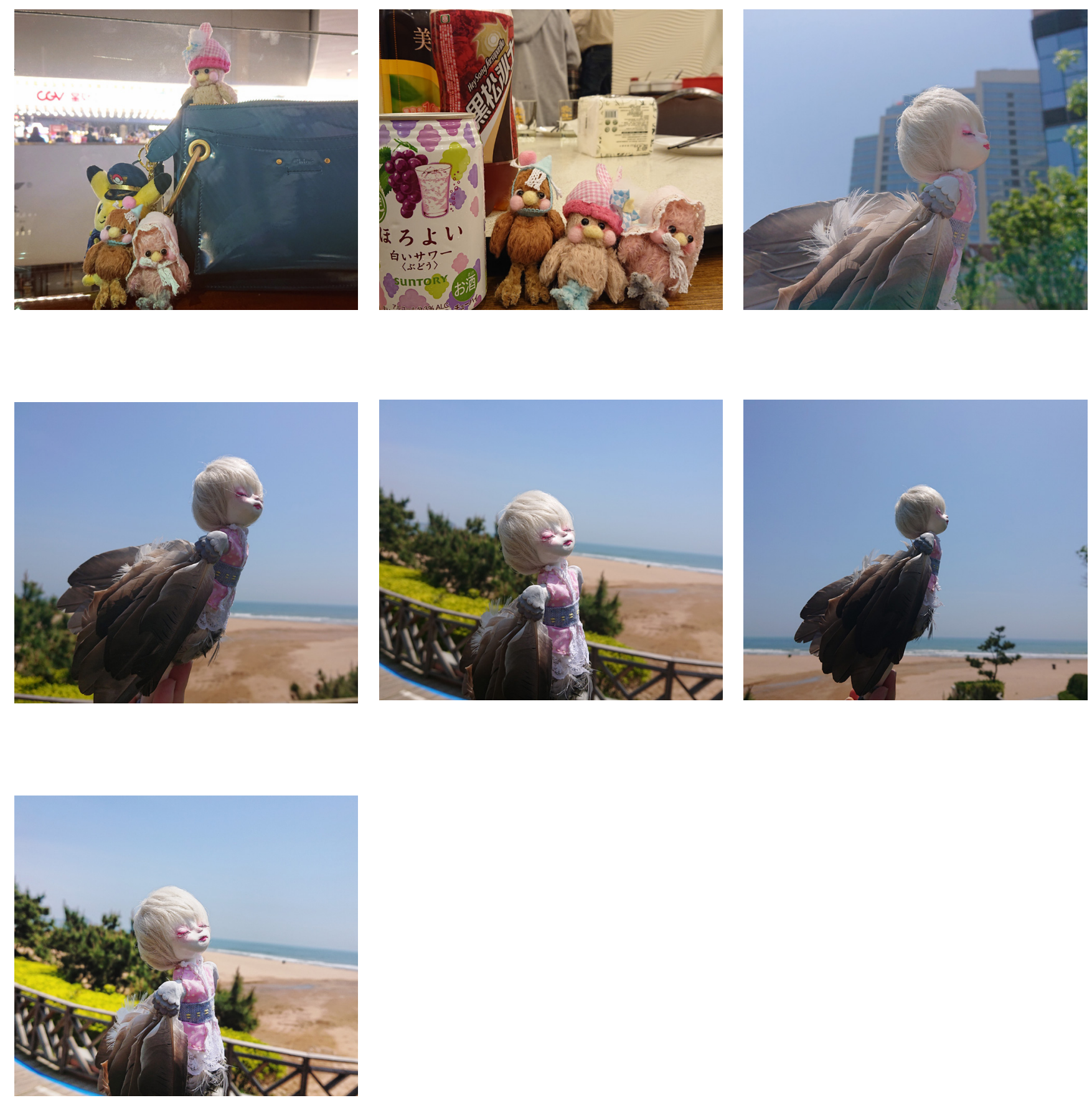


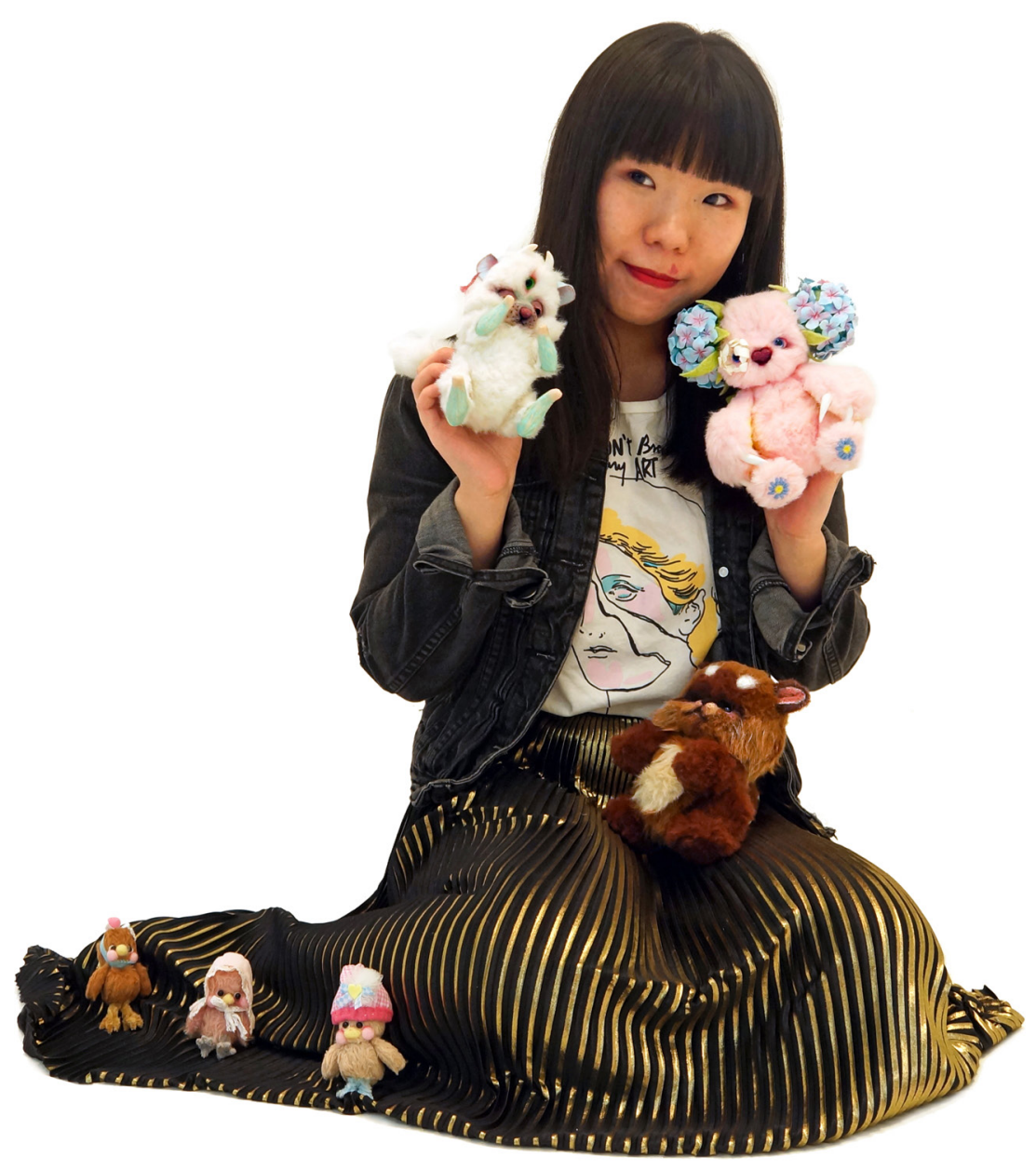




\section{Designing dolls according to}

Youkai stories and Shinto beliefs

in Eastern culture

Author: Liu Yanxiao

Supervisor: Dr Catherine Caudwell

2019 



\section{Availability and Deposit of Thesis Form - Open Research Archive}

\begin{tabular}{|c|c|}
\hline Author's Name & LIUYANXIAO \\
\hline Thesis Title & Designing dolls according to Youkai stories and Shinto beliefs in Eastern culture \\
\hline Degree Name & Master of Design Innovation \\
\hline Discipline & Faculty of Architecture and Design \\
\hline School & Victoria University of Wellington \\
\hline Supervisor(s) & Catherine Caudwell \\
\hline Year & 2019 \\
\hline Keywords (3) & Doll-making, cultural beliefs, illustration \\
\hline \multicolumn{2}{|l|}{ Research Code } \\
\hline $\begin{array}{l}\text { Availability } \\
\text { Statement }\end{array}$ & $\begin{array}{l}\text { I hereby consent to the above research paper being consulted, borrowed, copied or } \\
\text { reproduced in accordance with the provisions of the Library Regulations from time to time } \\
\text { made by the Academic Board. }\end{array}$ \\
\hline \multicolumn{2}{|l|}{ Signature } \\
\hline \multicolumn{2}{|l|}{ Date } \\
\hline Deposit Statements & $\begin{array}{l}\text { I agree to Victoria University of Wellington having the non-exclusive right to } \\
\text { archive digitally and make publicly available this thesis. } \\
\text { Creator/Contributor(s) } \\
\text { I am the sole creator of this work as a whole and can archive digitally and make accessible } \\
\text { the work. I own the intellectual property rights inherent in the work as a whole. I have } \\
\text { explicitly acknowledged in the work any significant contribution made to the work by } \\
\text { others and the sources that I have used. } \\
\text { Third Party Content } \\
\text { I declare that this work does/does not include third party content (strike out one). } \\
\text { The third party content included is (tick what is included) } \\
\square \text { maps } \\
\square \text { images (including photos or film) } \\
\square \text { translation } \\
\square \text { unattributed quotes } \\
\text { Verification } \\
\text { I am supplying the digital file that is a direct equivalent of the work which is described and } \\
\text { referred to in this declaration. } \\
\text { Preservation and Distribution } \\
\text { I agree to Victoria University of Wellington having the right to keep this work in any file } \\
\text { format and copy the research paper and transfer it to any file format for the purposes of } \\
\text { preservation and distribution. }\end{array}$ \\
\hline \multicolumn{2}{|l|}{ Signature } \\
\hline Date & \\
\hline
\end{tabular}



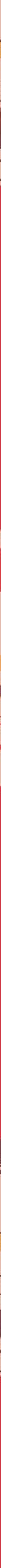


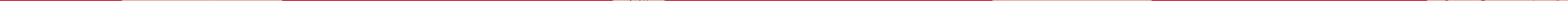


